\title{
Roberto Rozenberg
}

\section{ANÁLISE MOLECULAR DAS DOENÇAS DE GAUCHER E TAY-SACHS NO BRASI L}

São Paulo 2006 


\section{Roberto Rozenberg}

\section{ANÁLISE MOLECULAR DAS DOENÇAS DE GAUCHER E TAY-SACHS NO BRASI L}

Tese apresentada ao Instituto de Biociências da Universidade de São Paulo, para a obtenção de Título de Doutor em Ciências, na Área de Genética.

Orientadora:

Profa. Dra. Lygia da Veiga Pereira Carramaschi

São Paulo

2006 
Rozenberg, Roberto

Análise molecular das doenças de

Gaucher e Tay-Sachs no Brasil

123 páginas

Tese (Doutorado) - Instituto de Biociências da Universidade de São Paulo. Departamento de Genética e Biologia Evolutiva.

1. Doença de Gaucher. 2. Doença de Tay-Sachs. 3. Diagnóstico molecular. Universidade de São Paulo. Instituto de Biociências. Departamento de Genética e Biologia Evolutiva.

Comissão Julgadora

Profa. Dra. Lygia da Veiga Pereira Carramaschi Orientadora 
Agradecimentos

Agradeço aos meus pais pelo apoio e incentivo.

À profa Lygia da Veiga Pereira Carramaschi, pela orientação.

Aos estagiários Fabiano Tófoli de Araújo e Débora Catharine Fox pela calorosa amizade.

Aos médicos, enfermeiras e profissionais de saúde pelas ajudas nas coletas, re-coletas e informações prestadas. Em particular agradeço aos Drs Ana Maria Martins, Cecília Miccheleti, Alexandre Nonino, Cristina Bortolheira, Eugenia Ribeiro Valadares, Cristina Pozzi, Marcelo Kerstenetzki, Paulo Aranda, Gilda Porta, Maria de Fátima Montoril, Maria Cristina Pereira, Maria Teresa de Paula, Renata Cravo, Roberto Giugliani, Janice Coelho e Kristiane Michelin. Agradeço a Dra Elisa Sobreira por ter sido uma parceira durante todo meu doutorado.

Agradeço ao dr Egberto Barbosa pelo entusiasmo e pela prontidão em estabelecermos o estudo colaborativo das doenças de Gaucher e Parkinson. À dra Mariana Spitz, pela colaboração.

Em particular agradeço ao $\mathrm{Dr}$ Zan Moustacchi pelo grande incentivo e confiança depositada. Ao excelentíssimo Dr Fernando Kok, pela amizade e pela possibilidade de compartilhar os achados.

À todo o pessoal da Genzyme pela bolsa de doutorado e pela admiração e seriedade que sempre demonstraram. Agradeço ao $\mathrm{Dr}$ Rogério Vivaldi, Eliana Tameirão, Roberto Fernandes, Rodrigo Azambuja, Daniella Jorge, Andréia Callipo e Claudia Mattos. À querida Cristiana Petriz e ao Dr Carlos Ruchaud pela convivência calorosa e pela eficiência e prontidão em ajudar. Aos queridos colegas de laboratório Fê, Raquel, Joana, Bruno, Gustavo, Denilse, Salame, Ana, Karla, Gaëlle, Enrico, Alexandre e Irina Kerkis, Marina Soukoian e todos os outros que passaram pelo nosso sensacional estabelecimento. Ao Christian pela grande amizade. Aos colegas de outros laboratórios e do Centro de Estudos do Genoma Humano, Cibele Masotti, Juliana, Luciana, Cinthia Fridman, Carol Morgante, Rafaella, Jacaré, Cris, 
Marília, Larissa, Lincoln, Freddy, Zé, Carla, Rominy, Renata e Karen. Em particular à Silvia e a Martha pelas ajudas com o seqüenciamento e dHPLC. Agradeço em particular a Claudia Blanes Angeli pelas revisões dos trabalhos.

Aos professores do depto de Genética e Biologia Evolutiva do IB-USP com os quais tive a oportunidade de aprender: Regina Célia Mingroni Neto, Célia Koiffmann, Ângela Morgante, Lyria Mori e Maria Rita Passos Bueno. A profa Mariz Vainzoff pela oportunidade de compartilhar momentos muito enriquecedores em sala de aula e na frente do computador. Aos espirituosos profs Bernardo Beiguelman, Henrique Krieger e Paulo Alberto Otto agradeço pela genialidade cotidiana.

À todos os que trabalham no depto de genética e no IB, em particular ao Paulo, Deisy, Helenice, Lurdes, Helder, Neide e Maraísa. Às queridas Fátima e Mara pela amizade e aos meus amigos pessoais Ozzy, Sandro, Paulê e Gera.

Enfim agradeço a todos os que tenham contribuído para a execução desta tese de doutorado. 


\section{Índice}

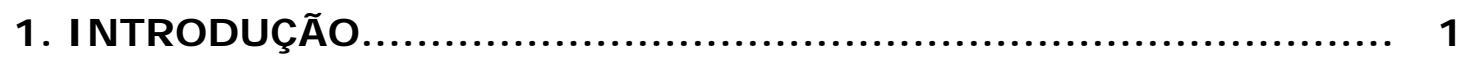

1.1. As doenças de Gaucher e Tay-Sachs: paradigmas em genética humana.

1.2. A doença de Tay-Sachs......................................... 3

1.3. A doença de Gaucher........................................... 7

1.3.1. Aspectos clínicos e bioquímicos........................... 7

1.3.2. Aspectos do diagnóstico................................ 12

1.3.3. Aspectos genéticos e moleculares......................... 13

a) Relação genótipo-fenótipo............................... 14

b) Mutações no gene GBA............................... 18

c) Pseudogene............................................. 21

1.3.4. Terapia de reposição enzimática e outros tratamentos...... 22

1.4. Objetivos..................................................... 27

\section{ANÁLISE MOLECULAR DE FORMAS CLÁSSICAS E NÃO- CLÁSSI CAS DA DOENÇA DE TAY-SACHS.................................}

2.1. A doença de Tay-Sachs em pacientes Brasileiros: prevalência da mutação IVS7+1g>c.

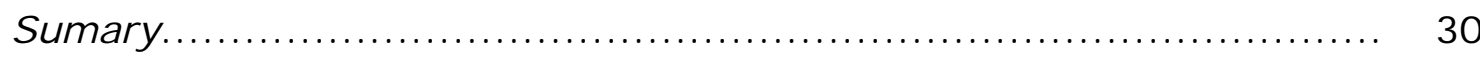

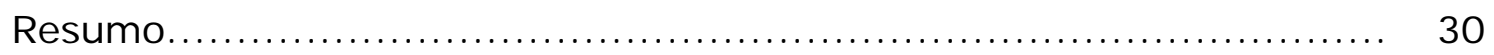

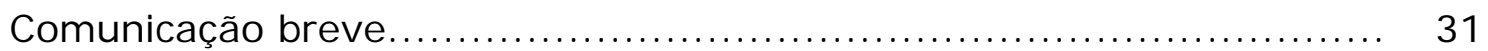

2.2. Diagnóstico e caracterização molecular de formas não-clássicas da doença de Tay-Sachs no Brasil....................................... 33

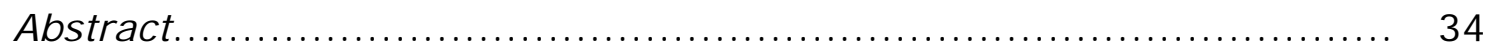

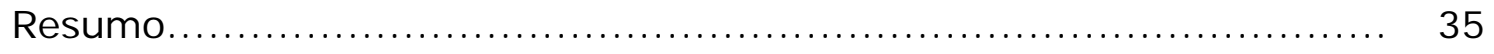

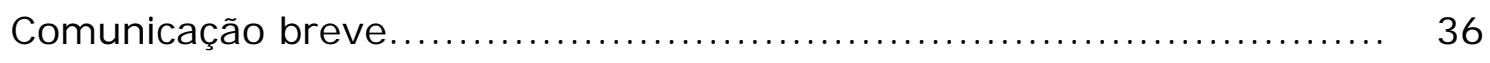

2.3. Discussão....................................................... 43

2.3.1. Pacientes da forma clássica da DTS...................... 43

2.3.2. Pacientes das variantes da DTS ......................... 45 
3.1. Análise molecular da doença de Gaucher no Brasil: prevalência da mutação G377S em pacientes de tipo 3.

Abstract.

Resumo.

Introdução.

Pacientes e métodos

Resultados

Discussão.

3.2. Detecção de mutações causadoras da doença de Gaucher por dHPLC seguido de seqüenciamento de DNA...

3.2.1. Introdução.

3.2.2. Material e métodos.

a) Pacientes estudados................................................ 67

b) Amplificação dos fragmentos de DNA............................ 67

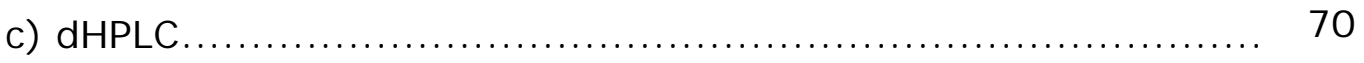

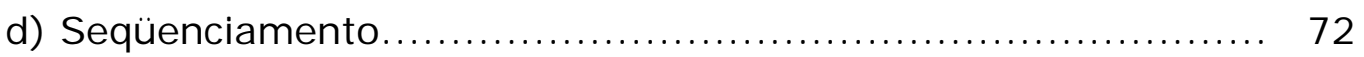

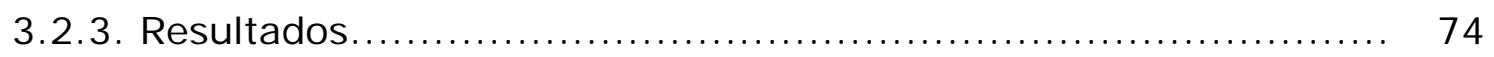

a) Análise por dHPLC seguido de seqüenciamento................. 74

b) Alterações silenciosas........................................... 77

c) Exemplos de cromatogramas alterados........................ 78

d) Mutações encontradas e relação genótipo-fenótipo................ 80

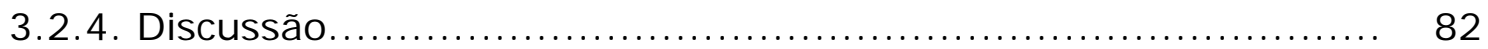

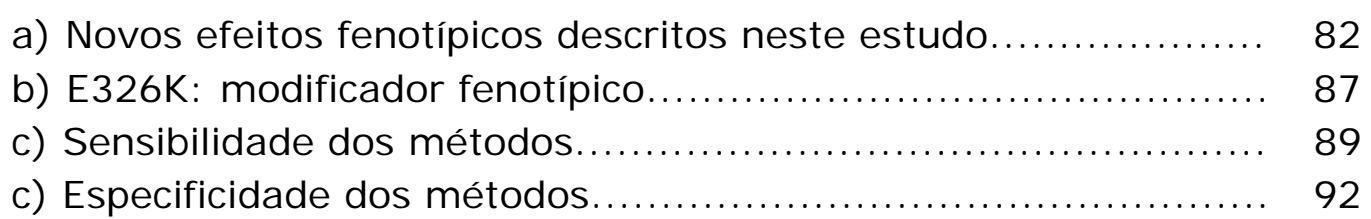

3.3. A doença de Parkinson e mutações no gene GBA no Brasil........... 94

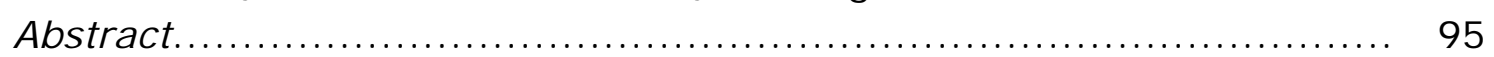

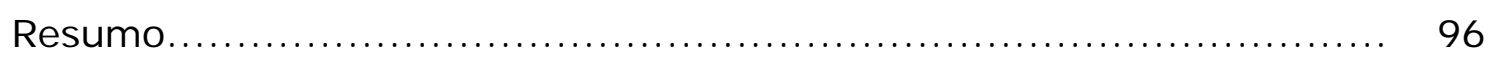

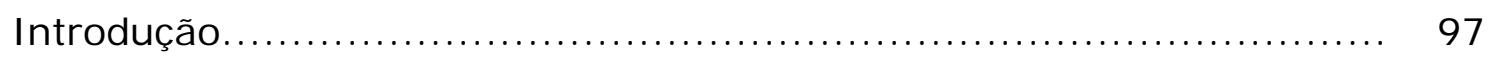

Material e métodos...................................................... 100

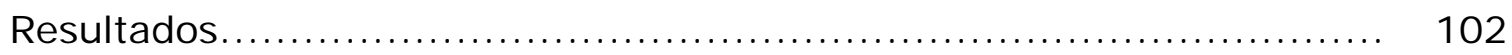

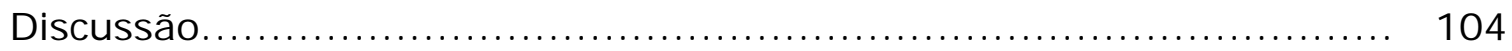

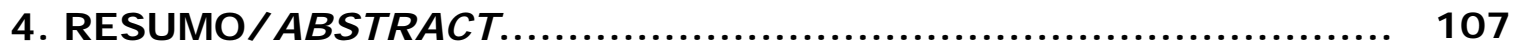

5. REFERÊNCI AS BI BLI OGRÁFI CAS........................................ 110 
Siglas e abreviaturas utilizadas neste trabalho

\author{
A: alanina \\ C: cisteína \\ CRIM SA: cross-reacting immunological material specific activity \\ D: ácido aspártico \\ DAL: doenças de armazenamento lisossômico \\ DG: doença de Gaucher \\ dHPLC: cromatografia líquida denaturante de alta performance \\ DNA: ácido desoxirribonucléico \\ dNTP: desoxirribonucleotídeos \\ DP: doença de Parkinson \\ DTS: doença de Tay-Sachs (forma clássica) \\ E: ácido glutâmico \\ EUA: Estados Unidos da América \\ F: fenilalanina \\ G: glicina \\ GCase: $\beta$-glicosidase ácida (glicocerebrosidase) \\ $\mathrm{H}$ : histidina \\ I: isoleucina \\ $\mathrm{K}$ : lisina \\ $\mathrm{Kb}$ : quilobases \\ $\mathrm{Kg}$ : quilogramas \\ L: leucina \\ M: metionina \\ $\mathrm{ml}$ : mililitro \\ $\mathrm{mM}$ : milimolar \\ $\mathrm{mV}$ : milivolts \\ $\mu \mathrm{l}$ : microlitros \\ $\mu \mathrm{M}$ : micromolar \\ $\mathrm{N}$ : asparagina \\ P: prolina \\ pb: pares de base \\ PCR: reação em cadeia da polimerase \\ Q: glutamina \\ R: arginina \\ RECs: alelos recombinantes \\ RFLP: polimorfismos de tamanhos de fragmentos de restrição \\ rpm: rotações por minuto \\ S: serina \\ $\mathrm{T}$ : treonina \\ TRE: terapia de reposição enzimática \\ UV: ultravioleta \\ V: valina \\ W: triptofano \\ Y: tirosina
}




\section{I NTRODUÇÃO}

\subsection{As doenças de Gaucher e Tay-Sachs: paradigmas em genética humana}

A doença de Gaucher (DG) e a doença de Tay-Sachs (DTS) são erros inatos do metabolismo de herança autossômica recessiva que pertencem ao grupo das doenças de armazenamento lisossômico (DAL). As duas são consideradas paradigmas de intervenção em genética humana: a DTS por ter sido a primeira doença para a qual se desenvolveu um programa preventivo de triagem populacional de heterozigotos e a DG por ser a primeira para a qual se estabeleceu a terapia de reposição enzimática (TRE). Tanto o programa de prevenção estabelecido para a DTS como o de tratamento desenvolvido para a DG são atualmente aplicados com sucesso a diversas outras doenças genéticas humanas (Kaback et al., 1993; Brady \& Schiffman 2004; Desnick 2004).

Em se tratando da prevalência, a DG e a DTS também apresentam uma acentuada importância. Entre as DAL, a DG é a que apresenta maior incidência e impacto econômico (Beutler \& Grabowski, 2001). No entanto, em Portugal, uma variante juvenil da DTS é ainda mais freqüente que a DG, indicando a relevância de seu estudo no Brasil (Pinto et al., 2004).

As DAL são um grupo de aproximadamente 50 doenças conhecidas, causadas pela deficiência ou ausência de atividade de uma enzima lisossômica, com conseqüente acúmulo do substrato em tecidos específicos. Essa especificidade tecidual determina os diferentes fenótipos clínicos de cada uma delas (Pastores \& Barnett, 2005). Muitas DAL, entre elas a DG e a DTS, apresentam alterações na via metabólica dos esfingolipídeos (figura 1.1). 


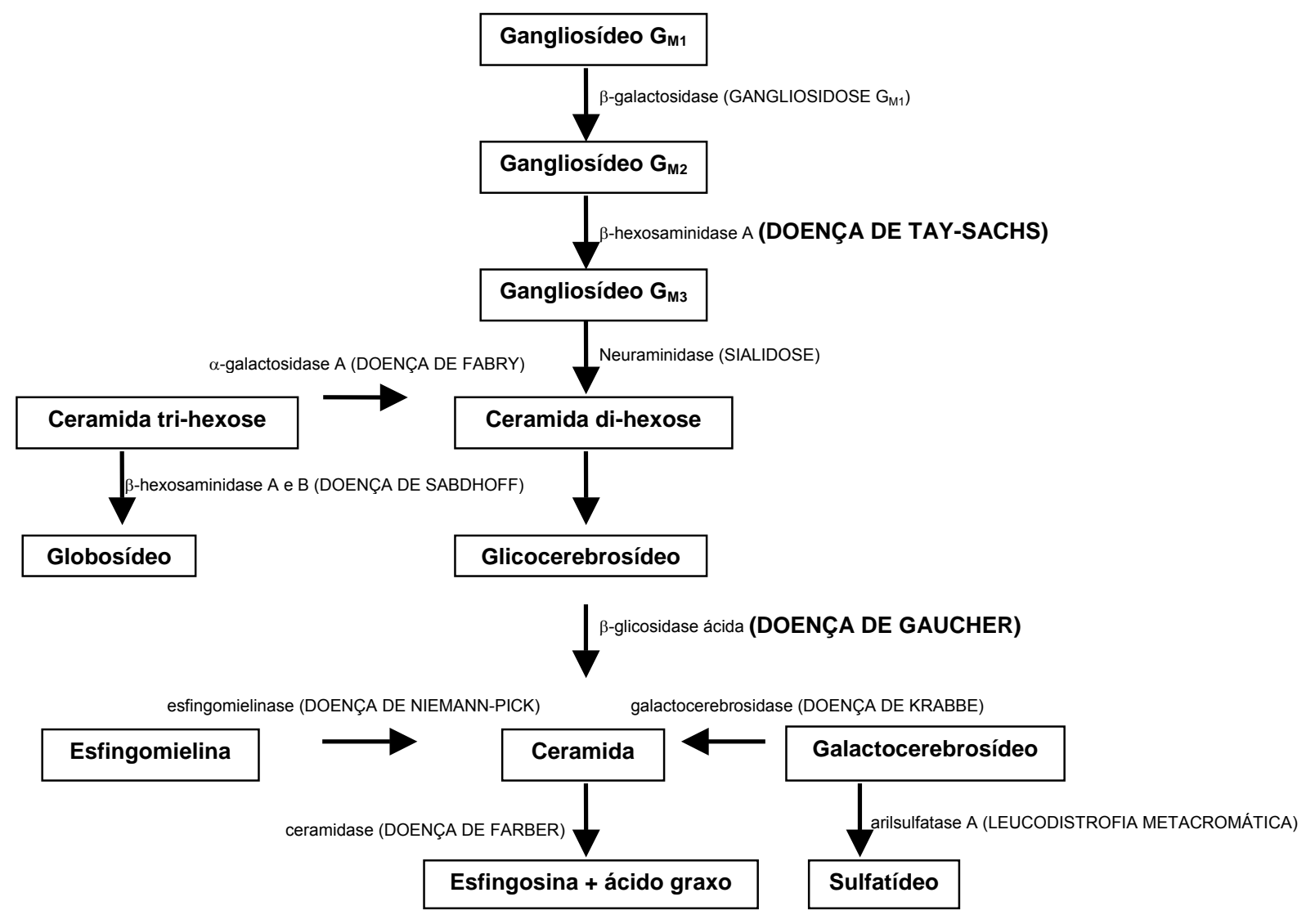

Figura 1.1: Mapa do catabolismo dos esfingolipídeos e distúrbios associados (Glew et al., 1985). Os esfingolipídeos estão descritos nas caixas, ao passo que as enzimas responsáveis pela sua degradação assim como a doença associada estão mostradas ao lado ou acima das setas.

A maioria das DAL conhecidas tem padrão de herança autossômico recessivo, à exceção das três formas ligadas ao cromossomo $\mathrm{X}$ : doença de Danon, doença de Fabry e síndrome de Hunter ou Mucopolissacaridose tipo 2. Embora cada uma das DAL tenha baixa prevalência, a incidência combinada é de 1 em cada 5.000 a 1 em cada 8.000 nascimentos (Meikle \& Hopwood, 2003; Pastores \& Barnett, 2005). Algumas populações possuem incidências mais altas de DAL específicas, tais como a DG e a DTS, discutidas adiante. O diagnóstico pré-natal é possível para todas as DAL embora em alguns casos dependa do conhecimento das mutações que segregam nas famílias envolvidas. Atualmente o estudo das DAL vem promovendo um extenso desenvolvimento de novas terapias. A tabela 1.1 mostra as opções terapêuticas já aprovadas e aquelas que ainda se encontram em fase de estudo. Uma vez que os tratamentos para essas doenças 
raras são extremamente custosos, a alocação de recursos para financiá-los tornou-se uma importante questão de saúde pública em todo o mundo, inclusive no Brasil, onde segundo a Lei $n^{\circ}$ 10.938, de 19 de outubro de 2001, os Estados devem arcar com o custo dos medicamentos especiais.

Tabela 1.1. Tratamentos já aprovados e em fase de estudo para diversas doenças de armazenamento lisossômico (Pastores \& Barnett, 2005).

\begin{tabular}{|ll|}
\hline Tratamento & Doenças-alvo \\
\hline Terapia de reposição enzimática & $\begin{array}{l}\text { Aprovada para DG, Fabry, Hurler-Scheie (MPS I) e Marateaux-Lamy (MPS VI); } \\
\text { em fase de aprovação para doença de Pompe e Síndrome de Hunter (MPS II) }\end{array}$ \\
\hline Terapia de redução de substrato & $\begin{array}{l}\text { Aprovada para DG; em estudo para Fabry, DTS (variantes de início tardio), } \\
\text { Niemann-Pick tipo C e DG tipo 3 }\end{array}$ \\
\hline Terapia com chaperones & Em estudo para DG e Fabry \\
\hline Transplante de medula óssea & Hurler (MPS IV), Marateaux-Lamy (MPS VI), Krabbe (Leucodistrofia de célula \\
& globóide), Leucodistrofia metacromática, a-manidose \\
\hline Terapia gênica & Em estudo para DG (triagem clínica) e estudo em modelos animais para outras \\
& DAL \\
\hline
\end{tabular}

DAL: doenças de armazenamento lisossômico; DG: doença de Gaucher; MPS: Mucopolissacaridose.

\subsection{A doença de Tay-Sachs}

A DTS (MIM 272800) é causada por mutações no gene HEXA, localizado em 15q23-24, que codifica a subunidade $\alpha$ da enzima $\beta$-hexosaminidase A (Hex A). Na ausência dessa enzima ou de sua proteína ativadora, o seu substrato, gangliosídeo $\mathrm{G}_{\mathrm{M} 2}$, acumula-se progressivamente nos neurônios do sistema nervoso central levando a um quadro clínico de degeneração neurológica progressiva. Na forma clássica da DTS, as crianças afetadas apresentam os primeiros sintomas ao redor dos 6 meses de idade e o óbito acontece geralmente entre 2 e 3 anos de idade, nunca após os 5 anos.

Entre as doenças do armazenamento lisossômico, a DTS pertence a um subgrupo de doenças denominadas gangliosidoses $\mathrm{G}_{\mathrm{M} 2}$. Esse conjunto inclui as formas raras da DTS de início juvenil e tardio, a doença de Sandhoff (MIM 268800) e a deficiência de ativador do complexo gangliosídeo $G_{M 2}$-hex A (MIM 272750). A hex A é uma proteína do tipo heterodímero, composta por uma cadeia 
a e uma cadeia $\beta$. A hexosaminidase $B$ é um homodímero formado por duas cadeias $\beta$.

Clinicamente, a forma clássica da DTS é marcada pela constância da idade de início das manifestações patológicas e pela uniformidade do seu progresso. $\mathrm{Na}$ maioria dos casos não há associação com a pré-maturidade ou com intercorrências decorrentes da doença durante a gravidez. A criança apresenta um desenvolvimento normal logo após o nascimento. Freqüentemente, os primeiros sinais são observados por volta dos 6 meses de vida, incluindo falta de tônus muscular, apatia, deficiência auditiva e visual, acompanhada de nistagmo. Ao exame clínico pode se observar uma resposta estereotipada de sobressalto a estímulos auditivos agudos. Em casos duvidosos, o exame oftalmológico pode ser um forte indicador da doença. A fundoscopia revela um ponto vermelho-cereja na retina dos afetados. Essa mancha macular é devida à deposição lipídica nas células ganglionares da retina, o que desnuda a camada pigmentar subjacente (Kolodny, 1979). Embora não seja patognomônica, a mancha vermelho-cereja é encontrada nos pacientes com a forma clássica da DTS e da doença de Sandhoff (deficiência das hexosaminidases $A$ e $B$ ), sendo um forte indício dessas doenças (Gravel et al., 1995). A suspeita clínica pode ser confirmada em análise bioquímica mostrando baixa atividade da Hex A, ou através do diagnóstico molecular.

No primeiro ano de vida, a criança pode ser atraída pela luz e mover os olhos, seguindo objetos. Posteriormente, advém uma cegueira total. $O$ paciente torna-se incapaz de manter a cabeça firme ou de sentar e não aprende a falar. $O$ estado mórbido progride rapidamente até a perda total de movimentação. Na fase terminal, a criança não se alimenta sem a ajuda de tubos e tornam-se típicos os problemas bronquiais, a pneumonia e as convulsões. O paciente torna-se letárgico e vai a óbito normalmente por complicações respiratórias até os dois anos de idade, podendo sobreviver até o quinto ano de vida em alguns casos (Slome, 1933; Mange \& Mange, 1989; Gravel et al., 1995).

Pacientes de variantes juvenis (ou subagudas) da DTS são raramente encontrados, mas quando presentes, mostram uma sobrevida até a segunda ou terceira década. Uma variante de início tardio (ou forma crônica) da DTS também 
pode ser encontrada, onde o diagnóstico é feito geralmente na idade adulta e cujos pacientes apresentam sobrevida prolongada. Uma forma juvenil da DTS, denominada variante $\mathrm{B} 1$, é caracterizada pela presença de uma enzima de estrutura inalterada, porém com mutações que afetam seu sítio ativo, prejudicando a afinidade da Hex $A$ ao gangliosídeo $G_{M 2}$. A existência dessas variantes menos ominosas se deve a uma atividade residual das enzimas mutantes (Conzelmann et al., 1983). A tabela 1.2 mostra um resumo das variantes da DTS e suas nomenclaturas alternativas.

Tabela 1.2. Variantes das gangliosidoses $\mathrm{G}_{\mathrm{M} 2}$.

\begin{tabular}{|c|c|c|c|c|c|c|}
\hline & NOME & $\begin{array}{c}\text { Hex } \\
\text { A }\end{array}$ & $\begin{array}{c}\text { Hex } \\
\text { B }\end{array}$ & Ativador & $\begin{array}{c}\text { GENE e } \\
\text { Loci }\end{array}$ & $\begin{array}{l}\text { Produto } \\
\text { alterado ou } \\
\text { ausente }\end{array}$ \\
\hline Variante B & DTS & - & + & + & $\begin{array}{c}\text { HEXA } \\
15 q 23-q 24\end{array}$ & $\begin{array}{c}\text { subunidade } \\
\text { alfa da } \\
\text { Hex A }\end{array}$ \\
\hline Variante 0 & Doença de Sandhoff & - & - & + & $\begin{array}{c}\text { HEXB } \\
5 q 13\end{array}$ & $\begin{array}{c}\text { subunidade } \\
\text { beta das } \\
\text { hex } A \text { e } B\end{array}$ \\
\hline Variante $A B$ & Deficiência de ativador & + & + & - & $\begin{array}{c}G M 2 A \\
5 q 31.3-q 33.1\end{array}$ & Ativador \\
\hline Variante B1 & Variante pseudo $A B$ & + & + & + & $\begin{array}{c}H E X A \\
15 q 23-q 24\end{array}$ & $\begin{array}{l}\text { Sítio ativo da } \\
\text { Cadeia alfa }\end{array}$ \\
\hline
\end{tabular}

-: ausência de atividade enzimática; +: presença de atividade enzimática.

A DTS se apresenta com maior prevalência nas populações judaica Ashkenazita (descendentes de judeus que habitaram as regiões do Centro e Leste europeu na Idade Média) e Franco-Canadense, com uma incidência de aproximadamente 1 afetado em cada 4.000 nascimentos, que é cem vezes maior que a da população em geral de diversos países (Kaback et al., 1993). Alguns outros isolados populacionais também apresentam maior prevalência da doença, incluindo um no Norte de Portugal, onde se encontra preferencialmente a variante B1, causada pela mutação R178H (Santos et al., 1991), que também já foi descrita em pacientes italianos (Montalvo et al., 2005).

Com o desenvolvimento do diagnóstico pré-natal para a DTS em 1969, diversos casais passaram a buscar essa opção após terem tido uma criança 
afetada. Após o estabelecimento desse tipo de diagnóstico, apenas casais com histórico familial da DTS poderiam buscar essa alternativa. Para detectar todos os casais em risco de determinada população e não apenas aqueles com histórico familial, foram estabelecidos programas de detecção populacional de heterozigotos.

Os programas de triagem populacional são desenvolvidos desde a década de 70 nas populações judaicas de diversos países e também entre Francocanadenses. Esses programas visam possibilitar que casais em risco sejam identificados e recebam aconselhamento genético antes do nascimento de uma criança afetada. Na sua maioria, os casais em risco optam pelo diagnóstico prénatal, seguido de interrupção de gravidez no caso do feto ser afetado pela DTS. Apesar desse aspecto seletivo, os casais em risco passaram a ter mais filhos como conseqüência desses programas. As outras opções para casais em risco incluem a abstenção reprodutiva, "correr o risco", a adoção, a utilização de gametas de doadores testados e mais recentemente o diagnóstico préimplantação (Fasouliotis \& Schenker, 1998).

Desde que o diagnóstico pré-natal tornou-se disponível para casais em risco, e com o estabelecimento desses programas preventivos a incidência da DTS foi reduzida em 90\% (Kaback et al., 1993; Mitchell et al., 1996). Em 1993, pela primeira vez pode-se verificar que os casais que buscavam aconselhamento genético haviam sido detectados na sua maioria nos programas de detecção de heterozigotos, ao passo que anteriormente, o histórico familiar era a indicação mais freqüente (Kaback et al., 1993). Atualmente, o modelo desenvolvido para a DTS é aplicado a diversas outras doenças, tais como a anemia falciforme na população negra de diversos países, a $\beta$-talassemia em Gregos e Italianos, a $\alpha$ talassemia no Sudeste da Ásia e em Chineses, e a fibrose cística em nórdicos Europeus (Jorde et al., 2000).

Um estudo realizado por nosso grupo demonstrou a importância de se desenvolver tal programa na população judaica Brasileira (Rozenberg \& Pereira, 2001). No entanto, é importante notar o tamanho reduzido dessa população. Segundo o censo de 2.000, a população judaica Brasileira é composta por 
aproximadamente 100.000 indivíduos, o que corresponde a apenas $0,06 \%$ da população Brasileira. Dessa forma, um programa preventivo deve ser discreto e proporcional, tendo sido destacada a importância de uma abordagem nãoalarmista da questão.

Não existem dados sobre a prevalência da DTS no Brasil. No entanto, em diversos países observou-se que a incidência é cerca de 100 vezes menor na população em geral do que aquela observada na população judaica. Como os judeus representam menos que $0,1 \%$ da população Brasileira pode-se especular que uma minoria dos casos da DTS no Brasil deve se apresentar em famílias dessa origem étnica. Essa hipótese foi confirmada no estudo apresentado no capítulo 2.1 deste trabalho e se refletiu na presença de mutações diferentes das encontradas na população judaica e curiosamente na prevalência de uma mutação já descrita em pacientes Portugueses. Alguns pacientes das formas nãoclássicas da DTS também foram remetidos ao nosso laboratório para análise molecular. Esses casos são apresentados no capítulo 2.2 e mostram uma prevalência da mutação $\mathrm{R} 178 \mathrm{H}$ nos casos da variante $\mathrm{B} 1$, também associada à origem Portuguesa.

\subsection{A doença de Gaucher}

\subsubsection{Aspectos clínicos e bioquímicos}

A DG é a principal doença de armazenamento lisossômico, sendo causada por mutações que afetam a enzima $\beta$-glicosidase ácida, também chamada glicocerebrosidase (GCase). A atividade deficiente da GCase leva ao acúmulo do glicocerebrosídeo, um esfingolipídeo derivado do catabolismo de hemácias e leucócitos (figura 1.2). O sítio de acúmulo são as células do sistema reticuloendotelial, principalmente os macrófagos. Diversas moléculas derivadas da ativação de macrófagos aparecem em níveis elevados no plasma de pacientes da DG, mas ainda não se sabe se estão associadas a manifestações patológicas (Jmoudiak \& Futerman, 2005). As células com excesso de armazenado 
lisossômico assumem um aspecto característico, baloniforme, e são chamadas células de Gaucher, podendo ser usadas no diagnóstico da doença. As células de Gaucher acumulam-se principalmente no fígado, baço, ossos, medula óssea e às vezes nos pulmões, levando assim às manifestações clínicas da doença. Assim, é comum o afetado apresentar sintomas como dores abdominais e ósseas, fadiga, limitações físicas nos exercícios, fraqueza, atraso no crescimento, entre outros (Beutler \& Grabowski, 1995). Em suma, os sintomas são normalmente multissistêmicos, às vezes desfigurantes e podem levar à morte. Indivíduos heterozigotos possuem quantidade suficiente de GCase para a digestão do glicocerebrosídeo, não apresentando nenhum sintoma da doença.

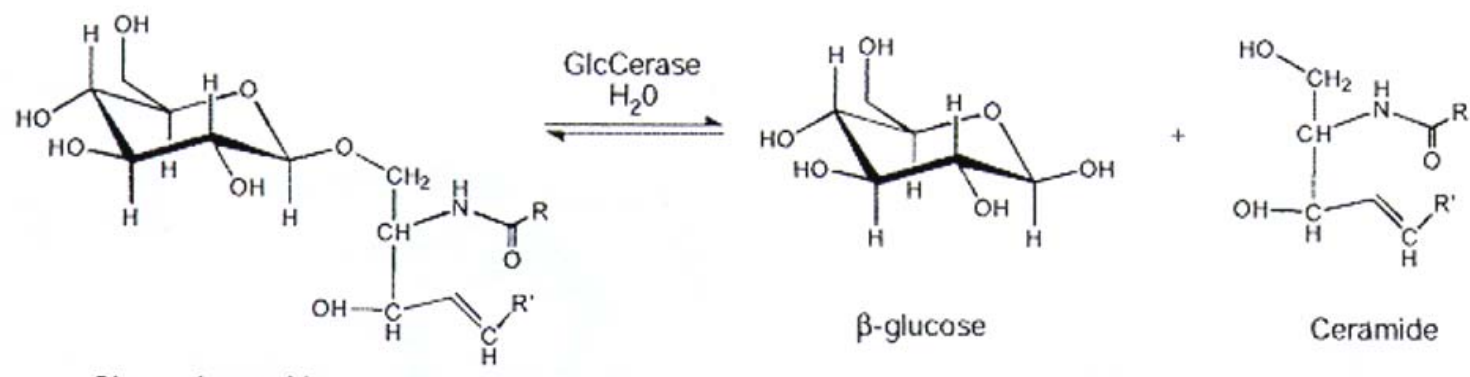

Glucosylceramide $\mathrm{R}, \mathrm{R}^{\prime}=\left(\mathrm{CH}_{2}\right)_{13-21} \mathrm{CH}_{3}$

Figura 1.2. Reação de hidrólise do glicocerobrosídeo (glicosilceramida) (Dvir et al., 2003).

O médico francês Philippe Charles Ernest Gaucher, em 1882, descreveu pela primeira vez a doença em uma mulher de 32 anos, tendo observado tamanhos anormais do baço e fígado. De fato, dentre os principais efeitos da DG, decorrentes da presença das células de Gaucher, o que mais chama a atenção é a hepatoesplenomegalia (figura 1.3A). O fígado pode atingir um volume 10 vezes maior que o normal, enquanto o baço pode apresentar aumento de até 70 vezes. Apesar da maioria dos pacientes da DG ser diagnosticada pelas alterações hematológicas e/ou pela hepatoesplenomegalia, complicações esqueléticas tais como a osteopenia generalizada (diminuição da densidade mineral óssea), a necrose avascular e as crises de dor óssea geralmente coexistem e podem ser a 
causa de sérias debilitações. Aproximadamente $80 \%$ dos pacientes apresentam a deformidade "em frasco de Erlenmeyer", uma deformação óssea que ocorre devido à falha do remodelamento ósseo e perda da concavidade normal, principalmente no fêmur dos afetados. O número de leucócitos, plaquetas e hemoglobinas pode estar diminuído em relação ao normal. É possível também a substituição, ao longo do tempo, da medula óssea por células de Gaucher. Dependendo da gravidade da doença pode existir também um comprometimento neurológico, como será discutido adiante.

A DG pode ser dividida em três tipos principais (tabela 1.3). A doença tipo 1 (MIM 230800) é a mais freqüente, representando cerca de $95 \%$ dos casos da DG e com sintomas menos comprometedores (Beutler \& Grabowski, 2001). Os pacientes de tipo 1 apresentam sinais, sintomas e curso variáveis, mesmo entre indivíduos com as mesmas mutações. A variação do quadro clínico vai desde a existência de homozigotos recessivos sem sintomas, ou com sintomas leves, até o risco de vida. No entanto, não ocorre envolvimento neurológico grave no quadro clínico dos pacientes de tipo 1. O início dos sintomas pode ocorrer em qualquer idade (figura 1.3A).

Os tipos 2 (OMIM 230900) e 3 (OMIM 231000) da DG apresentam complicações neurológicas. O tipo 2 é mais grave, sendo também denominado forma neuronopática "infantil", por aparecer precocemente e progredir rapidamente, com óbito do paciente até os dois anos de idade. $O$ início das manifestações ocorre em torno dos três meses de idade e os achados mais freqüentes são: visceromegalia, irritabilidade exagerada, estrabismo e retroflexão da cabeça em opstótono que é bastante característico (figura 1.3B). 


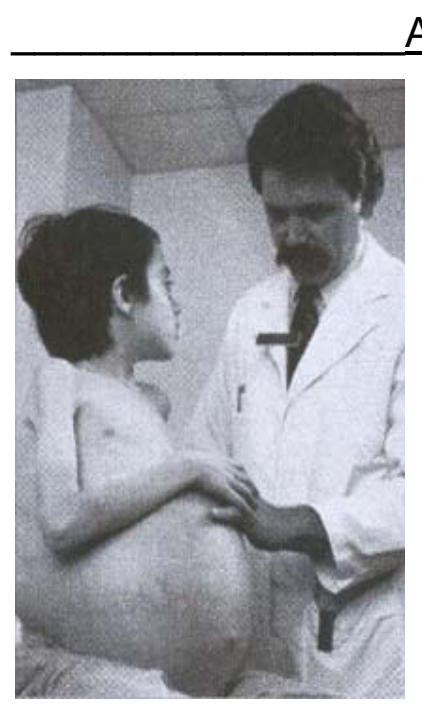

A

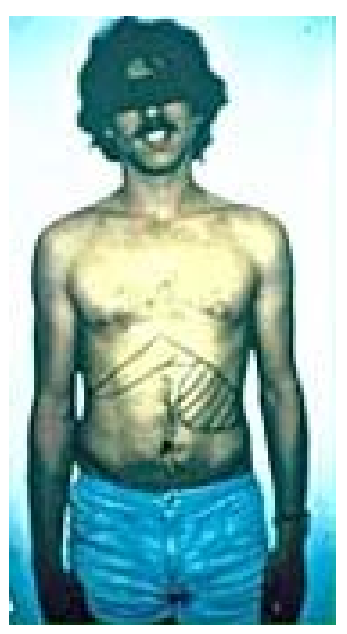

B

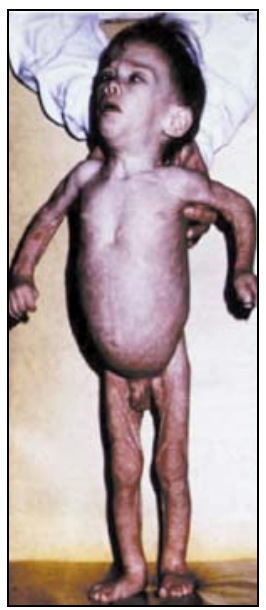

C

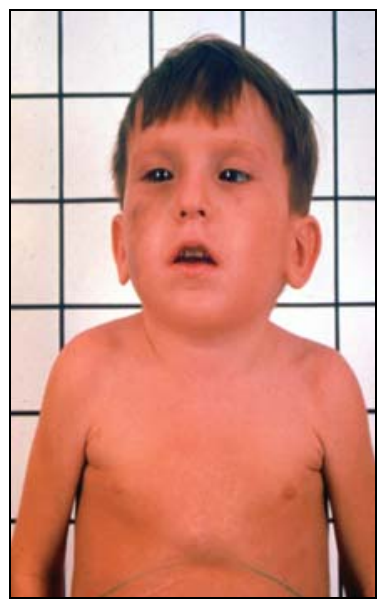

Figura 1.3. A: pacientes da DG de tipo 1; B: paciente tipo 2; C: paciente tipo 3 (veja texto).

Uma variante rara da DG, conhecida por forma letal-perinatal, é freqüentemente considerada como tipo 2. No entanto, é uma entidade clínica diferente (Mignot et al., 2003). Nessa variante, é freqüente observar hidropsia fetal, ictiose, dismorfia facial, hepatoesplenomegalia e óbito intra-uterino ou perinatal, até 3 meses de idade. O genótipo geralmente apresenta alelos recombinantes (descritos adiante).

O tipo 3 da DG é denominado forma neuronopática juvenil já que os distúrbios aparecem mais tarde e de forma mais gradual que no tipo 2. A idade média do início dos sintomas é 1 ano de idade, variando do início da vida até a pré-adolescência. O primeiro sintoma neuronopático são as alterações oculomotoras (figura 1.3C), que se apresentam, na metade dos casos, até o fim da primeira década de vida (Beutler \& Grabowski, 2001). Alguns autores sugerem a divisão dos pacientes de tipo 3 em dois subgrupos: tipos $3 a$ e $3 b$, conforme as diferenças de idade no início da doença, do fenótipo e das complicações.

O tipo 3a, mais ominoso, é típico de pacientes da região Norrbotten, no Norte da Suécia. No início da doença, geralmente no fim da infância, o acometimento sistêmico é leve, sendo caracterizado por hepatoesplenomegalia seguido de apraxia oculomotora ou estrabismo convergente que progride para paralisia ocular, mioclonia, demência, ataxia e crises convulsivas. A morte deve-se 
a degeneração funcional do sistema nervoso central em idades mais avançadas, variando entre a segunda e a quarta década de vida. A segunda forma de apresentação (tipo3b) é pan-étnica e tem início no começo da infância e com sintomas sistêmicos graves, mas com envolvimento neurológico mínimo, às vezes restritos a paralisia da motilidade ocular supranuclear. No começo pode ser difícil diferenciá-la do tipo 1 , pela lentidão na progressão dos sintomas neurológicos. A DG do tipo 3b é marcada por hepatomegalia, complicações esqueléticas e cárdiorespiratórias. Antes do advento da terapia de reposição enzimática, esses pacientes morriam na infância ou início da adolescência por complicações pulmonares ou hepáticas, podendo em alguns casos atingir até a quarta década de vida.

Alguns autores sugerem ainda a existência do tipo 3c, associada ao genótipo D409H/D409H e D409H/REC, na qual os afetados apresentam apraxia oculomotora, visceromegalia mínima e doença cardíaca valvular com calcificação progressiva da aorta. Essas subdivisões do tipo 3 da DG não são amplamente utilizadas na literatura especializada (Vellodi et al., 2001). Alguns autores argumentam a favor de um contínuo fenotípico nas variantes neuronopáticas da DG (Goker-Alpan et al., 2003; Sidransky, 2004), ao passo que outros argumentam que o tipo 2 da DG é caracterizado como uma entidade clínica homogênea (Mignot et al., 2006).

Tabela 1.3. Principais características das variantes da DG.

\begin{tabular}{|l|c|c|c|}
\hline & TIPO 1 & TIPO 2 & TIPO 3 \\
\hline $\begin{array}{l}\text { Envolvimento neurológico } \\
\text { primário }\end{array}$ & não & +++ & + a ++ \\
\hline Idade de início & infantil, juvenil ou adulta & infantil & juvenil \\
\hline Incidência & $\begin{array}{c}1 \text { em } 40.000 \text { a 1 em } 60.000 \\
1 \text { em 450 a 1 em 1.500 na PJA }\end{array}$ & $\begin{array}{c}\text { menor que 1 em } \\
100.000\end{array}$ & $\begin{array}{c}\text { menor que 1 em } \\
50.000 \text { a } 1 \text { em 100.000 }\end{array}$ \\
\hline Idade do diagnóstico & qualquer idade & primeira infância & infância \\
\hline $\begin{array}{l}\text { Expectativa de vida } \\
\text { (sem TRE) }\end{array}$ & 6 a 80 anos & $\begin{array}{c}\text { menos de } 2 \\
\text { anos }\end{array}$ & 2 a 16 anos \\
\hline Hepatoesplenomegalia & + a +++ & + & + a +++ \\
\hline Anomalias hematológicas & + a +++ & +++ & + a +++ \\
\hline Anomalias esqueléticas & ausente a +++ & Ausente & Ausente a +++ \\
\hline
\end{tabular}

+: leve; + +: moderado; + + + : grave. PJA: População Judaica Asquenazita (Beutler \& Grabowski, 1995; Beutler \& Gelbart, 1998). 


\subsubsection{Aspectos do diagnóstico}

Após a suspeita clínica, o diagnóstico da DG é geralmente estabelecido através do teste bioquímico da atividade da GCase nos leucócitos ou fibroblastos extraídos da pele. O resultado geralmente mostra atividade entre 10 a $15 \%$ do normal para o tipo 1 e menos que 10\% para casos mais graves. Embora exista uma correlação entre os três tipos da doença e os níveis residuais de atividade da GCase, tais medidas não são confiáveis para o prognóstico da doença, havendo ainda extensa sobreposição de valores obtidos para heterozigotos com aqueles de pacientes e de indivíduos normais. Assim, o diagnóstico bioquímico não tem precisão para detectar heterozigotos, mas o diagnóstico molecular pode ser usado para esse fim. A detecção de mutações oferece ainda um complemento diagnóstico ao exame enzimático com a vantagem de ter valor prognóstico, uma vez que permite diferenciar os tipos neuropáticos da DG (tipo 2 e 3 ) do tipo não neuropático (tipo 1) quando são detectadas mutações que apresentam relações genótipo-fenótipo conhecidas. Esse é o caso das mutações mais freqüentes, como a N370S e a L444P, presentes em mais de $70 \%$ dos casos da DG na maioria das populações. A detecção precoce da DG, acompanhada do valor prognóstico do diagnóstico molecular podem ser críticos para se estabelecer um tratamento adequado, possibilitando prevenir ou diminuir a presença de sintomas debilitantes e irreversíveis.

Indica-se o aconselhamento genético para as famílias com pacientes afetados pela DG tipo 2, uma vez que ao contrário dos pacientes de tipo 1 e 3 , aqueles apresentando o tipo 2 vão a óbito precocemente e não são tratados por TRE. O diagnóstico pré-natal é possível após a detecção das mutações envolvidas. O conhecimento da condição de portador (heterozigoto) pode eventualmente afetar escolhas reprodutivas e determinar as decisões a respeito de exames em outros familiares. 


\subsubsection{Aspectos genéticos e moleculares}

A DG possui mecanismo de herança autossômico recessivo e é causada por mutações no gene GBA (1q21), que codifica a enzima GCase, cuja deficiência total ou parcial pode levar à manifestação da doença (Sorge et al., 1985). O gene GBA possui aproximadamente $7 \mathrm{~Kb}$ e está subdividido em 11 exons, originando após o processamento um polipeptídio maduro de 497 aminoácidos (Horowitz et al., 1989). O transporte da GCase até a membrana do retículo endoplasmático rugoso requer um peptídeo sinalizador, que é removido na fase de maturação da enzima. Como o gene GBA possui dois codons ATG iniciadores funcionais, a seqüência removida pode ser de 39 ou de 19 aminoácidos (Sorge et al., 1987). A GCase recém-sintetizada é transportada ao lisossomo por uma via manosedependente, sendo a glicosilação da enzima crítica para esse transporte (Rijnboutt et al., 1991). A GCase é uma enzima que quando ativa, está associada à membrana lisossomal (Grace et al., 1990).

Dados precisos de incidência populacional da DG são escassos para a maioria das populações. Os poucos estudos existentes indicam uma prevalência de 1 em 50.000 a 1 em 200.000 em populações européias (Beutler \& Grabowski, 2001). Apesar de rara, a DG é a mais comum entre as DAL e de modo geral tem uma distribuição pan-étnica. A população Norbotniana do norte da Suécia tem alta incidência da DG tipo 3 ao passo que na população judaica Ashkenazita existe uma alta freqüência da doença de tipo $1 \mathrm{com}$ uma prevalência populacional de aproximadamente 1 em cada 10.000 nascimentos (Fried, 1973). No entanto, uma vez que a maioria dos homozigotos para a mutação mais freqüente nessa população, a N370S, não são diagnosticados devido à ausência de sintomas claros da doença, a prevalência de homozigotos deve ser maior, podendo chegar a aproximadamente 1 em cada 1.000 nascimentos (Beutler \& Grabowski, 2001). 


\section{a) Relação genótipo-fenótipo}

O fenótipo clínico dos pacientes da DG é resultado principalmente da combinação da gravidade das mutações nos dois alelos do paciente. Essas podem ser classificadas em três tipos: alelos nulos (nenhuma enzima é produzida), mutações graves (a enzima tem atividade muito baixa e instável) e mutações leves (a enzima tem atividade baixa, mas estável) (Beutler \& Gelbart,1998).

Como é mostrado na tabela 1.4, a combinação de duas mutações onde uma delas é de efeito leve, sempre leva o paciente a desenvolver o tipo 1 da DG, independentemente da segunda mutação (podendo até ser um alelo nulo). Isso porque o alelo com a mutação de efeito leve produz uma enzima com atividade catalítica residual suficiente para evitar que sintomas neuronopáticos se desenvolvam. Duas mutações de efeito grave em conjunto levam aos fenótipos do tipo 2 e 3, envolvendo o sistema neurológico, assim como na associação de uma mutação de efeito grave com um alelo nulo. A combinação de dois alelos de efeito nulo é inviável, levando a interrupções precoces de gravidez (Beutler \& Gelbart, 1998; Beutler et al., 2005). Essa classificação das mutações causadoras da DG, mostrada na tabela 1.4, é a idéia central de toda a caracterização das relações genótipo-fenótipo nessa doença.

Tabela 1.4. Relação entre genótipo e fenótipo na DG.

\begin{tabular}{|l|l|l|l|}
\hline & $\begin{array}{l}\text { Mutação } \\
\text { Leve }\end{array}$ & $\begin{array}{l}\text { Mutação } \\
\text { Grave }\end{array}$ & $\begin{array}{l}\text { Alelo } \\
\text { nulo }\end{array}$ \\
\hline $\begin{array}{l}\text { Alelo } \\
\text { Nulo }\end{array}$ & Tipo 1 & Tipo 2/3 & Inviável \\
\hline $\begin{array}{l}\text { Mutação } \\
\text { Grave }\end{array}$ & Tipo 1 & Tipo 2/3 & \\
\hline $\begin{array}{l}\text { Mutação } \\
\text { Leve }\end{array}$ & Tipo 1 & \multicolumn{2}{|l}{} \\
\cline { 1 - 2 } & &
\end{tabular}


Na tentativa de relacionar a gravidade da doença, o tipo de mutação e a estrutura da proteína GCase, dois estudos, usando raios- $X$, revelaram a estrutura tridimensional dessa enzima. O estudo de Dvir et al. (2003) mostra a localização de algumas mutações já descritas na proteína, representadas na figura 1.4 e o trabalho de Liou et al. (2006) revelou uma estrutura protéica idêntica, representada na figura 1.5. A proteína contém três domínios. O domínio I é formado pelos aminoácidos 1 a 27 e 383 a 414. Ele contém duas pontes dissulfídicas (aminoácidos 4-16 e 18-23) que podem ser necessárias para a estrutura terciária da proteína. O domínio II é formado pelos aminoácidos 30-75 e 431-497 e tem estrutura similar a de uma imunoglobulina. O primeiro e segundo domínios possivelmente têm função regulatória ou estrutural. O domínio III é formado pelos aminoácidos 76-381 e apresenta o sítio catalítico, formado pelos aminoácidos E325 e E340 (figura 1.4). Os domínios II e III parecem estar conectados por uma dobra flexível ao passo que o domínio I interage estreitamente com o domínio III. Após essas descrições da GCase, Premkumar et al. (2005) estudaram através da análise com raios- $X$ a estrutura da GCase conjugada a um inibidor irreversível (conduritol B). Esse estudo analisou as propriedades de duas alças próximas ao sítio ativo da enzima, formada pelos aminoácidos 345 a 349 e 394 a 399, mostrando que essas alças funcionam como uma tampa para o acesso ao sítio ativo.

As mutações podem impedir, parcial ou totalmente, a atividade catalítica da proteína ou interferir na estabilidade dessa. Aparentemente não existe uma distribuição espacial preferencial das mutações entre os diferentes domínios da proteína. As mutações de efeito leve e grave têm distribuição homogênea nos diferentes domínios, no entanto, a região próxima ao sítio ativo da enzima apresenta mutações de efeito grave, provavelmente por impedir diretamente a atividade catalítica (figura 1.4B). 

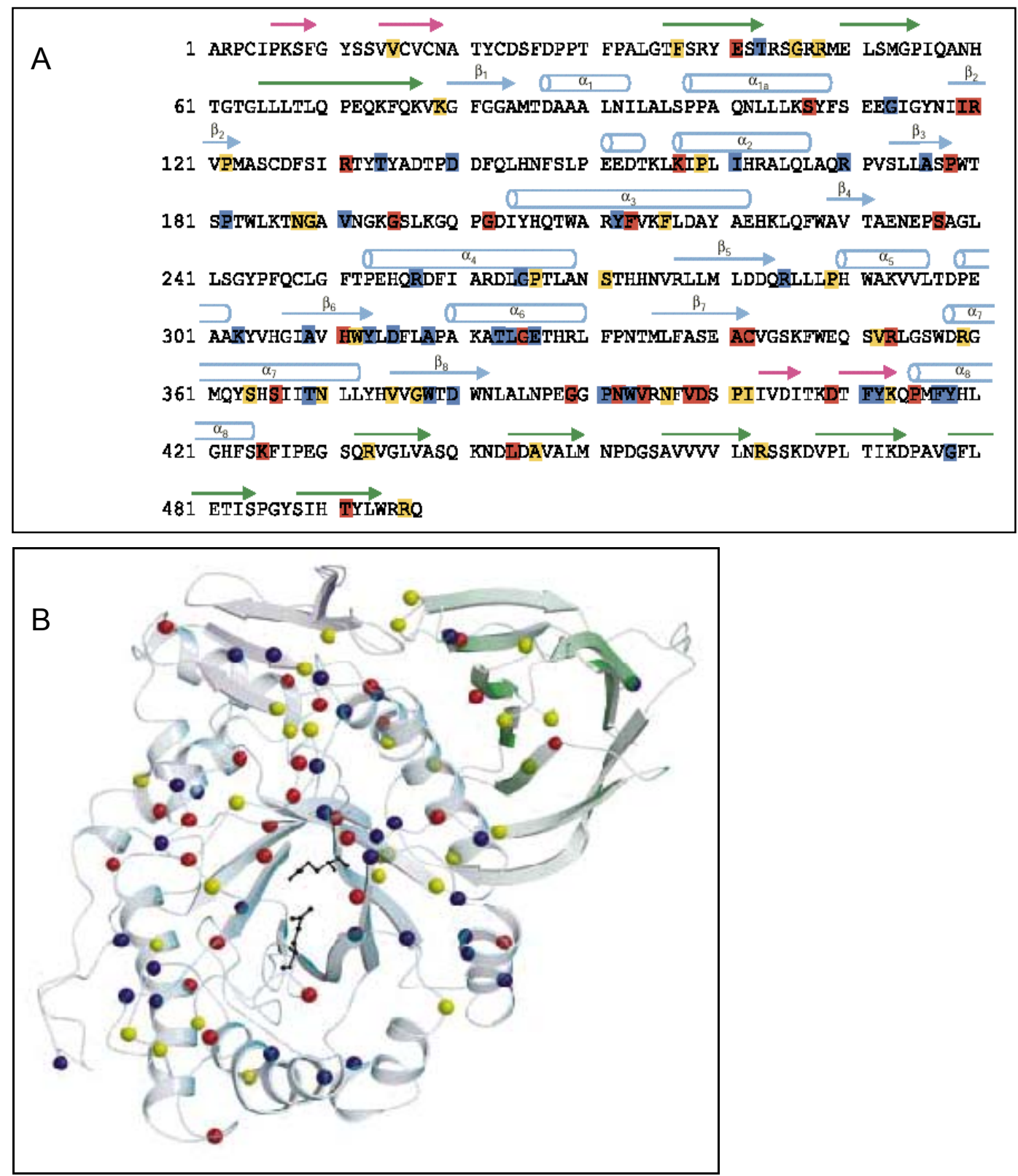

Figura 1.4. Mutações na estrutura tridimensional da GCase. A) Seqüência dos 497 aminoácidos da GCase. As mutações de efeito grave (http://life2.tau.ac.il/GeneDis/) são mostradas em vermelho, as de efeito leve em amarelo e aquelas sem dados clínicos descrevendo a gravidade em azul. Apenas mutações de ponto estão incluídas. B) Distribuição das mutações na estrutura tridimensional da GCase. O código de cores é o mesmo de A). Em alguns casos, a classificação dos fenótipos como leve (tipo 1) ou grave (tipos 2 e 3) foi baseado em poucos indivíduos e as vezes em apenas um. O fenótipo de diversas mutações é desconhecido, uma vez que as mutações foram detectadas em DNA genômico e a informação sobre o fenótipo não estava disponível. A estrutura dos aminoácidos glutamatos do sítio ativo são mostrados com retas e bolas pretas no centro da figura. A enzima recombinante usada na TRE, Cerezyme ${ }^{\circledR}$, difere da GCase por uma única substituição de aminoácido na posição 495 (His por Arg) (Dvir et al., 2003). 


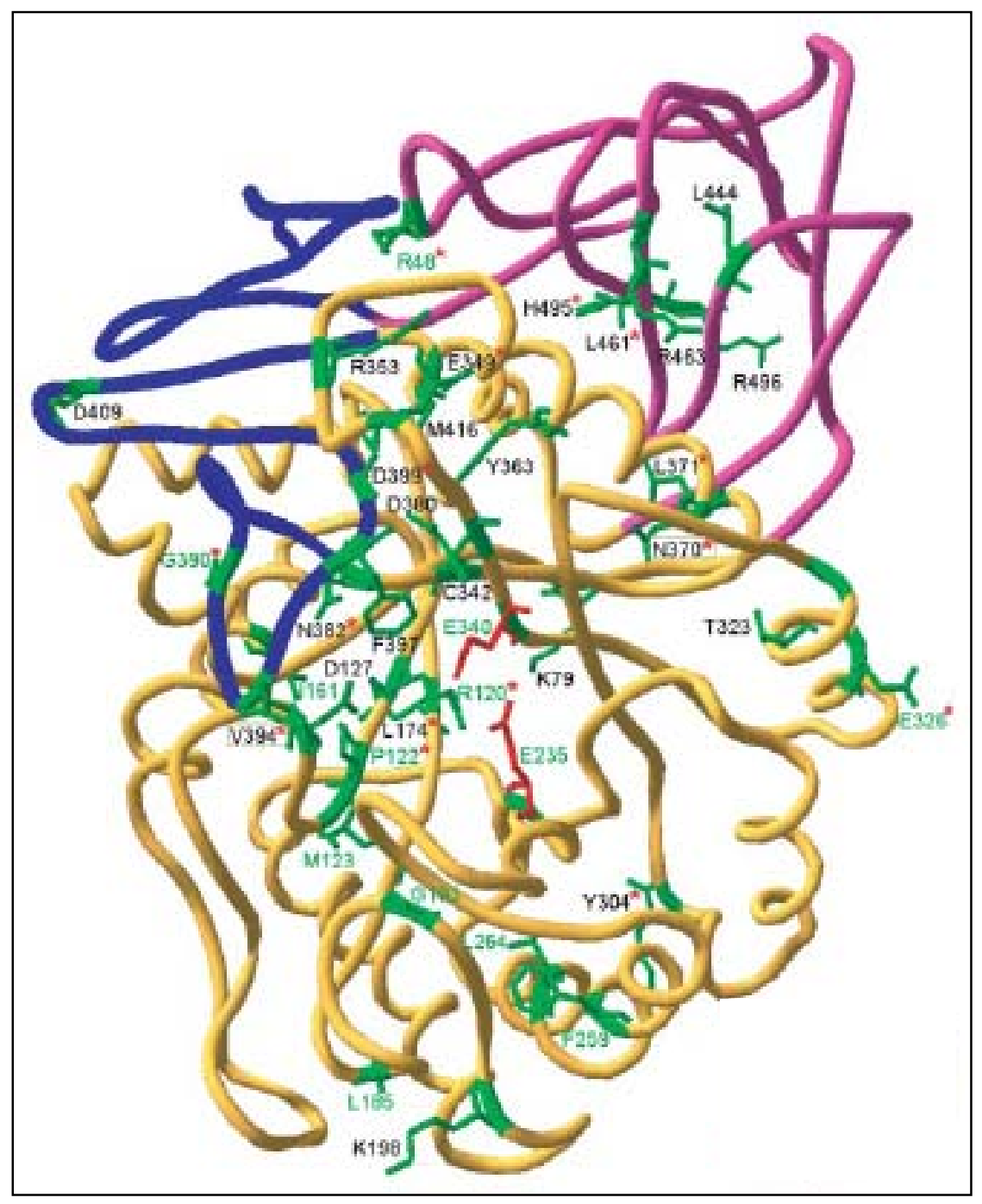

Figura 1.5. Estrutura tridimensional da GCase (Liou et al., 2006). Os domínios da proteína são mostrados em azul (domínio I), rosa (domínio II) e amarelo (domínio III). Os aminoácidos do sítio ativo, E325 e E340 são mostrados em vermelho. Alguns aminoácidos que já apresentaram mutações aparecem indicados, com um asterisco destacando aqueles com mutações levando a uma alta atividade enzimática residual (acima de 10\%).

Embora exista significativa relação genótipo e fenótipo na DG, a previsão do fenótipo baseada no genótipo não é absoluta. Há grande variedade clínica, inclusive entre pacientes com o mesmo genótipo (Beutler \& Grabowski, 1995; Cormand et al., 1998a; Goker-Alpan et al., 2004) e até mesmo entre gêmeos monozigóticos (Lachmann et al., 2004). Conforme descrito adiante, diversos genes modificadores, genes contíguos, proteínas transportadoras e fatores ambientais podem influenciar o fenótipo. Dentre os fatores genéticos estão a expressão do gene PSAP (10q21), que codifica o cofator saposina $C$, uma proteína ativadora da 
GCase composta por 80 aminoácidos e necessária para a atividade enzimática. Pessoas com mutações no gene PSAP podem também desenvolver a DG. Os sintomas encontrados nesses casos são típicos tais como hepatoesplenomegalia, envolvimento neurológico e oculomotor (Koprivica et al., 2000; Whitfield et al., 2002; Mignot et al., 2003). O fenótipo causado por mutações nesse gene está mais relacionado com o tipo 2 da DG e os poucos pacientes identificados sobreviveram apenas algumas semanas após o nascimento.

O gene GBA tem expressão diferente em tecidos específicos (Reiner \& Horowitz, 1988). Os fatores de transcrição responsáveis pela expressão diferencial incluem as proteínas OCTA, AP-1, PEA3 e CAAT (Moran et al., 1996). Outro fator associado à variedade fenotípica é a eficiência do mecanismo de transporte da GCase para os lisossomos. Deficiências nos genes que codificam proteínas de membrana associadas aos lisossomos (LAMP-1 e LAMP-2), e que participam do transporte intracelular da GCase do retículo endoplasmático para os lisossomos também podem estar presentes em indivíduos afetados pela DG (Koprivica et al., 2000; Whitfield et al., 2002). Além disso, um fator relacionado às manifestações ósseas é a possível presença de mutações no gene que codifica a interleucina-6, secretada por macrófagos, que estimula a reabsorção óssea (Altarescu et al., 2003). Recentemente demonstrou-se que a heterogeneidade clínica da DG é devida, ainda que parcialmente, a diferentes taxas de retenção e degradação das enzimas mutantes associadas ao retículo endoplasmático (Ron \& Horowitz, 2005; Schmitz et al., 2005). No entanto, os mecanismos mencionados ainda não explicam a ampla heterogeneidade clínica observada na DG.

\section{b) Mutações no gene GBA}

Já foram descritas aproximadamente 240 mutações no gene GBA causadoras da DG (Beutler et al., 2005). A maioria dessas mutações é rara e restrita a poucos indivíduos. No entanto, algumas são muito freqüentes, entre elas a N370S e a L444P (Tsuji et al., 1987; Tsuji et al., 1988). Na população Judaica Ashkenazita $97 \%$ das mutações nos pacientes são a N370S, a L444P, a 84insG, a 
Ivs2+1g>a ou a V394L (Beutler et al., 1991; He \& Grabowski, 1992; Beutler \& Grabowski, 1995; Beutler \& Gelbart, 1998). Pelo menos outras 16 mutações foram descritas nessa população (Koprivica et al., 2000). A maior prevalência nessa população pode ser conseqüência de deriva genética e/ou de vantagem heterozigótica (Slatkin, 2004).

A mutação N370S consiste na mudança da base adenina para guanina, na posição 1226 do cDNA, mudando o aminoácido asparagina para serina, na posição 370 do polipepitídeo. Trata-se de uma mutação de efeito leve, sua presença garante um fenótipo de tipo 1, provavelmente devido à alta atividade residual e estabilidade no lisossomo (Pasmanik-Chor et al., 1997; Dvir et al., 2003; Hodaňova et al., 2003; Monfort et al., 2004; Michelin et al., 2005). Em homozigose, observa-se um amplo espectro clínico, que varia desde a ausência de sintomas até uma doença de manifestação infantil, multissistêmica, incluindo graves alterações ósseas (Beutler et al., 1993; Horowitz et al., 1998). No entanto, a maioria dos homozigotos N370S/N370S não apresenta nenhum sintoma ou tem uma manifestação clínica pouco ominosa (Sibille et al., 1993).

Já a mutação L444P decorre de uma alteração da base timina para citosina, na posição 1448 do cDNA, mudando o aminoácido leucina para prolina, na posição 444 do polipepitídeo. Essa mutação, de efeito grave, leva a uma enzima cataliticamente ativa, porém instável apresentando assim uma baixa atividade residual (Pasmanik-Chor et al., 1997; Dvir et al., 2003; Hodaňova et al., 2003; Monfort et al., 2004). Em homozigose é causadora da DG tipo 3.

As mutações N370S e L444P são encontradas em 60 a 75\% dos alelos nos pacientes não-judeus, inclusive em pacientes Portugueses (Amaral et al., 2000; Zhao \& Grabowski, 2002). Assim, para a população de pacientes de DG nãojudeus, de 25 a $40 \%$ dos alelos possuem mutações diferentes, podendo ser uma das mais de 200 mutações raras já descritas ou alguma ainda não identificada, restrita a cada família.

Muitos estudos buscaram identificar as mutações em seus pacientes, na tentativa de estabelecer relações genótipo-fenótipo. Com isso, cada vez mais aumenta o número de mutações novas descritas. De 1997 para 1998, por 
exemplo, de 79 mutações já conhecidas passou-se para 109 descritas (Beutler \& Gelbart, 1998). Até 2000 o número consistia em cerca de 120 (Amaral et al., 2000), enquanto que em 2005 já chegava a 236 mutações descritas (Beutler et al., 2005). A figura 1.6 mostra algumas das principais mutações causadoras da DG e seu posicionamento nos 11 exons do gene GBA.

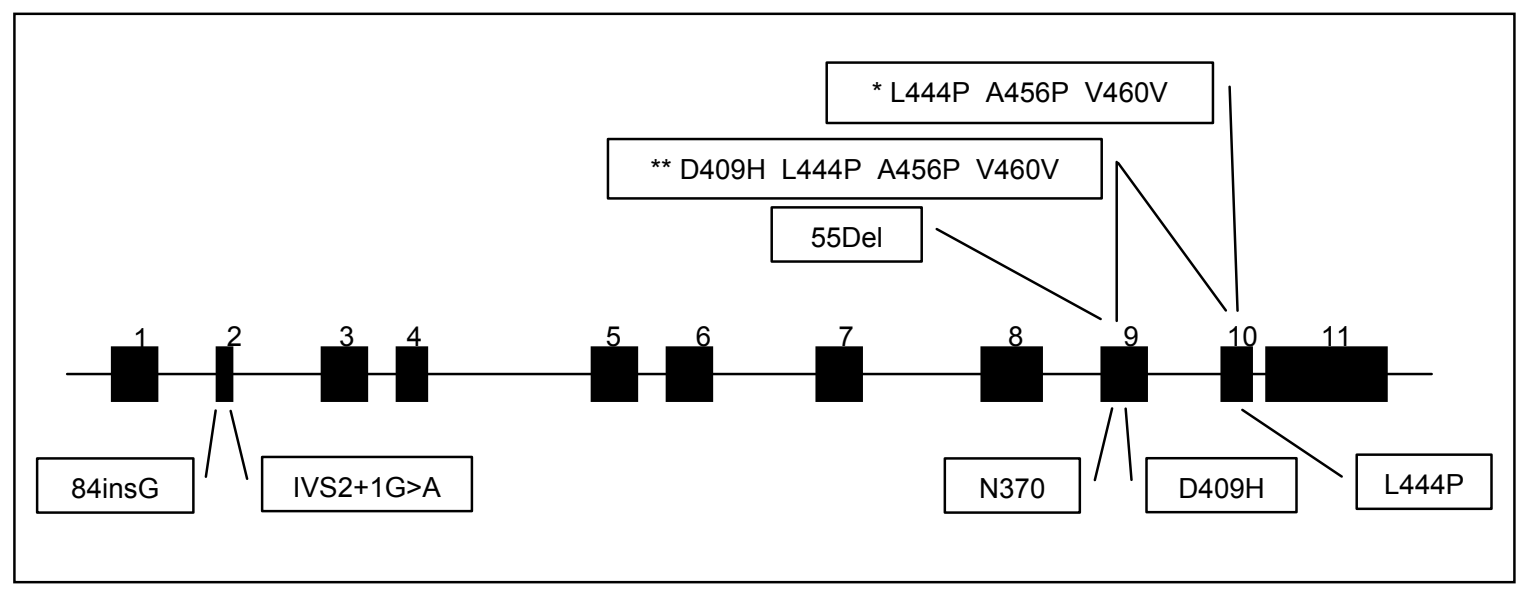

Figura 1.6. Esquema da estrutura do gene GBA e principais mutações causadoras da DG. Caixas pretas numeradas: Exons 1 a 11. Caixas brancas: principais mutações. *Alelo recombinante RecNcil; ** alelo recombinante RecTL.

As mutações já descritas em diversas populações parecem indicar a existência de uma região do gene GBA onde há maior concentração de mutações. Essa região se localiza entre os exons 8 e 11, onde também se encontram as duas principais mutações, N370S e L444P (Beutler et al., 2005). Dessa maneira, quando há interesse em se descobrir mutações em pacientes da DG pode ser interessante iniciar a busca pelos exons 8 a 11 e depois continuá-la pelo outros exons.

A identificação das mutações nos pacientes da DG está baseada em algumas justificativas. Além da confirmação diagnóstica, é possível estabelecer uma relação genótipo-fenótipo, que pode até orientar o tratamento devido ao seu valor preditivo (Germain et al., 1998). A descrição das mutações também é útil para o aconselhamento genético e eventualmente pode possibilitar o diagnóstico pré-natal. 


\section{c) Pseudogene}

O gene GBA possui um pseudogene (psGBA), localizado no próprio cromossomo 1 , distando $16 \mathrm{~Kb}$ do primeiro. Trata-se de uma cópia inativa do gene, de $5.769 \mathrm{pb}$, com $96 \%$ da seqüência idêntica à do GBA. Os dois se originaram de um gene ancestral e tiveram evolução divergente (Horowitz et al., 1989; Martinez-Arias et al., 2001a). A duplicação que originou o psGBA teve sua data estimada em $\sim 27$ milhões de anos antes do presente, sendo portanto compartilhada pelos outros primatas, mas não pelo macacos do novo-mundo (Martinez-Arias et al., 2001b; Waffaei \& Choy, 2005). A presença desse pseudogene pode levar à formação de alelos recombinantes (RECs), devido a erros de recombinação, onde o gene GBA de um cromossomo pareia-se erroneamente com o psGBA do outro, dando origem a um cromossomo com seqüências do gene e do pseudogene, e todas as alterações que esse último apresenta (Cormand et al., 1998a). Isso possibilita que, ao contrário do que ocorre na maioria das doenças monogênicas, sejam encontrados pacientes com diversas mutações no mesmo alelo. Curiosamente a recombinação na maioria dos casos é não-recíproca (conversão gênica) ao invés de recíproca (permuta desigual) (DiazFont et al., 2003; Tayebi et al., 2003). A presença do psGBA dificulta o trabalho de detecção de mutações no gene GBA, devido à grande homologia entre eles. É necessário criar estratégias particulares buscando analisar apenas o gene e excluindo o pseudogene, quando se realiza a amplificação do GBA por PCR. Ao contrário da maioria dos outros pseudogenes, que não são transcritos, o psGBA apresenta um alto nível de transcrição, mas ausência de tradução (Sorge et al., 1990).

Entre os principais RECs já identificados estão o RecNcil (com as mutações L444P, A456P e V460V) e o RecTL (com as mutações do RecNcil e D409H) mostrados na figura 1.6. Ambos levam a uma proteína com atividade enzimática residual quase nula (Latham et al., 1990; Pasmanik-Chor et al., 1997; Cormand et al., 1998a). Os heterozigotos compostos apresentando L444P em trans com um 
alelo recombinante desenvolvem na maioria dos casos a doença de tipo 2 (Zhao et al., 2003).

\subsubsection{Terapia de reposição enzimática e outros tratamentos}

O paciente da DG pode apresentar diversas complicações patológicas durante sua vida. Complicações ósseas podem exigir redução em certas atividades e até intervenções cirúrgicas, implicando muitas vezes em um atraso de desenvolvimento motor nos pacientes infantis. A esplenomegalia pode exigir a esplenectomia, realizada em $50 \%$ dos pacientes antes do surgimento da TRE. Além disso, a anemia grave em alguns casos pode requisitar freqüentes transfusões de sangue (Beutler \& Grabowski, 2001).

A DG é a primeira DAL com tratamento efetivo desenvolvido, a TRE, que é eficiente para tratar os sintomas não-neuropáticos da doença. A idéia de desenvolver a TRE já estava presente desde a década de 60 (deDuve, 1964; Brady, 1966; Neufeld et al., 1968), tendo sido inclusive testada em pacientes, mas sem sucesso (Desnick et al., 1973). Diversos mecanismos tiveram que ser elucidados para que essa terapia se tornasse viável para a DG, particularmente o modo de direcionamento e internalização celular da GCase recombinante infundida (Barton et al., 1990; Pastores \& Barnett, 2005). Os receptores dos macrófagos reconhecem a enzima recombinante de forma manose-dependente, portanto só quando as modificações após o isolamento da enzima recombinante incluíram a exposição de resíduos de manose, a TRE obteve eficiência clínica. Esse processo de descoberta levou quase duas décadas, e em 1992 a agência norte-americana FDA (Food and drugs administration) aprovou a TRE para a DG. Inicialmente a enzima era extraída de placentas humanas (a Alglucerase, Ceredase $^{\circledR}$ ). Eram necessárias aproximadamente 10 a 12 toneladas ou cerca de 50.000 placentas humanas para extração de enzima suficiente para o tratamento anual de apenas um paciente (Grabowski et al., 1995). Além dessa dificuldade, a descoberta das doenças priônicas, impossibilitou a confiabilidade dos procedimentos de purificação, levando ao desenvolvimento de uma enzima 
recombinante produzida em um sistema celular com técnicas de engenharia genética (a Imiglucerase, $\operatorname{Cerezyme}{ }^{\circledR}$ ). Seu potencial antigênico é um pouco menor, sendo responsável por um número menor de casos de reação imunológica em pacientes. Atualmente essa enzima é produzida em escala industrial em biorreatores, utilizando células de ovário de hamster chinês. As células eucarióticas são usadas nesse caso pois, ao contrário das procarióticas, fazem as modificações pós-traducionais necessárias para a estabilidade e atividade lisossomal.

A administração da enzima é por infusão intravenosa, geralmente com uma freqüência de uma vez a cada duas semanas e com uma dosagem enzimática individualizada de acordo com o peso, o quadro clínico e a resposta de cada paciente. Existe uma preocupação em tentar estabelecer a quantidade mínima eficiente, levando em consideração o alto custo do tratamento. Os pacientes devem ser acompanhados regularmente e as doses podem ser diminuídas pelo médico depois de avaliações das manifestações clínicas e da resposta ao tratamento.

Embora a TRE seja altamente eficiente para tratar os sintomas viscerais da doença, ela não impede a progressão das complicações neurológicas nos pacientes de tipo 2 e 3 . Dessa forma, sua aplicação está atualmente limitada aos pacientes de tipo 1 e 3 , embora diversos estudos têm buscado direcioná-la ao sistema nervoso central (Dobrenis et al., 1992, Kyrkanides et al., 2005; Vogler et al., 2005)

Como a eficiência da TRE é diferente para cada paciente, várias dosagens já se mostraram eficazes. Para pacientes com o tipo 1 , doses iniciais de 60 unidades de enzima por kilograma de massa corpórea $(\mathrm{U} / \mathrm{Kg})$ a cada duas semanas mostraram ser eficientes, ao levar a uma rápida melhora hematológica e visceral, enquanto que doses de $2,5 \mathrm{U} / \mathrm{Kg}$ três vezes por semana ou $15 \mathrm{U} / \mathrm{Kg}$ uma vez por semana tiveram efeito apenas nos casos mais leves da doença (Beutler \& Grabowski, 2001). O Ministério da Saúde estabeleceu um protocolo, que determina de forma geral o início do tratamento com a menor dose eficaz (15 U/Kg a cada 15 dias), que pode ser aumentada caso não haja melhora nos parâmetros 
clínicos (Portaria 499 de julho de 2002). No entanto, doses iniciais de $30 \mathrm{U} / \mathrm{Kg} \mathrm{a}$ cada 15 dias são recomendadas para crianças e adolescentes (Beutler \& Grabowski, 1995). Se o quadro clínico for muito grave deve ser utilizado $60 \mathrm{U} / \mathrm{Kg}$ quinzenalmente, o que também é aconselhado para os pacientes com tipo 3 da DG, acompanhado de reavaliações semestrais com vistas à otimização da dose. O consenso Brasileiro de tratamento da DG estabelece um procedimento similar, porém sugerindo uma dose de $120 \mathrm{U} / \mathrm{Kg}$ a cada 14 dias para os pacientes de tipo 3 (Martins et al., 2003). Essa sugestão de dose alta para pacientes de tipo 3 é compartilhada pelo consenso europeu para tratamento da DG, que inclui os pacientes pré-neuronopáticos nessa recomendação (Vellodi et al., 2001).

A venda mundial de enzima recombinante, que em 2005 foi produzida ao restrito grupo de aproximadamente 4.000 pacientes do mundo inteiro, chega a 1 bilhão de dólares por ano (Pastores \& Barnett, 2005). O Brasil é o terceiro país do mundo em número de pacientes em tratamento. Aqui existem aproximadamente 450 pacientes em TRE, cujo tratamento é financiado pelas Secretarias Estaduais de Saúde, conforme determinação do Ministério da Saúde. O custo do tratamento depende da dose administrada, mas o tratamento de um paciente médio de $50 \mathrm{Kg}$, recebendo a dose média de $40 \mathrm{U} / \mathrm{Kg}$ a cada duas semanas custa $U \$ 175.000$ por ano nos Estados Unidos da América. É fácil perceber a importância econômica desse tratamento no Brasil, onde a terapia é subsidiada pelo sistema de saúde pública, mostrando que essa doença pode ser de baixa incidência, mas de significativo impacto econômico. Embora a legislação brasileira considere o fornecimento de medicamentos para o tratamento de doenças raras uma obrigação do Estado, alguns especialistas levantam um dilema ético trazido pelo alto custo dessa terapia (Beutler et al., 1993). Ela acontece enquanto outros problemas básicos de saúde pública continuam não solucionados, afetando milhares de pessoas (Kanamura, 2003; Raw, 2003). Por outro lado, a falta de verba em alguns Estados, pode implicar na interrupção ou ausência de tratamento, podendo levar a quadros clínicos irreversíveis ou óbito dos pacientes. Deve-se ter em vista que o desenvolvimento da TRE para diversas outras DALs levantam uma importante questão de alocação de recursos de saúde pública. 
Cerca de $1 \%$ dos pacientes tem reações adversas à TRE e produzem anticorpos contra a enzima sintética, necessitando de outras opções terapêuticas. Existe hoje um tratamento alternativo aprovado: a terapia de redução de substrato. Essa terapia é feita com a utilização de inibidores da síntese de substrato que atuam na via dos esfingolipídeos (Platt et al., 1997; Cox et al., 2000; Pastores \& Barnett, 2005). Ao invés de aumentar a presença da enzima deficitária, a terapia de redução de substrato visa diminuir a síntese do glicocerebrosídeo que se acumula nos tecidos de pacientes da DG. Para tal, a N-butildeoxinojirimicina (Miglustat, Zaveska ${ }^{\circledR}$ ) recebeu aprovação da agência européia de medicamentos (EMEA) em 2002 e do FDA em 2003 para uso em pacientes de tipo 1 que apresentaram reação alérgica à TRE. A vantagem do Miglustat é que por ser uma molécula pequena, de administração oral, não provoca resposta imunológica e pode cruzar a barreira hemato-encefálica. Além de atuar como inibidor da glicosiltranferase, envolvida na síntese do glicocerebrosídeo, esse mesmo composto pode funcionar como um chaperone, aumentando a atividade enzimática da GCase quando usado em baixas concentrações, conforme descrito adiante (Alfonso et al., 2005). No entanto, os efeitos colaterais dessa terapia são bem mais significativos do que os da TRE, incluindo diarréia, tremor e parestesia, entre outros (McCormack \& Gloa, 2003).

Por atuar em um ponto inicial da via metabólica de síntese da glicosilceramida e dos gangliosídeos, esse medicamento pode ter aplicação em outras glicoesfingolipidoses, como a DTS, para a qual triagens clínicas estão em andamento com pacientes das variantes de início tardio (Neudorfer \& Kolodny, 2004). A terapia de redução de substrato com Miglustat aplicada a dois pacientes infantis da DTS não foi capaz de interromper a degeneração neurológica mas preveniu a macrocefalia (Bembi et al., 2006). Outros compostos que podem diminuir a síntese de substrato estão sendo estudados através de culturas de células e modelos animais (análogos de açúcar: NB-DGJ, AMP-DNJ e o Genz 78132 análogo da ceramida). Os inibidores de síntese de substrato estão sendo estudados quanto à possibilidade de associá-los à TRE para o tratamento da DG (Brady \& Schiffmann, 2004). 
Uma outra possibilidade de terapia em estudo para a GD é o uso de chaperones para aumentar a atividade residual de enzimas com mutações. Em alguns casos, quando uma mutação leva a uma proteína truncada que é rapidamente degradada, a intervenção de um chaperone pode estabilizar a proteína defeituosa e permitir sua movimentação e atividade lisossômica (Sawkar et al., 2002; Desnick, 2004; Tropak et al., 2004; Muchowski \& Wacker, 2005). Nesses casos, é importante o conhecimento da mutação e da alteração conformacional. Em alguns casos a terapia poderá ser mutação-específica. Assim como na terapia de redução de substrato, as moléculas envolvidas são pequenas e poderiam ser usadas para tratar sintomas neurológicos na DG e em qualquer outra das DAL com acometimento neuronopático (Pastores \& Barnett, 2005).

Outros tratamentos para as DAL estão em desenvolvimento e representam uma perspectiva futura de tratamento para a DG, incluindo a terapia gênica (Sly \& Vogler, 2002) e o transplante de células-tronco (Kim et al., 2005; Martin et al., 2006; Ringdén et al., 2006). Essas terapias marcam um novo e importante momento da genética clínica (Desnick, 2004; Pastores \& Barnett, 2005). São terapias promissoras já que algumas poderiam reverter quadros neurológicos devido ao seu potencial de cruzar a barreira hemato-encefálica. Ademais, o alto custo da TRE pode restringir seu potencial de uso, o que já ocorre em alguns países (Zimran et al., 1994; Chan \& Lin, 2002; Heitner et al., 2004). Eventualmente esses novos tratamentos poderão ser utilizados de forma complementar à TRE (Grabowski, 2001). 


\subsection{Objetivos}

O objetivo geral deste trabalho foi realizar uma análise molecular das doenças de Gaucher e Tay-Sachs, para as quais programas de tratamento e prevenção estão bem estabelecidos. Particularmente, buscou-se fazer uma análise molecular de pacientes Brasileiros, verificando as freqüências gênicas e genotípicas e descrevendo relações genótipo-fenótipo, que em muitas vezes são fundamentais para o tratamento e para o aconselhamento genético das famílias estudadas.

Especificamente, esse trabalho visou analisar as principais mutações causadoras da DTS em pacientes da forma clássica infantil e em casos de variantes de início juvenil e tardio. Para a DG, a análise molecular buscou identificar as mutações mais freqüentes, sua distribuição nos casos Brasileiros e a detecção de mutações raras através de técnicas mais abrangentes. Por fim, buscou-se verificar se mutações causadoras da DG podem constituir um fator de risco para a doença de Parkinson, através da obtenção de amostras suficientemente grandes para testar essa hipótese. 


\section{ANÁLI SE MOLECULAR DE FORMAS CLÁSSI CAS E NÃO-CLÁSSI CAS DA DOENÇA DE TAY-SACHS EM PACIENTES BRASI LEI ROS}

Esta parte está subdividida em dois itens, tratando das formas clássicas (2.1) e não-clássicas (2.2) da DTS e foi escrito com base nos trabalhos: "Tay-Sachs disease in Brazilian patients: prevalence of the IVS7+1g>c mutation" publicado no Journal of Inherited Metabolic Disease 27(1): 109-110, 2004 e “Diagnosis and molecular characterization of non-classic forms of Tay-Sachs disease in Brazil" aceito em 2005 para publicação no J ournal of Child Neurology. 


\title{
2.1. A DOENÇA DE TAY-SACHS EM PACIENTES BRASI LEI ROS: PREVALÊNCI A DA MUTAÇÃO I VS7 + 1G >C
}

\section{R Rozenberg ${ }^{1}$, AM Martins ${ }^{2}$, C Micheletti $^{2}$, Z Mustacchi $^{3}$, LV Pereira $^{1}$}

\author{
Comunicação breve
}

Publicado em: J Inherit Metab Dis 27(1): 109-10, 2004

1Centro de Estudos do Genoma Humano, Depto de Genética e Biologia Evolutiva, Instituto de Biociências, Universidade de São Paulo, São Paulo, Brasil

2Departamento de Pediatria, Universidade Federal do Estado de São Paulo, Escola Paulista de Medicina, São Paulo, Brasil

3Departamento de Genética, Universidade Paulista, Brasil 


\section{Summary}

Seven Brazilian Tay-Sachs disease cases were screened for the most frequent causative mutations. They all presented at least one copy of the IVS7+1g>c mutation. Three patients were homozygotes, three were compound heterozygotes, and in one case only the mother was tested and shown to carry the IVS7+1g>c mutation. In the second allele the compound heterozygotes presented: $\mathrm{R} 178 \mathrm{H}$ (the DN allele), InsTATC1278 and an unidentified mutation. The IVS7+1g>c mutation has already been described in three Portuguese patients. In this study, all families were unaware of any Portuguese ancestry. Since Brazil was a Portuguese colony, the mutation most probably came from ancient common ancestry. The initial molecular analysis of Tay-Sachs disease patients in Brazil indicated a prevalence of the IVS7+1g>c mutation, possibly as a result of genetic drift.

\section{Resumo}

Sete casos Brasileiros da DTS foram analisados para a presença das principais mutações. Todos apresentaram pelo menos uma cópia da mutação IVS7+1g>c. Três pacientes eram homozigotos, três eram heterozigotos compostos e num dos casos apenas a mãe foi testada e portava a mutação IVS7+1g>c. No segundo alelo os heterozigotos compostos apresentaram: R178H (o alelo DN), InsTATC1278 e uma mutação não identificada. A mutação IVS7+1g>c já foi descrita em três pacientes Portugueses. Neste estudo, todas as famílias desconheciam qualquer ancestralidade Portuguesa. Uma vez que o Brasil foi uma colônia Portuguesa, a presença da mesma mutação é provavelmente devida à ancestralidade comum. A análise molecular inicial de pacientes da DTS no Brasil indicou a prevalência da mutação IVS7+1g>c, possivelmente como resultado de deriva genética. 


\section{Comunicação breve}

A análise molecular de 7 pacientes Brasileiros da DTS foi realizada para identificar as mutações mais freqüentes. As famílias estudadas foram encaminhadas ao nosso centro após uma busca ativa em serviços de genética médica pelo país. A maioria era da região Nordeste. Embora mais de 90 mutações tenham sido descritas em pacientes da DTS, nós analisamos as mutações mais freqüentes: três judaicas (InsTATC1278, IVS12+1g>c e G269S) e duas Portuguesas (IVS7+1g>c e R178H). Todos os casos apresentaram pelo menos uma cópia da mutação IVS7+1g>c. Três eram homozigotos (dois apresentando consangüinidade), três eram heterozigotos compostos e num caso a criança já havia ido a óbito e apenas a mãe estava disponível para coleta de DNA. Ela era portadora da mutação IVS7+1g>c.

Os homozigotos para a IVS7+1g>c apresentaram um fenótipo da forma clássica da DTS, corroborando a relação genótipo-fenótipo já estabelecida (Fernandes et al., 1992). Em dois casos de heterozigotos compostos, as mães eram irmãs. Um dos casos apresentou a R178H (também chamada alelo DN) em combinação com a IVS7+1g>c e o fenótipo era de variante B1, forma infantiltardia. O início dos sintomas deu-se aos 10 meses e o paciente já passa dos 7 anos de idade. Embora esse genótipo não tenha sido descrito na literatura, está de acordo com publicações prévias sugerindo que uma cópia de R178H leva a uma progressão mais lenta da doença em conseqüência da atividade enzimática residual. O outro heterozigoto composto tinha uma segunda mutação que não foi identificada. No único caso que apresentava ancestralidade judaica, o paciente herdou a InsTATC1278 do pai judeu. A mãe, que não apresentava ancestralidade judaica, era heterozigota para a IVS7+1g>c. O fenótipo era da forma clássica da DTS.

No Brasil, a freqüência de heterozigotos para a DTS na população judaica Ashkenazita é similar à encontrada em outros países (Rozenberg \& Pereira, 2000), mas uma vez que essa população representa menos de $0,1 \%$ da população Brasileira em geral, pode se antecipar que uma minoria dos casos da 
DTS no Brasil apresentará ancestralidade judaica. Por outro lado, a mutação IVS7+1g>c já foi descrita em três pacientes Portugueses (Fernandes et al., 1992; Ribeiro et al., 1995). Neste estudo, todas as famílias desconheciam a existência de ancestralidade Portuguesa. Uma vez que o Brasil foi uma colônia Portuguesa, os alelos com a mutação devem ter uma origem comum. Embora novos estudos possam corroborar essa observação, a análise molecular inicial da DTS no Brasil indicou a prevalência da mutação IVS7+1g>c, possivelmente como resultado de deriva genética. 


\title{
2.2. DI AGNÓSTI CO E CARACTERI ZAÇÃO MOLECULAR DE FORMAS NÃO-CLÁSSI CAS DA DOENÇA DE TAY-SACHS NO BRASIL
}

\author{
R Rozenberg ${ }^{1}, \mathrm{~F} \mathrm{Kok}^{2}$, MG Burin ${ }^{3}, \mathrm{MC}$ Sá-Miranda ${ }^{4}$, C Vasques $^{2}, \mathrm{AMM}$ \\ Henrique-Souza ${ }^{5}$, R Giugliani ${ }^{3}$, M Vainzof $^{1}$, LV Pereira ${ }^{1}$
}

\author{
Comunicação breve
}

Aceito para publicação em 2005: J Child Neurol

${ }_{1}$ Centro de Estudos do Genoma Humano, Depto de Genética e Biologia Evolutiva, Instituto de Biociências, Universidade de São Paulo, São Paulo, Brasil

2Deptartamento de Neurologia, Faculdade de Medicina, Universidade de São Paulo, São Paulo, Brasil

3Serviço de Genética Medica, Hospital de Clínicas de Porto Alegre, Universidade Federal do Rio Grande do Sul, Porto Alegre, Brasil

4I nstituto de Biologia Molecular e Celular, Universidade de Porto, Porto, Portugal

5IMIP: Instituto Materno Infantil de Pernambuco, Ceará, Brasil 


\section{ABSTRACT}

Molecular analysis of five Brazilian families, including eight patients presenting non-classic Tay-Sachs disease, was performed to identify frequent causative mutations and their correlation with clinical course. Three patients were affected by the $B 1$ subacute variant and shown to carry the $R 178 H$ mutation (the DN allele), which is also common among Portuguese patients. Two of them were compound heterozygotes, whereas the third presented with the mutation in both alleles. Since Brazil was a Portuguese colony for over two centuries, common ancestry might be the probable explanation. The fourth patient presented with a juvenile phenotype and carries the $\mathrm{R} 499 \mathrm{H}$ mutation, which has been reported only once worldwide and is associated with residual enzyme activity, responsible for a slower clinical course. The fifth family, of an Ashkenazi Jewish background, showed an extensive intrafamilial clinical variability among three affected sibs presenting with muscle atrophy, ataxia and psychiatric symptoms. They were first diagnosed as having atypical spinal muscular atrophy, and subsequently, spinocerebellar ataxia, but recently the diagnosis of late-onset Tay-Sachs disease was confirmed based on reduced plasma hexosaminidase $A$ activity and the G269S/InsTATC1278 genotype. It is therefore highly recommended to test patients with a similar clinical history for Tay-Sachs disease. In the same family, one first cousin committed suicide at the age 24 years, presenting with a clinical phenotype that suggested an undiagnosed case and highlighting the effect of the intrafamilial clinical variability in delaying a prompt diagnosis. It is now recognized that his parents are, in fact, a carrier couple. Additionally, another relative had been previously identified as a heterozygote in a Tay-Sachs disease screening program, but the information was not shared among the family. Since this information might anticipate diagnosis and genetic counseling, it is advisable that heterozygote screening programs encourage families to share genetic information. 


\section{RESUMO}

A análise molecular de 5 famílias Brasileiras que incluem oito pacientes de formas não-clássicas da DTS foi realizada visando identificar as mutações mais freqüentes e suas correlações com o fenótipo clínico. Três pacientes eram afetados pela variante subaguda B1 e portavam a mutação R178H (o alelo DN), comum em pacientes Portugueses. Dois deles eram heterozigotos compostos, ao passo que o terceiro apresentava a mutação nos dois alelos. Uma vez que o Brasil foi colônia Portuguesa por mais de dois séculos, a ancestralidade comum é a explicação mais provável. O quarto paciente apresentou um fenótipo juvenil e é portador da mutação $\mathrm{R} 499 \mathrm{H}$, descrita apenas uma vez e associada a uma atividade enzimática residual responsável por um curso clínico mais lento. A quinta família, de origem judaica Ashkenazita, mostrou uma acentuada heterogeneidade clínica entre três irmãos afetados, apresentando atrofia muscular, ataxia e sintomas psiquiátricos. Eles foram diagnosticados inicialmente com atrofia espinomuscular atípica e posteriormente com ataxia espinocerebelar, porém recentemente o diagnóstico correto da variante de início tardio da DTS foi confirmado, baseado na atividade plasmática reduzida da Hex A e o genótipo G269S/InsTATC1278. Assim, é altamente recomendável testar para a DTS pacientes com histórico clínico similar. Na mesma família, um primo de primeiro grau cometeu suicídio aos 24 anos, apresentando um fenótipo clínico sugestivo de um caso não-diagnosticado da DTS, ressaltando o efeito que a variabilidade clínica intrafamilial tem, em dificultar o diagnóstico correto. Demonstrou-se nesse caso, que os pais são de fato um casal de heterozigotos. Adicionalmente, outro parente na família havia sido identificado como heterozigoto num programa preventivo de triagem de portadores, mas a informação não foi compartilhada na família. Uma vez que essa informação pode antecipar o diagnóstico e o aconselhamento genético, é recomendável que programas de triagem populacional encorajem as famílias a compartilhar informação genética. 


\section{Comunicação breve}

A DTS é uma doença autossômica recessiva do armazenamento lisossômico, caracterizada clinicamente por uma degeneração neurológica progressiva (MIM 272800). Crianças afetadas pela forma clássica apresentam os primeiros sintomas ao redor dos 6 meses de idade e apresentam uma doença neurodegenerativa de progressão rápida que leva ao óbito antes dos 5 anos de idade. A DTS é causada por mutações no gene HEXA (15q23-q24) que codifica a subunidade alfa da enzima $\beta$-hexosaminidase $A$. Na ausência da enzima, seu substrato, o gangliosídeo $\mathrm{G}_{\mathrm{M} 2}$ acumula-se progressivamente nos neurônios do sistema nervoso central (Gravel et al., 2001).

As formas não-clássicas da DTS são variantes fenotípicas raras, que incluem a forma crônica, de início tardio e uma forma subaguda de apresentação infanto-juvenil ou juvenil. Esses fenótipos menos ominosos resultam de atividade enzimática residual (Conzelman et al., 1983). Na forma de início tardio, os primeiros sinais da doença podem aparecer na primeira ou apenas na segunda década de vida e a progressão é lenta. A manifestação neurológica e a ominosidade são variáveis e podem incluir fraqueza de músculos proximais, marcha irregular, ataxia, tremor de mãos, disartria, distonia e/ou discinesia. As anormalidades psiquiátricas incluem esquizofrenia, agitação, ilusões, alucinações, paranóia e depressão (MacQueen et al., 1998). Nas formas juvenis observa-se uma apresentação clínica intermediária e sobrevida até a adolescência ou idade adulta (Navon et al., 1986; Navon \& Proia, 1989). Outra forma rara da DTS é a variante $B 1$, na qual a estrutura da hex $A$ está inalterada, mas mutações que afetam o sítio ativo da enzima impedem a atividade catalítica da enzima contra seu substrato natural, o gangliosídeo $\mathrm{G}_{\mathrm{M} 2}$ e contra a forma sulfatada do substrato artificial usado no diagnóstico bioquímico (MUGS). Os casos da variante B1 apresentam um início infantil mais adiantado. Até o presente há menos de 100 referências bibliográficas a essa forma no Medline. A maioria dos casos foi descrita no norte de Portugal (Tutor, 2004). 
A análise molecular de cinco famílias Brasileiras sem consangüinidade, apresentando pacientes de formas não-clássicas da DTS foi realizada, visando identificar as mutações mais freqüentes e correlacioná-las com o fenótipo clínico dos pacientes. A tabela 2.1 mostra um sumário dos pacientes e as principais características do fenótipo. Nós verificamos a presença das três mutações mais freqüentes de origem judaica (InsTATC1278, IVS12+1g>c e G269S) e duas Brasileiras/Portuguesas (IVS7+1g>c e R178H) (Triggs-Raine et al., 1990; Hechtman \& Kaplan, 1993; Rozenberg et al., 2004). O seqüenciamento completo do gene foi realizado num dos indivíduos (paciente 4).

Três pacientes de diferentes famílias (tabela 2.1, pacientes 1 a 3) apresentam o fenótipo B1, confirmado pela atividade reduzida da hex A contra o substrato MUGS. Todos apresentaram resposta de sobressalto a estímulos sonoros agudos no primeiro ano de vida, mas a alteração de marcha e o declínio cognitivo foram os sinais que os levaram à atenção médica, entre 2 e 3 anos de idade. O ponto vermelho-cereja na retina estava presente nos pacientes 1 e 2 , mas não no 3.

Os pacientes 1 e 2, atualmente com 3 e 4 anos de idade apresentam degeneração neurológica progressiva, com espasticidade, declínio visual e cognitivo e crises epiléticas. Eles são heterozigotos compostos apresentando a mutação R178H (também chamado de alelo DN) e uma segunda mutação nãoidentificada. O paciente 3 , atualmente com 5 anos de idade, perdeu a capacidade de deambulação durante o último ano e está atualmente confinado à cama, apresentando distonia e crises epiléticas. Ela é homozigota para mutação R178H e o curso clínico é similar ao de outros homozigotos descritos (Santos et al., 1991). Essa mutação é a mais comumente associada à variante B1 da DTS e sua maior prevalência ocorre no Norte de Portugal, onde ela pode ter se originado (Tutor, 2004). Uma vez que o Brasil foi uma colônia Portuguesa por mais de dois séculos, uma ancestralidade comum pode ser a melhor explicação para a presença da $\mathrm{R} 178 \mathrm{H}$. De fato, as três famílias têm uma origem mista que inclui um importante componente Português. É interessante notar que entre pacientes 
Brasileiros da forma clássica da DTS, uma mutação descrita em pacientes Portugueses (IVS7+1g>c) também é a mais prevalente (Rozenberg et al., 2004).

O paciente 4 apresenta uma forma juvenil (não B1) da doença, tendo mostrado uma alteração na marcha como primeiro sinal clínico, entre 1 de 2 anos de idade, seguido de declínio cognitivo. A resposta de sobressalto a estímulos auditivos foi um sinal precoce, mas o ponto vermelho-cereja na mácula nunca foi observado. Atualmente o paciente tem 9 anos de idade e está perdendo capacidades adquiridas tais como a fala e a marcha. Sua manifestação clínica é menos ominosa do que a observada nos pacientes 1, 2 e 3 . O seqüenciamento genético revelou a presença da mutação $\mathrm{R} 499 \mathrm{H}$ em heterozigose, com a segunda mutação permanecendo não identificada. A mutação $\mathrm{R} 499 \mathrm{H}$ foi descrita anteriormente num paciente afetado pela forma subaguda da DTS, que sobreviveu até os 26 anos de idade e era um heterozigoto composto com uma segunda mutação que não permitia nenhuma atividade catabólica residual (Paw et al., 1990). A R499H permitia uma atividade residual de 3\% (d'Azzo et al., 1984; Mark et al., 2003) que também pode estar garantindo uma progressão mais lenta da doença ao paciente 4 deste estudo.

Os pacientes 5, 6 e 7 (figura 2.1) são irmãos de ancestralidade judaica Ashkenazita apresentando uma notável variabilidade clínica intrafamilial. O fenótipo deles inclui fraqueza muscular, alteração de marcha, anormalidade de fala e sintomas psiquiátricos, mas sem alterações sensoriais. A visão e audição são normais e não são visualizadas manchas vermelho-cerejas na mácula. Os três ingressaram em cursos universitários mas a progressão da doença impediu a conclusão em dois deles. O propósito (paciente 5) era reconhecidamente "desajeitado" desde os 6-7 anos de idade e apresentava cãibras e quedas freqüentes, associadas à dificuldade de correr ou pular durante atividades físicas na infância. A fala é má articulada e por vezes incompreensível. Ele está confinado à cadeira de rodas desde os 27 anos de idade e atualmente, aos 37, tremores e fasciculação são observados. A mais velha de suas duas irmãs tem 35 anos de idade e os sinais clínicos se iniciaram aos 9, com disartria, seguida de uma instabilidade progressiva de marcha e fraqueza geral, associada a surtos 
psicóticos recorrentes, com alucinações e ansiedade. A irmã mais nova também apresentou sinais da doença aos 10 anos de idade, mas agora, aos 32, apresenta apenas uma leve deficiência motora proximal de membros inferiores e é notavelmente menos afetada que seus irmãos.

A presença de três pacientes na mesma família foi reportada em 1976 (Rapin et al., 1976) mas o fenótipo homogêneo desses pacientes levou a sugestão de que a manifestação clínica tendia a ser consistente em cada família. No entanto, estudos posteriores descreveram variação fenotípica em pacientes da mesma família (Navon et al., 1986). Os casos aqui apresentados confirmam que variabilidade clínica intrafamilial pode estar presente na variante de início tardio da DTS, apesar da manifestação clínica uniforme, observada na forma clássica infantil. Como observado em outras doenças monogênicas, é possível que a variante de início tardio da DTS é herdada de modo Mendeliano, mas a manifestação clínica é um traço complexo.

Por mais de 10 anos esses três irmãos estiveram com um diagnóstico incorreto. Inicialmente, foi aventado o diagnóstico de atrofia músculo-espinal tipo III, baseado no fenótipo clínico do caso índice. Uma reavaliação clínica recente por um de nós (FK) trouxe a suspeita da variante de início tardio da DTS, que foi confirmada pela baixa atividade plasmática da Hex A e pela análise molecular revelando as mutações G269S e InsTATC1278, herdadas respectivamente do pai e da mãe (figura 2.2). O diagnóstico ajudou a estabelecer a correta medicação antipsicótica para os três irmãos, uma vez que a maioria dos neurolépticos pode piorar o quadro da doença.

Durante uma sessão de aconselhamento genético da família verificou-se que havia um primo de primeiro grau do lado paterno (figura 2.1, III-3) que cometeu suicídio aos 24 anos de idade e apresentou alguns sinais da doença, incluindo depressão (paciente 8). Outras descrições de casos já mostraram um risco aumentado de suicídio entre pacientes da variante de início tardio da DTS (Navon et al., 1986; Navon \& Proia, 1989). Os pais do paciente 8 foram testados e são portadores das mutações G269S (pai) e InsTATC1278 (mãe), sugerindo que de fato o filho era um paciente não-diagnosticado da variante de início tardio da 
DTS e mostrando o efeito da variabilidade clínica intrafamilial na dificuldade de estabelecer o diagnóstico.

A freqüência de heterozigotos para mutações no gene $H E X A$ na população judaica é de cerca de 1 em cada 31 indivíduos e a população judaica Brasileira apresenta uma freqüência de portadores similar (Rozenberg \& Pereira, 2001). Na família de origem judaica aqui estudada, os pais eram irmãos, e as mães, embora não aparentadas eram ambas judias Ashkenazitas. Assim, o risco de doenças recessivas, presente em determinadas populações, está claramente ilustrado por essa família e encerra a importância dos programas de triagem de portadores nas populações em risco. De fato, outro parente nessa família havia sido identificado como portador da mutação InsTATC1278 num programa de triagem populacional de heterozigotos (figura 2.1, indivíduos III-1), antes do estabelecimento do diagnóstico correto dos parentes afetados, mas a informação não foi compartilhada na família. Uma vez que essa informação pode antecipar um diagnóstico e considerando os esforços atuais de se estabelecer um tratamento para essa forma da DTS, é aconselhável que programas de triagem populacional encorajem as famílias a compartilhar informação sobre seus riscos de doenças genéticas. Adicionalmente, devido à manifestação tardia da doença, a identificação de homozigotos é importante para indicar o aconselhamento genético para casais de portadores. Uma vez que a prevenção ainda é a melhor opção para evitar a doença, os indivíduos em idade reprodutiva na família foram convidados para uma sessão de aconselhamento genético. Cinco indivíduos testados apareceram como portadores de uma das mutações que segregam nessa família e a triagem para a condição de portador foi oferecida aos cônjuges. Nesses casos, a análise bioquímica é o método de escolha pois permite a identificação de heterozigotos para qualquer mutação no gene HEXA, independentemente da origem étnica. Nenhum outro casal em risco foi identificado na família.

Diversos estudos enfatizam a baixa prevalência de variante de início tardio da DTS no mundo, com menos de 100 casos publicados. É interessante especular se muitos pacientes podem estar sem diagnóstico. De fato, alguns pacientes da variante de início tardio da DTS foram diagnosticados erroneamente com ataxia 
espinocerebelar, doença de Kugelberg-Welander, atrofia espinomuscular ou esclerose amiotrófica lateral (Navon et al., 1986; Neudorfer \& Kolodny, 2004). A família aqui descrita também demonstra a dificuldade em se estabelecer o diagnóstico correto num cenário de variabilidade clínica e sintomas sobrepostos. Portanto, é altamente recomendável testar para a DTS os pacientes com atrofia espinomuscular tipo III atípica, especialmente se os sintomas neurogênicos estiverem acompanhados por ataxia ou manifestações psiquiátricas.

Tabela 2.1. Pacientes da forma não-clássica da DTS estudados. A numeração é de acordo com a do texto. São apresentados a idade atual, os primeiros sinais, o genótipo, a variante e a origem étnica.

\begin{tabular}{|c|c|c|c|c|c|}
\hline Paciente & $\begin{array}{l}\text { Idade } \\
\text { (anos) }\end{array}$ & $\begin{array}{l}\text { Primeiros Sinais/ } \\
\text { Idade de início }\end{array}$ & Genótipo & $\begin{array}{l}\text { Variante da } \\
\text { DTS }\end{array}$ & Ancestralidade \\
\hline 1 & 4 & $\begin{array}{l}\text { Alteração de marcha/ } \\
2 \text { anos }\end{array}$ & $\mathrm{R} 178 \mathrm{H} / ?$ & $\begin{array}{l}\text { B1 } \\
\text { (subaguda; } \\
\text { forma infantil } \\
\text { tardia) }\end{array}$ & $\begin{array}{l}\text { Portuguesa; } \\
\text { Italiana }\end{array}$ \\
\hline 2 & 4 & $\begin{array}{l}\text { Hipotonia, atraso de } \\
\text { desenvolvimento } \\
\text { neuropsicomotor, } \\
\text { alteração de marcha/ } \\
1 \text { ano }\end{array}$ & $\mathrm{R} 178 \mathrm{H} / ?$ & $\begin{array}{l}\text { B1 } \\
\text { (subaguda; } \\
\text { forma infantil } \\
\text { tardia) }\end{array}$ & $\begin{array}{l}\text { Portuguesa; } \\
\text { Espanhola; } \\
\text { Italiana }\end{array}$ \\
\hline 3 & 6 & $\begin{array}{l}\text { Alteração de marcha/ } \\
2 \text { anos }\end{array}$ & R178H/R178H & $\begin{array}{l}\text { B1 } \\
\text { (subaguda; } \\
\text { forma infantil } \\
\text { tardia) }\end{array}$ & Portuguesa \\
\hline 4 & 9 & $\begin{array}{l}\text { Alteração de marcha/ } \\
1 \text { ano e } 6 \text { meses }\end{array}$ & $\mathrm{R} 499 \mathrm{H} / ?$ & $\begin{array}{l}\text { subaguda; } \\
\text { forma juvenil }\end{array}$ & $\begin{array}{l}\text { Portuguesa; } \\
\text { Italiana }\end{array}$ \\
\hline $5^{\star}$ & 37 & $\begin{array}{l}\text { Hipotonia, desarticulação } \\
\text { da fala/ } \\
6-7 \text { anos }\end{array}$ & G269S/InsTATC1278 & $\begin{array}{l}\text { Crônica; } \\
\text { Variante de } \\
\text { início tardio }\end{array}$ & $\begin{array}{l}\text { Judaica } \\
\text { Ashkenazita }\end{array}$ \\
\hline $6^{*}$ & 35 & $\begin{array}{l}\text { Desarticulação da fala, } \\
\text { instabilidade de marcha/ } \\
9 \text { anos }\end{array}$ & G269S/InsTATC1278 & $\begin{array}{l}\text { Crônica; } \\
\text { Variante de } \\
\text { início tardio }\end{array}$ & $\begin{array}{l}\text { Judaica } \\
\text { Ashkenazita }\end{array}$ \\
\hline $7^{*}$ & 32 & $\begin{array}{l}\text { Desarticulação da fala/ } \\
10 \text { anos }\end{array}$ & G269S/InsTATC1278 & $\begin{array}{l}\text { Crônica; } \\
\text { Variante de } \\
\text { início tardio }\end{array}$ & $\begin{array}{l}\text { Judaica } \\
\text { Ashkenazita }\end{array}$ \\
\hline $8^{*}$ & $\begin{array}{l}\text { Suicídio } \\
\text { aos } 24\end{array}$ & $\begin{array}{l}\text { Desarticulação da fala, } \\
\text { instabilidade de marcha/ } \\
9 \text { anos }\end{array}$ & Não analisado & $\begin{array}{l}\text { Crônica; } \\
\text { Variante de } \\
\text { início tardio (?) }\end{array}$ & $\begin{array}{l}\text { Judaica } \\
\text { Ashkenazita }\end{array}$ \\
\hline
\end{tabular}

*Pacientes 5, 6 e 7 são irmãos, o paciente 8 é primo em primeiro grau (figura 2.1).

${ }^{* *}$ A análise de DNA incluiu as mutações InsTATC1278, IVS12+1g>c, G269S, IVS7+1g>c e R178H. 


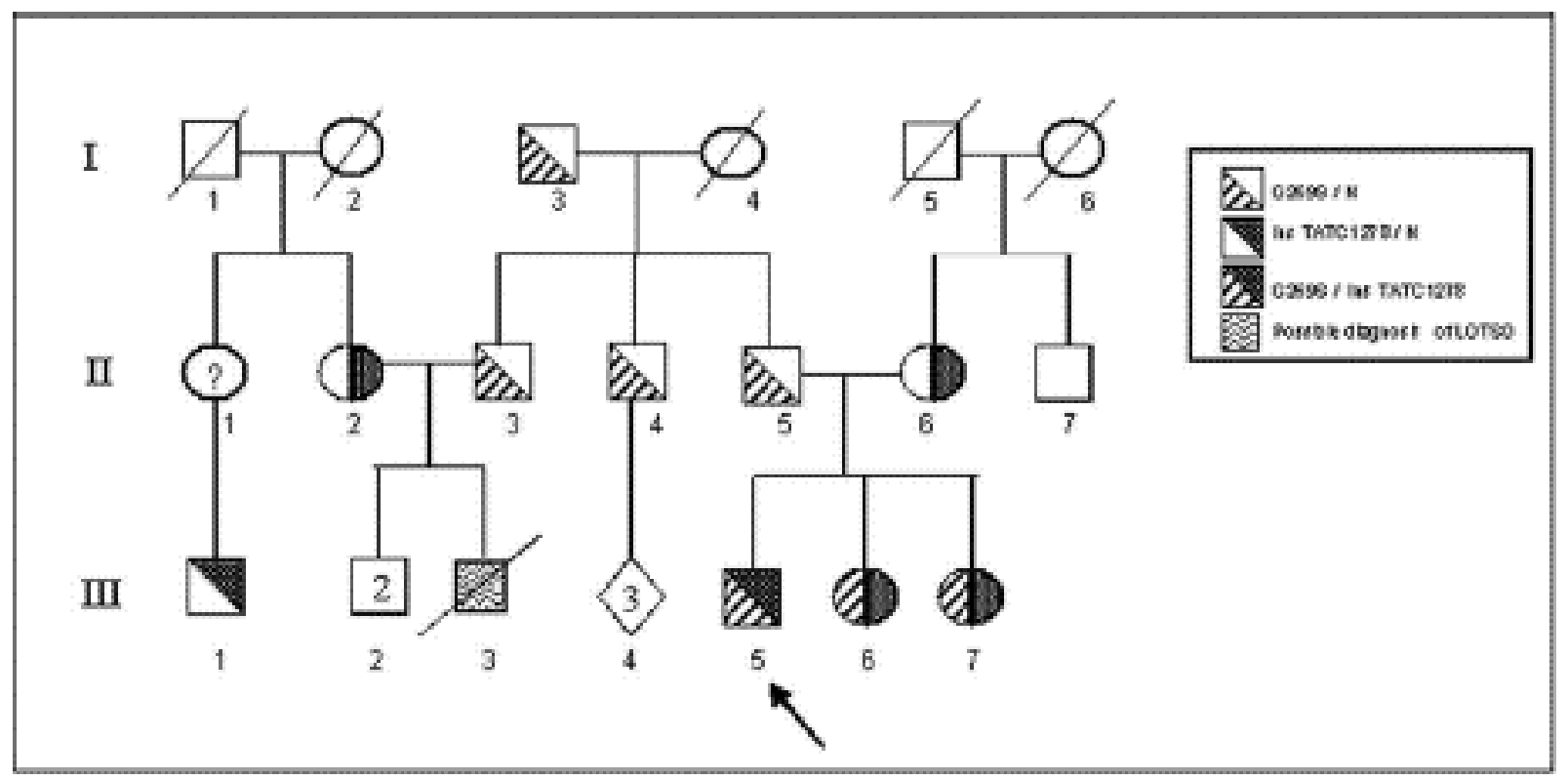

Figura 2.1. Genealogia da família Ashkenazita, mostrando a segregação das duas mutações. Os pacientes III-3, III-5, III-6 e III-7 são respectivamente os pacientes 8, 5, 6 e 7 na tabela II.1.

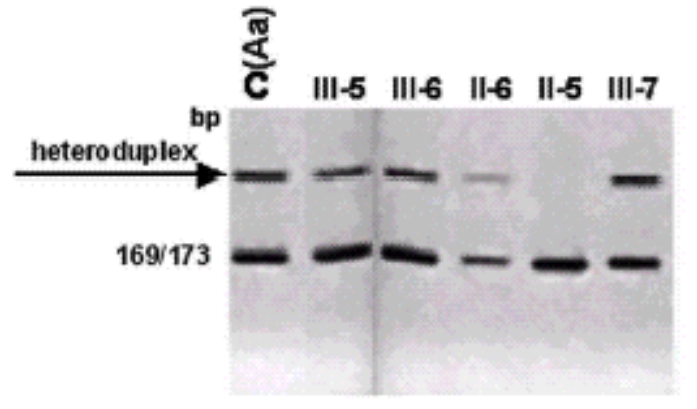

Ins TATC1278

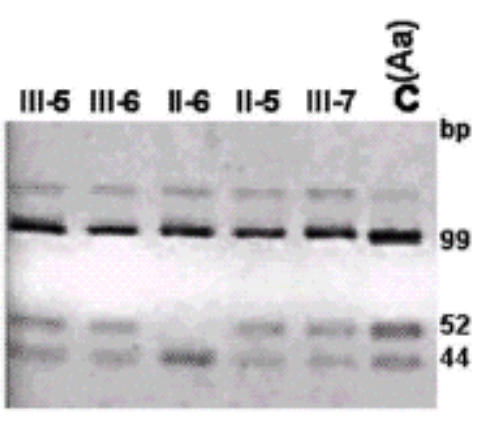

G269S

Figura 2.2. Visualização dos resultados da análise de DNA das mutações G269S e InsTATC1278 em gel de poliacrilamida $12 \%$. O tamanho dos fragmentos de restrição estão expressos em pares de base (pb) ao lado das respectivas bandas. A seta indica a nova banda criada na presença das mutações. O asterisco indica os portadores. A estratégia utilizada foi descrita por Triggs-Raine et al. (1990). (A) A estratégia para detectar a mutação InsTATC1278 é baseada na formação de heteroduplex causada pela inserção de 4 pb. A estratégia para detectar a mutação G269S requer a digestão com 4 unidades da enzima de restrição EcoRII por 4 horas. Na ausência da mutação, o produto normal de PCR de 167 pb é clivado em fragmentos de 99 e 44 pb, que são visualizados em gel, e dois fragmentos de 16 e 8 pb que não são visualizados. A mutação abole um sítio de restrição e o fragmento de PCR de 167 pb é clivado em fragmentos de 99, 52 e 16 pb. Heterozigotos (Aa) usados como controles positivos são incluídos nas duas análises. (C) As amostras estão numeradas de acordo com a genealogia da Figura 2.1. 


\subsection{Discussão}

\subsubsection{Pacientes da forma clássica da DTS}

O diagnóstico molecular dos pacientes da forma clássica da DTS estudados permitiu verificar uma prevalência no Brasil da mutação IVS7+1g >c (Rozenberg et al., 2004). Após a publicação do artigo (item 2.1) outros dois pacientes apresentando a forma clássica infantil da DTS foram analisados. Esses dois novos casos (filhos de casais consangüíneos) mostraram-se homozigotos para a IVS7+1g>c, confirmando sua alta prevalência nos casos Brasileiros da DTS. Os casos da forma clássica da DTS apresentados neste estudo também indicam que a ausência de ancestralidade judaica não deve ser um fator de exclusão na suspeita clínica dessa doença no Brasil. Ademais, indicam que a presença da DTS em pacientes Brasileiros, não se deve a um fluxo gênico de mutações presentes na população judaica.

Os heredogramas dos casos Brasileiros da DTS apresentados no item 2.1 (casos 1 a 7) e de duas novas famílias (casos 8 e 9) mostram que os pacientes da DTS são filhos de casais consangüíneos em 44\% (4/9) dos casos (figura 2.3). Essa alta freqüência de casais consangüíneos nos pais de pacientes, fala a favor de uma baixa freqüência populacional de heterozigotos para a DTS no Brasil (Beiguelman, 1995).

Os Estados de origem dos portadores da mutação IVS7+1g>c mostram uma concentração nos Estados nordestinos (figura 2.4). Essa concentração pode ser incidental, mas se novos casos mostrarem uma alta incidência de afetados numa região específica isso poderia indicar a necessidade de um programa preventivo. 


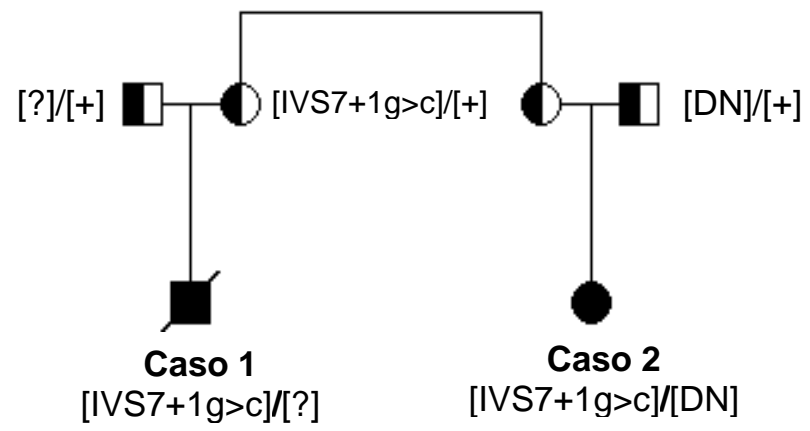

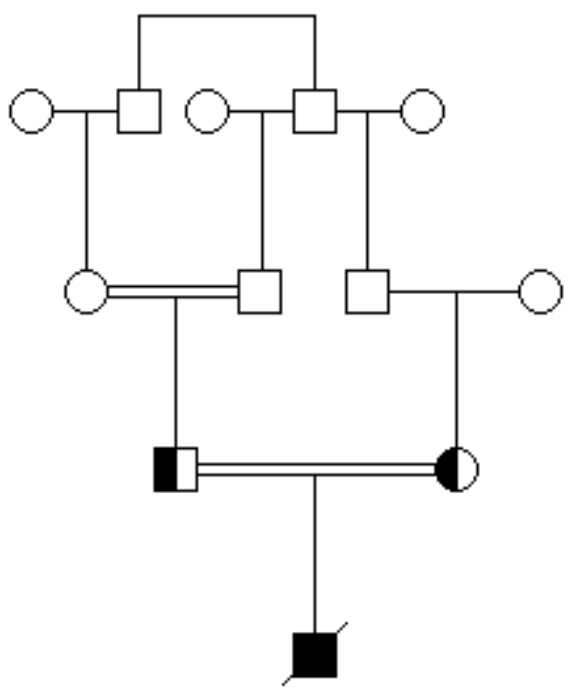

Caso 4

[IVS7+1g>c]/[IVS7+1g>c]

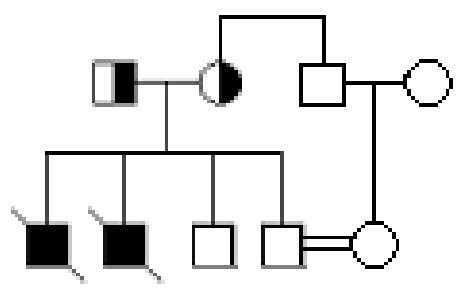

Caso 7

A mãe dos pacientes é portadora da mutação IVS7+1g>c. O casal consangüíneo não é portador.

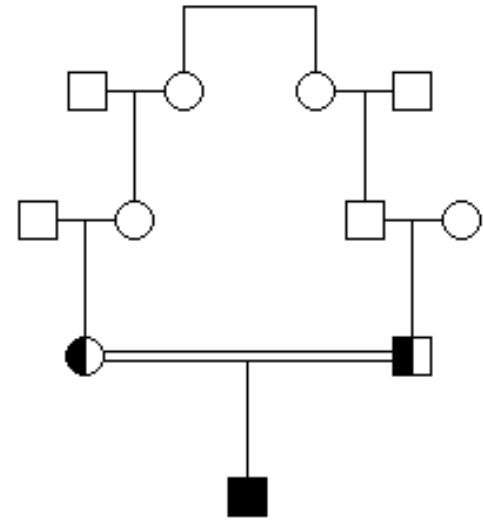

Caso 3

[IVS7+1g>c]][IVS7+1g>c]

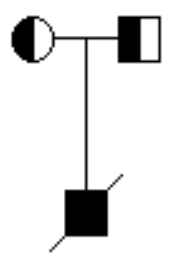

Caso 5

[IVS7+1g>c]][InsTATC1278]

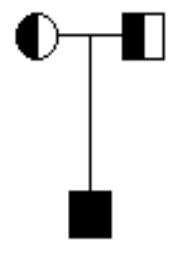

Caso 6

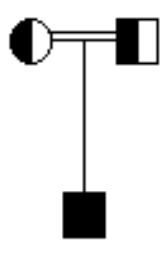

Caso 8

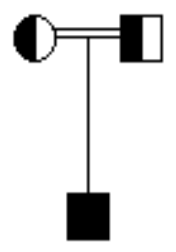

Caso 9

$[\mathrm{IVS} 7+1 \mathrm{~g}>\mathrm{c}] /[\mathrm{IVS} 7+1 \mathrm{~g}>\mathrm{c}] \quad[\mathrm{IVS} 7+1 \mathrm{~g}>\mathrm{c}] /[\mathrm{IVS} 7+1 \mathrm{~g}>\mathrm{c}]$

Figura 2.3. Heredogramas das famílias de formas clássicas da DTS apresentadas. Os avós dos pacientes não foram testados. Apenas os heterozigotos identificados por diagnóstico molecular são identificados por um ícone pintado ao meio, com exceção dos pais nos caso 1 e 7. Os genótipos são apresentados entre colchetes. [DN]: alelo DN (R178H); [+]: alelo normal; [?]: mutação não identificada. 


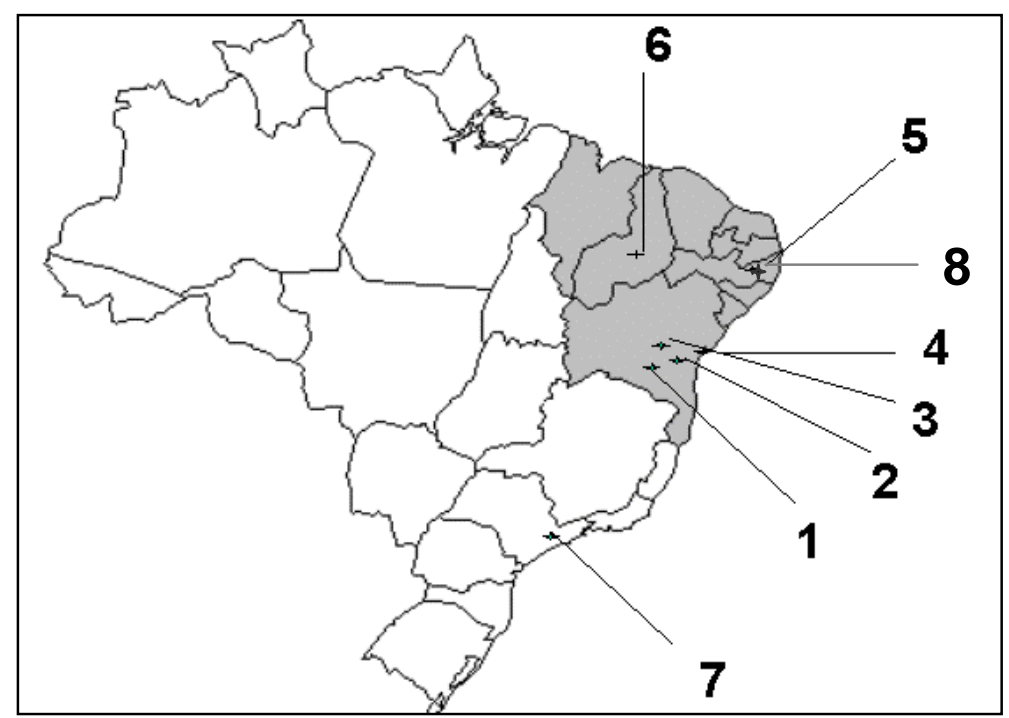

Figura 2.4. Distribuição geográfica dos portadores da mutação IVS7+1g >c mostrando uma concentração na região Nordeste do Brasil, particularmente nas cidades do Sudeste do Estado da Bahia. 1: Rio do Antônio (BA): cidade de nascimento dos pais nos casos 3 e 9. 2: Jequié (BA): cidade de nascimento da mãe no caso 4. 3:Livramento (BA): cidade de nascimento do pai no caso 4. 4: Salvador (BA): cidade de nascimento da mãe no caso 7. 5: Altinho (PE): cidade de nascimento das mães nos casos 1 e 2. 6: São João do Piauí (PI): cidade de nascimento dos pais no caso 6. 7: São Paulo (SP): cidade de nascimento da mãe no caso 5. 8: Palmares (PE): cidade de nascimento dos pais no caso 8.

\subsubsection{Pacientes das variantes da DTS}

Alguns pacientes das formas não-clássicas da DTS foram encaminhados ao nosso laboratório para análise molecular conforme descrito no item 2.2. A presença da mutação $\mathrm{R} 178 \mathrm{H}$, também associada à origem Portuguesa foi marcante nos casos da variante B1. Assim como na forma clássica da DTS, outros dois novos casos foram analisados após a aceitação do artigo para publicação. Um desses casos apresentou a variante B1, com uma cópia da mutação R178H, herdada da mãe portadora. O pai, de ancestralidade libanesa, mostrou uma redução de atividade da Hex $A$, mas a mutação não foi detectada, tendo sido excluídas as outras mutações estudadas.

O segundo paciente apresentou a forma crônica da DTS e também foi diagnosticado numa família de ancestralidade Judaica Ashkenazita. O paciente, atualmente com 26 anos de idade, apresenta dislexia, falta de equilíbrio e um quadro de atrofia cerebelar. O primeiro sinal clínico, comunicado pela mãe, foi um 
surto psicótico aos 15 anos de idade. A análise molecular revelou o genótipo típico da variante de início tardio da DTS na população judaica, InsTATC1278/G269S, o mesmo da primeira família estudada, embora não houvesse parentesco entre as duas. Durante o aconselhamento genético, levantou-se que o paciente tem duas irmãs casadas, uma das quais estava com a quarta gravidez em curso, apresentando um quadro de irritabilidade. Essa família foi encaminhada para contatar o programa Dor Yeshorim, que atende famílias de orientação ortodoxa. O aconselhamento genético dessa família está em andamento.

As famílias apresentando os casos juvenis e adultos da DTS, especialmente aquela com três irmãos afetados, apresentam grande ansiedade em relação aos esforços recentes de se estabelecer uma terapia para os pacientes dessa doença (Cox et al., 2000; Tropak et al., 2004). O estado atual dessas pesquisas inclui triagens clínicas de pacientes Norte-Americanos da variante de início tardio da DTS utilizando a terapia de redução de substrato com o medicamento Zavesca ${ }^{\circledR}$, usado no tratamento de pacientes da DG que apresentam reação imunológica à TRE (Neudorfer \& Kolodny, 2004). Adicionalmente, um paciente da forma clássica da DTS, que recebeu um transplante de medula óssea, seguido de terapia de redução de substrato com Zaveska $^{\circledR}$ teve um aumento de atividade da Hex A, mas não houve interrupção do quadro de degeneração neurológica progressiva (Jacob et al., 2005). Por fim, um grupo canadense está realizando uma triagem de novas drogas com efeitos inibidores e chaperones. Assim, novos resultados devem ser aguardados, para que se possa oferecer um tratamento a esses casos Brasileiros da DTS. 
Esta parte está subdividida em três itens, tratando do diagnóstico molecular de mutações causadoras da DG. O item 3.1 descreve a análise das principais mutações e foi escrita com base no trabalho: "Molecular diagnosis of Gaucher disease in Brazil: high frequency of mutation G377S among type 3 patients" submetido em 19/12/2005 ao Brazilian Journal of Medical and Biological Research. O item 3.2 descreve a análise por dHPLC e seqüenciamento de mutações novas e raras não detectadas na primeira parte. $O$ item 3.3 descreve a análise de mutações causadoras da DG entre pacientes apresentando Parkinsonismo e foi escrita com base no artigo "Parkinson's Disease and GBA Mutations in Brazil" submetido em 06/06/2006 ao periódico Neurology. 


\title{
3.1. ANÁLI SE MOLECULAR DA DOENÇA DE GAUCHER NO BRASI L: PREVALÊNCI A DA MUTAÇÃO G377S EM PACIENTES DE TI PO 3
}

\author{
Rozenberg $\mathrm{R}^{1}$, Araújo $\mathrm{FT}^{1}$, Fox $\mathrm{DC}^{1}$, Aranda $\mathrm{P}^{2}$, Nonino $\mathrm{A}^{3}$, Micheletti $\mathrm{C}^{4}$, \\ Martins $\mathrm{AM}^{4}$, Cravo $\mathrm{R}^{5}$, Sobreira $\mathrm{E}^{6}$, Pereira $\mathrm{LV}^{1}$.
}

Artigo submetido ao Brazilian Journal of Medical and Biological Research

\footnotetext{
${ }^{1}$ Departamento de Genética e Biologia Evolutiva, Instituto de Biociências, Universidade de São Paulo, São Paulo, Brasil

${ }^{2}$ Hospital Evangélico de Londrina, Londrina, Brasil

${ }^{3}$ Hospital de base do Distrito Federal, Distrito Federal, Brasil

${ }^{4}$ Depto de Pediatria, Escola Paulista de Medicina, Universidade Federal do Estado de São Paulo, São Paulo, Brasil

${ }^{5}$ Servico de Hemoterapia HEMORIO, Rio de Janeiro, Brasil

${ }^{6}$ Serviço de Hemato-Oncologia da Faculdade de Ciências Médicas Santa Casa de São Paulo, São Paulo, Brasil
} 


\section{ABSTRACT}

Gaucher disease (GD), the most prevalent lysosome storage disorder, presents an autosomal recessive mode of inheritance. It is a paradigm for therapeutic intervention in medical genetics due to existence of an effective enzyme replacement therapy. Here we report the molecular analysis of GD in 262 not-related Brazilian patients, aiming to establish the frequency of the most common mutations and to provide prognostic information based on genotypephenotype correlations. Among 247 type 1 GD patients, mutation N370S was detected in $47 \%$ of all the alleles, but homozigosity N370S/N370S was found in only $10 \%$ of patients, a frequency much lower than expected, highlighting that most individuals presenting this genotype may not come to medical attention. Recombinant alleles were detected at a high frequency: $44 \%$ of the chromosomes bearing mutation L444P had other mutations derived from pseudogene sequence, present in $25 \%$ of patients. Three neuronopathic type 2 patients were homozygous for L444P, all presenting additional mutations (E326K or recombinant alleles) that are probably leading to the more severe phenotypes. Six children, classified as type $1 \mathrm{GD}$ patients, had a L444P/L444P genotype, disclosing that neuronopathic symptoms may only manifest latter in life. This would indicate the need for a higher treatment dose during enzyme replacement therapy. Finally, mutation G377S was present in four homozigous type 1 patients but also in compound heterozigosity in five (42\%) type 3 patients. These findings contribute to new insights in genotype-

phenotype correlation, highlighting that G377S cannot be unambiguously classified as mild and suggesting an allele-dose effect for this mutation. 


\section{RESUMO}

A DG é a principal doença de armazenamento lisossômico e apresenta herança autossômica recessiva. Essa doença é um paradigma de intervenção terapêutica em genética médica devido à existência de uma eficiente terapia de reposição enzimática. Neste trabalho foi realizada a análise molecular da DG em 262 pacientes Brasileiros não-aparentados visando estabelecer a freqüência das principais mutações e prover informação prognóstica baseada em relações genótipo-fenótipo. Entre 247 pacientes de tipo 1, a mutação N370S foi detectada em $47 \%$ de todos os alelos, mas a homozigose N370S/N370S foi encontrada em apenas $10 \%$ dos pacientes, uma freqüência menor do que esperada, mostrando que a maior parte dos indivíduos com esse genótipo não vêm à atenção médica. Alelos recombinantes foram detectados numa alta freqüência: $44 \%$ dos cromossomos com a mutação L444P tinham outras mutações advindas do pseudogene, presentes em $25 \%$ dos pacientes. Três pacientes de tipo 2 eram homozigotos para a L444P, todos apresentando mutações adicionais (E326K ou alelos recombinantes) que estão provavelmente levando a fenótipos mais ominosos. Seis crianças, classificadas como pacientes de tipo 1, apresentaram o genótipo L444P/L444P, mostrando que sintomas neuronopáticos podem aparecer futuramente. Isso indicaria a necessidade de uma maior dosagem na terapia de reposição enzimática. Por fim, a mutação G377S, estava presente em homozigose em quatro pacientes de tipo 1, mas também em heterozigose composta em 5 pacientes (42\%) de tipo 3. Esse achado corrobora que a mutação G377S não pode ser inequivocamente classificada como leve e sugere um efeito de dose alélica para essa mutação. 


\section{INTRODUÇÃO}

A doença de Gaucher (DG), a mais prevalente doença de armazenamento lisossômico, apresenta herança autossômica recessiva. Clinicamente, é uma doença multissistêmica, caracterizada por hepatoesplenomegalia, anemia e trombocitopenia. Doença óssea e pulmonar podem também estar presentes. A presença e gravidade de sintomas neuronopáticos definem as 3 formas da doença. Aproximadamente 95\% dos pacientes apresentam a DG tipo 1 (MIM 230800) sem envolvimento neurológico e com início na infância ou idade adulta (Beutler \& Grabowski, 2001). As variantes neuronopáticas são o tipo 2 da DG (MIM 230900) caracterizado por início precoce e sobrevida até 2 anos de idade e a DG tipo 3 (231000) apresentando início infantil ou juvenil e um curso menos ominoso que o tipo 2, com sobrevida até a idade adulta.

A DG é causada por mutações no gene GBA (1q21). Esse gene possui 7 Kbs distribuídos em 11 exons e codifica a enzima $\beta$-glicosidase ácida, também chamada de glicocerebrosidase (GCase) (Sorge et al., 1985). A ausência dessa enzima leva ao acúmulo de glicocerebrosídeo nas células do sistema reticuloendotelial e ao fenótipo clínico da DG. Mais de 200 mutações causadoras da DG já foram identificadas e as mais freqüentes são a [c.1226A>G;N370S] e a [c.1448T>C;L444P], aqui chamadas respectivamente de N370S e L444P. O diagnóstico clínico da DG pode ser confirmado pelo ensaio bioquímico de atividade da GCase. Ao contrário do diagnóstico enzimático, a detecção de mutações tem considerável valor prognóstico, embora essa previsão não seja absoluta (Beutler \& Grabowski, 2001). Oportunamente, uma extensa relação genótipo-fenótipo está presente nas principais mutações. As mutações causadoras da DG são classificadas como leves, graves ou alelos nulos de acordo com seu efeito fenotípico (Beutler et al., 2005). Na presença de uma mutação de efeito leve manifesta-se a DG tipo 1, mesmo em combinação com uma segunda mutação grave, ou um alelo nulo. As variantes neuronopáticas são devidas a homozigose de mutações graves, ou à combinação de uma mutação grave e um alelo nulo. A homozigose de alelos nulos não é encontrada, sugerindo que esse 
genótipo é incompatível com a vida. Assim, a presença da mutação leve N370S num dos alelos resulta num fenótipo de tipo 1, uma vez que essa mutação leva a uma enzima com atividade residual suficiente para prevenir a doença neuronopática (Zhao \& Grabowski, 2002). Os homozigotos para essa mutação apresentam ampla variabilidade clínica e alguns deles podem nunca ir à atenção médica devido à ausência de sintomas ou à baixa expressão desses (Beulter et al., 1993; Lacerda et al., 1994). Por outro lado, a homozigose da mutação de efeito grave L444P leva às variantes neuronopáticas da DG. Apesar dessas claras correlações genótipo-fenótipo, uma variabilidade clínica está presente em pacientes com o mesmo genótipo indicando a existência de outros fatores, genéticos e/ou ambientais, influenciando o fenótipo (Goker-Alpan et al., 2005). A heterogeneidade clínica da DG é devida, ainda que parcialmente, a diferentes taxas de degradação das enzimas mutantes no retículo endoplasmático (Ron \& Horowitz, 2005).

A presença de um pseudogene (psGBA), contíguo ao gene GBA pode complicar a identificação de mutações causadoras da DG. A seqüência do GBA e do psGBA tem 97\% de homologia, não havendo genes ativos entre eles (Horowitz et al., 1989). A recombinação entre o $G B A$ e o psGBA pode originar alelos recombinantes (RECs), apresentando uma seqüência inicialmente do gene mas depois do ponto de recombinação, a seqüência é do pseudogene, portando assim todas as suas mutações (Tayebi et al., 2003). A mutação L444P, quando detectada, indica a possibilidade de um alelo recombinante (REC), uma vez que a transição 1448T>C é parte da seqüência do psGBA. O REC mais freqüente é o RecNcil, composto pela combinação das mutações L444P, A456P e V460V. Similarmente, o RecTL é formado pelas mutações presentes em RecNcil mais a D409H. Os RECs estão associados a uma menor atividade enzimática residual e a fenótipos clínicos mais ominosos (Koprivica et al., 2000; Stone et al., 2000).

Dados de prevalência da DG são escassos para a maioria das populações. As estimativas variam de 1/20.000 para a população Portuguesa a 1/100.000 para a população Holandesa (Lacerda et al., 1994; Beutler \& Grabowski, 2001). Algumas populações apresentam uma incidência alta da doença, como os judeus 
Ashkenazitas onde prevalece a DG tipo 1 e a população Norbotniana do Norte da Suécia, onde prevalece o tipo 3 da DG, causado pelo genótipo L444P/L444P.

A DG é a primeira doença de armazenamento lisossômico para a qual foi desenvolvida uma eficiente terapia de reposição enzimática (TRE) tornando-se um paradigma de intervenção terapêutica em genética humana (Germain, 2004). Esse tratamento é o padrão terapêutico para os tipos 1 e 3 da DG e reverte os sintomas não neurológicos da doença de forma eficiente. A dose de infusão durante a TRE é estabelecida conforme o peso corpóreo e as manifestações clínicas. A individualização de dose está sujeita à decisão médica incluindo a dose inicial e sua redução durante o tratamento, que é vitalício. O alto custo do tratamento faz com que a TRE deva ser administrada na dose mais eficiente possível. No Brasil, a terapia é subsidiada pelo sistema público de saúde mostrando que essa doença apresenta baixa incidência, mas um significativo impacto econômico. Não há estimativas da prevalência da DG no Brasil mas existem aproximadamente 400 pacientes diagnosticados (Michelin et al., 2005), a terceira maior população de pacientes em TRE do mundo. Este trabalho apresenta a freqüência das mutações mais comuns num grupo de 262 pacientes Brasileiros da DG. Algumas relações genótipo-fenótipo inesperadas foram encontradas e suas implicações para o diagnóstico e tratamento da DG são discutidas.

\section{PACIENTES E MÉTODOS}

\section{Pacientes e familiares}

No total, 581 amostras foram recebidas no laboratório, incluindo pacientes, familiares e casos de suspeita clínica da DG. As amostras vieram de diferentes regiões do Brasil, durante um período de 3 anos (2000-2003). Os pacientes da DG foram diagnosticados pelos seus médicos após exame clínico e uma análise bioquímica mostrando atividade reduzida da GCase medida em leucócitos. Apenas 3 pacientes tinham ancestralidade judaica Ashkenazita. Amostras de mucosa bucal foram coletadas pelos médicos ou profissionais de saúde que 
participam no tratamento desses pacientes e enviadas ao laboratório em microtubos. Os participantes assinaram formulários de consentimento e a pesquisa foi aprovada pelo comitê nacional de ética em pesquisa (CONEP).

A triagem de mutações para fins estatísticos foi realizada num caso de cada família, perfazendo um total de 262 casos, dos quais 247 foram classificados por seus médicos como sendo de tipo 1, três foram classificados como tipo 2 e 12 como tipo 3. A maioria dos pacientes está em TRE, exceto os casos de tipo 2, que não são tratados e apresentam baixa expectativa de vida. Os genótipos foram considerados em separado para os casos de tipo 2 e 3, para evitar tendências na avaliação das freqüências gênicas e genotípicas.

\section{Diagnóstico molecular}

As amostras de mucosa bucal tiveram seu DNA extraído de acordo com o protocolo descrito por Richards et al. (1993). As mutações N370S, L444P, G377S, c.84insG (84insG), IVS2+1G>A, c.1263_1317del (55del), V460V, D409H e E326K foram analisadas baseadas nos polimorfismos de fragmentos de restrição. $\mathrm{Na}$ tabela 3.1.1 estão descritos o efeito enzimático dessas mutações, sua estratégia de detecção, os primers e as endonucleases usadas para sua detecção e o método de referência quando previamente estabelecido. Após a digestão com enzimas de restrição o DNA foi submetido à eletroforese em gel de poliacrilamida 12\% (mutações N370S, G377S, 84insG e IVS2+1G>A) ou em gel de agarose 2\% (mutações L444P, V460V, D409H, 55del e E326K).

Todos os pacientes foram triados para as mutações N370S e L444P, as mais freqüentes em diversas populações. A mutação G377S é a terceira mais freqüente em Portugal e foi portanto incluída na análise inicial. $\mathrm{Na}$ ausência dessas mutações num dos alelos, os primeiros 100 pacientes foram analisados para as mutações 84insG e IVS2+1G>A. Pacientes homozigotos para N370S, G377S ou L444P foram investigados para a presença da mutação 55del, derivada do psGBA. Essa deleção, caso presente no GBA, estaria localizada no sítio de 
anelamento dos primers utilizados na detecção das mutações N370S, G377S e L444P (Tayebi et al., 1996).

Todos os pacientes que apresentaram a mutação L444P foram testados para a mutação V460V, visando identificar a presença de um REC. Ao se detectar a V460V, indicativa de um REC, as mutações 55del e D409H foram analisadas para determinar a extensão da recombinação entre o GBA e o psGBA. Adicionalmente, quando um REC foi detectado, os pais do paciente foram testados, sempre que possível, para confirmar que as mutações derivadas do psGBA estavam no mesmo alelo. Os RECs mais freqüentes são o RecNcil (L444P, A456P e V460V) e o RecTL (D409H, L444P, A456P e V460V). Devido à ausência de análise da A456P, optamos em apresentar os RECs pelas mutações de fato detectadas. Por fim, os 15 pacientes classificados como tipos 2 e 3 foram testados para a 55del, D409H e E326K devido à alta freqüência dessas mutações nessas variantes.

\section{RESULTADOS}

A amostra analisada foi composta por 247 (94\%) pacientes da DG de tipo 1, três (1\%) de tipo 2 e $12(5 \%)$ de tipo 3. Os pacientes de tipo 2 podem estar subrepresentados, uma vez que não são tratados pela ERT e têm uma expectativa de vida reduzida. No entanto, a distribuição é similar a de outros estudos em diferentes populações (Beutler \& Grabowski, 2001).

A distribuição genotípica nos 247 pacientes de tipo 1 é mostrada na figura 3.1.1. Entre os 100 primeiros pacientes analisados apenas um alelo com a mutação 84insG e nenhum com a IVS2+1G>A foram detectados. Assim, a triagem dessas mutações foi interrompida e elas foram consideradas como nãoidentificadas. Aproximadamente metade dos pacientes eram heterozigotos compostos apresentando o genótipo N370S/L444P. A combinação da N370S com uma segunda mutação não-identificada é o segundo genótipo mais freqüente, presente em aproximadamente $30 \%$ dos alelos. O restante dos pacientes tinha diversos outros genótipos. 
O diagnóstico molecular de 6 crianças com um diagnóstico clínico do tipo 1 da DG mostrou um genótipo característico da DG tipo 3 (homozigose para a L444P). Para fins estatísticos essas crianças foram consideradas como pacientes de tipo 1, conforme classificação clínica, embora seus genótipos sugerissem que sintomas neurológicos são esperados numa fase de vida posterior.

A freqüência de mutações independentemente da distribuição genotípica é apresentada na primeira coluna da tabela 3.1.2. Ao passo que quase a metade dos alelos dos pacientes apresentam a N370S (47\%), a outra metade divide-se em L444P (27\%), G377S (2\%) e uma mutação não identificada (24\%).

Uma vez que a mutação L444P pode estar presente isoladamente ou como parte de um REC, essa possibilidade foi sempre averiguada. Entre os pacientes de tipo 1, 46\% (62/134) dos alelos com a L444P apresentaram adicionalmente a V460V. A análise da D409H seguiu-se à triagem da V460V e apenas 2\% (3/134) dos alelos com a L444P foram positivos, mostrando um REC com L444P+V460V+D409H. A mutação 55del não foi identificada entre os RECs, sugerindo que eles tinham mutações derivadas do pseudogene restritas aos exons 9 e 10. No entanto, outros eventos de recombinação, anteriores à 55del podem estar presentes. Quando incluídos os pacientes de tipo 2 e 3, os RECs foram identificados em 44\% (66/150) dos cromossomos com a L444P e 25\% (66/262) de todos os pacientes da DG.

Os 15 pacientes de tipo 2 e 3 da DG foram triados para as mutações N370S, G377S, L444P, V460V, 55del, D409H e E326K. A tabela 3.1.3 apresenta os genótipos detectados. Foi encontrado um homozigoto, de pais consangüíneos, apresentando a E326K em combinação com a L444P em ambos alelos com um fenótipo clínico de tipo 2. O único heterozigoto composto apresentando a L444P num alelo e um REC no outro também apresentou o tipo 2 da DG. Entre os pacientes de tipo 3, a presença das mutações N370S num caso e da G377S em outros cinco foi inesperada uma vez que essas mutações são geralmente consideradas como tendo efeito leve. 


\section{DISCUSSÃO}

\section{Freqüência das principais mutações}

A freqüência das duas principais mutações causadoras da DG entre pacientes Brasileiros é similar àquela descrita em outras populações, onde a N370S e a L444P representam respectivamente metade e um quarto dos alelos, aproximadamente (Beutler \& Grabowski, 2001). As mutações 84insG e IVS2+1G>A tinham freqüência muito baixa nos primeiros 100 casos analisados e foram portanto excluídas da triagem. De fato, essas mutações têm uma alta freqüência em pacientes judeus, mas não na população em geral de diversos países (Beutler \& Grabowski, 2001). A baixa freqüência dessas mutações neste estudo pode refletir a baixa representatividade de judeus $(<0,1 \%)$ na população Brasileira.

Na tabela 3.1.2 é possível observar que a freqüência das principais mutações causadoras da DG em pacientes Brasileiros de tipo 1 encontrada neste estudo é similar àquela encontrada numa amostra de pacientes não-judeus NorteAmericanos (Zhao \& Grabowski, 2002) $(P=0,263)$, mas significativamente diferente $(P=0,028)$ quando comparada a 27 casos de Portugal (Lacerda et al., 1994), de acordo com análise de $\chi^{2}$.

A mutação G377S é a terceira mais freqüente entre os pacientes da GD em Portugal e na Espanha (Amaral et al., 1996). No Brasil, ela também apareceu numa freqüência considerável $(2,2 \%)$ indicando ser importante numa análise molecular preliminar. Uma correspondência entre mutações causadoras de outra doença de armazenamento lisossômico também foi descrita para a doença de Tay-Sachs e sugere uma origem comum dos alelos mutados, anterior à colonização Portuguesa do Brasil (Rozenberg et al., 2004).

Entre os alelos com L444P, 44\% (66/150) eram RECs, presentes em 25,2\% (66/262) dos pacientes e correspondendo a 12,6\% (66/524) dos alelos estudados. A estratégia utilizada foi limitada pela ausência de análise da mutação $A 456 P$, presente nos RECS. Assim, optamos por apresentar os RECs pelas mutações de 
fato diagnosticadas. Uma vez que alguns pacientes podem apresentar a A456P, mas não a V460V, a freqüência de RECs nesta amostra pode ser ainda maior. Uma alta freqüência de RECs também foi encontrada em outros países (Koprivica et al., 2000), incluindo a Argentina, onde $20 \%$ dos pacientes da DG apresentaram a RecNcil (Cormand et al., 1998). Outros estudos mostraram que os RECs têm um impacto mais grave na manifestação clínica dos pacientes do que a L444P isolada (Koprivica et al., 2000; Stone et al., 2000; Mignot et al., 2003; Tayebi et al., 2003). De acordo com essa observação, os três homozigotos para a L444P deste estudo apresentando adicionalmente a E326K ou RECs manifestaram o tipo 2 da DG, ao passo que os homozigotos L444P/L444P sem essas alterações adicionais tinham fenótipos mais brandos. É possível que os fenótipos mais ominosos dos pacientes de tipo 2 mostrem um efeito modificador da E326K e dos RECs levando a uma menor atividade enzimática residual. No entanto, outros locos também podem estar influenciando a manifestação clínica (Monfort et al., 2004; Goker-Alpan et al., 2005). O paciente de tipo 2 apresentando 0 genótipo L444P+E326K/L444P+E326K não apresentou a variante letal-perinatal da DG, mostrando não ser essa uma relação genótipo-fenótipo universal (Chabás et al., 2005).

\section{Crianças diagnosticadas com o tipo 1 da DG em fase pré-neuronopática}

Entre os pacientes de tipo 3 da DG, as manifestações neurológicas aparecem após os 10 anos de idade em 50\% dos casos (Beutler \& Grabowski, 2001). Assim, é possível que crianças em idade inferior a essa, diagnosticadas com a DG tipo 1, podem ser pacientes de tipo 3 numa fase pré-neuronopática. $O$ diagnóstico molecular pode ajudar a identificar esses casos e isso ocorreu de fato em 6 crianças neste estudo, de 5 a 6 anos de idade, nas quais a mutação L444P isolada foi identificada em homozigose. É possível que outras crianças deste estudo, classificadas clinicamente como pacientes de tipo 1, com mutações não identificadas e sem mutações de efeito leve, estejam na mesma situação. Embora apenas $\sim 5 \%$ dos pacientes da DG apresentem o tipo 3, a doença se apresenta na infância na maior parte dos casos, fazendo com que a possibilidade de um 
paciente pré-neuronopático seja uma dúvida freqüente. A antecipação do diagnóstico de uma variante neuronopática da DG, promovida pelos testes de DNA, traz a necessidade de se informar a família, uma vez que tais pacientes apresentam geralmente problemas de desenvolvimento e de aquisição de linguagem (Erikson et al., 1995; Goker-Alpan, 2005). Não menos importante é o impacto na TRE. Existe a possibilidade de que um tratamento de alta dosagem possa atrasar os sintomas neuronopáticos (Erikson et al., 1995; Vogler et al., 2005) mas evidência conclusiva ainda não existe para a DG. De qualquer forma, o consenso Europeu para tratamento da DG neuronopática estabeleceu que a TRE dos pacientes de tipo 3 , incluindo os pré-neuronopáticos identificados por testes de DNA, deve ser feito com doses mais altas (120 U/Kg a cada duas semanas) que não deve ser diminuída mesmo após a melhora do quadro geral (Vellodi et al, 2001). No entanto, o protocolo do ministério da saúde para o tratamento da DG no Brasil não contempla esses casos, encerrando a necessidade de melhorias nesse sentido.

\section{Penetrância reduzida do genótipo N370S/N370S}

Neste estudo, tornou-se evidente que embora a N370S representasse $47 \%$ das mutações entre os pacientes da DG (tabela 3.1.2), apenas $\sim 10 \%$ dos pacientes são homozigotos N370S/N370S (figura 3.1.1), uma freqüência muito abaixo dos $22 \%$ esperados $\left(0.47^{2}\right)$. Esses dados refletem provavelmente o fato de que muitos homozigotos para a N370S não vêm à atenção médica devido à ausência de sintomas. Os 24 homozigotos detectados neste estudo indicam uma penetrância desse genótipo de $45 \%(0,10 / 0,22)$, um valor próximo ao descrito para a população judaica Ashkenazita (Beutler et al., 1993) e para os Portugueses (Lacerda et al., 1994). Essa penetrância reduzida tem implicações para o aconselhamento genético, especialmente quando programas de triagem populacional de heterozigotos detectam casais em risco. A expressão variável e a penetrância incompleta desse genótipo são bem caracterizados, como no caso de um par de gêmeas monozigóticas que viveram juntos durante toda a vida 
(Lachmann et al., 2004). Uma delas apresentou o tipo 1 da DG, com manifestações ósseas, ao passo que a outra permaneceu assintomática até sua morte aos 82 anos. Embora apresente um modo de herança autossômico recessivo, a DG apresenta uma manifestação complexa.

\section{Pacientes neuronopáticos com correlações genótipo-fenótipo inesperadas}

Seis pacientes apresentando classificação clínica do tipo 3, com sintomas neurológicos, apresentaram uma cópia das mutações N370S ou G377S. Essas mutações deveriam estar garantindo um fenótipo de tipo 1, mesmo em heterozigose composta com uma segunda mutação de efeito grave, ou com um alelo nulo. Em cinco casos, a mutação era a G377S (tabela 3.1.3), mostrando que a classificação da G377S como leve ou "neuroprotetora" é inconsistente com o fenótipo desses pacientes.

As evidências para se considerar a G377S como tendo efeito leve são baseadas na sua alta atividade enzimática residual (17,6\%) (Amaral et al., 2000) e no fato de que os homozigotos para a G377S descritos na literatura são todos pacientes de tipo 1 (Amaral et al., 1999; Giraldo et al., 2000; Koprivica et al., 2000; Bembi et al., 2003; http://life2.tau.ac.il/GeneDis). Os quatro homozigotos encontrados neste estudo também apresentam o fenótipo de tipo 1. No entanto, cinco heterozigotos compostos neste estudo com uma cópia da G377S num dos alelos eram pacientes de tipo 3. Uma busca no Medline mostrou que outros trabalhos também encontraram pacientes de tipo 3 com uma cópia da G377S (Germain et al., 2001; Park et al., 2003; Wong et al., 2004). Essas observações sugerem a possibilidade de em efeito de dose alélica, aonde duas cópias da G377S levariam a uma atividade enzimática residual suficiente para não haver envolvimento neurológico, mas uma cópia da G377S com uma segunda mutação de efeito mais grave causariam o tipo 3 da DG. Isso está em desacordo com a classificação fixa dessa mutação como sendo de efeito leve.

Um efeito de dose alélica já foi descrito para a mutação K79N (Zhao et al., 2003), onde um homozigoto apresentou a DG tipo 1, mas um heterozigoto composto com um segundo alelo nulo apresentou o tipo 3 da DG. Nesse caso, a 
atividade enzimática residual de enzimas mutantes produzidas pelos dois alelos deve ser considerada de modo aditivo, ao invés de separadamente. Algumas mutações, tais como a G377S, a K79N, a N188S, a V394L e a R463C podem estar no limite de atividade que não compromete o sistema nervoso quando em homozigose (Koprivica et al., 2000; Zhao et al., 2003; Beutler et al., 2005).

Os pacientes aqui descritos representam uma evidência adicional para um papel crítico de uma mutação causadora da DG no desenvolvimento de uma doença neurológica, no entanto a participação de outros modificadores não pode ser excluída. Neste estudo, uma outra família Brasileira apresentou dois irmãos com o genótipo G377S/L444P que não apresentam sintomas neurológicos (figura 3.1.1). Esses irmãos foram testados para a E326K e não apresentam essa mutação (dados não apresentados), ao passo que dois outros pacientes com o genótipo G377S/L444P+E326K apresentaram sintomas neuronopáticos (tabela 3.1.3). Esses casos reforçam a existência de um efeito modificador negativo da E326K.

O sexto caso que apresentou a DG associada a sintomas neurológicos inconsistentes com seu genótipo foi uma menina heterozigota composta N370S/L444P+V460V, com 12 anos de idade. A mutação N370S está em trans com o REC, herdado da mãe. O efeito leve da N370S está bem caracterizado em centenas de pacientes de tipo 1 da DG e contrasta com a manifestação neurológica desse caso. No entanto, existem alguns casos onde não se pode diferenciar se as manifestações neurológicas são uma conseqüência da deficiência enzimática ou um efeito secundário (Beutler \& Grabowski, 2001). De fato, o paciente aqui descrito pode sofrer de encefalopatia devido a hipóxia isquêmica e portanto sua manifestação neuronopática pode não ser uma conseqüência da DG.

Em suma, torna-se claro que os testes de DNA resultam em informações importantes para o diagnóstico e o prognóstico da DG e novos conhecimentos das relações genótipo-fenótipo devem ser prontamente incorporados à prática médica. Uma vez que a TRE é individualizada e que a dose de tratamento é estabelecida pelo médico, o diagnóstico molecular pode ser imprescindível para se estabelecer 
uma dose correta, como no caso das crianças homozigotos para a L444P ainda sem comprometimento neurológico. Por fim, é possível que um efeito de dose alélica esteja associado à mutação G377S. Essa mutação deve ser incluída na triagem em pacientes da DG dos países ibéricos e de suas ex-colônias, sendo que estudos adicionais poderão estabelecer a exata correlação genótipo-fenótipo dessa mutação.

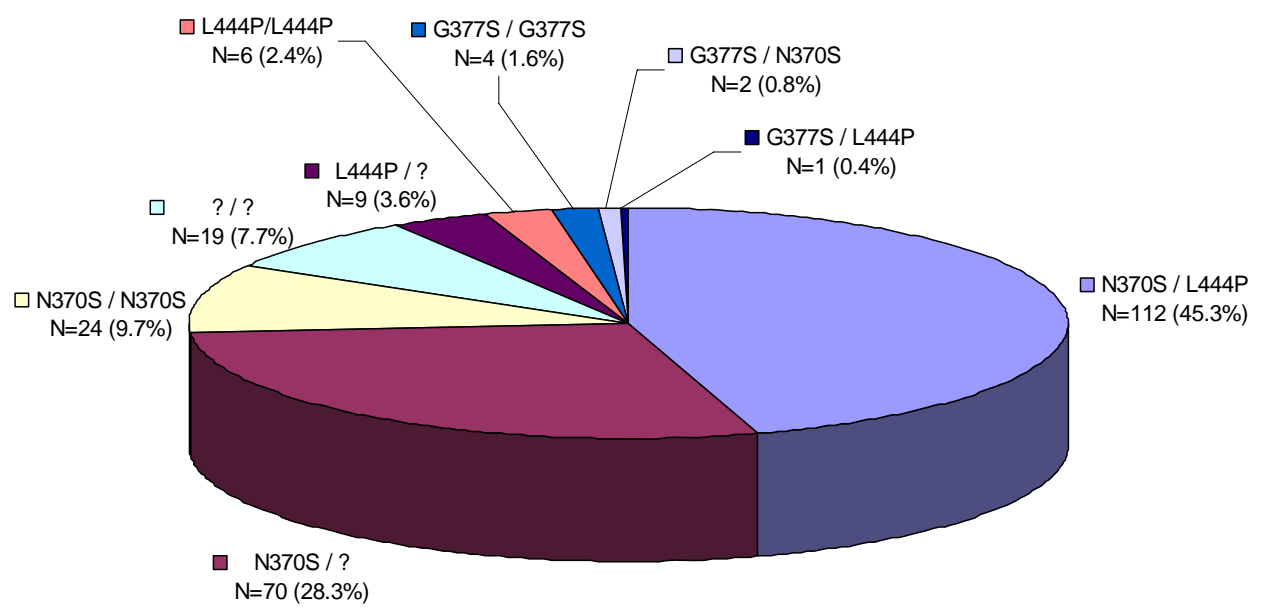

Figura 3.1.1. Freqüência genotípica em 247 pacientes Brasileiros da DG tipo 1. N: número de pacientes (freqüência). ?: mutação não-identificada. 
Tabela 3.1.1. Estratégia de detecção das mutações causadoras da DG analisadas.

\begin{tabular}{|c|c|c|c|c|}
\hline $\begin{array}{c}\text { MUTAÇÃO } \\
\text { (seqüência do cDNA) }\end{array}$ & $\begin{array}{c}\text { * EFEITO } \\
\text { FENOTÍPICO }\end{array}$ & $\begin{array}{l}\text { PACIENTES } \\
\text { TESTADOS }\end{array}$ & $\begin{array}{c}\text { PRIMERS F e } R \\
\text { (referência) }\end{array}$ & $\begin{array}{l}\text { ENZIMA DE } \\
\text { RESTRIÇÃO }\end{array}$ \\
\hline N370S (c.1226A>G) & Leve & Todos & $\begin{array}{l}\text { F: 5' gcctttgtccttaccctcg } \\
\text { R: 5'acgaaagttacgcacccaatt } \\
\text { (Beutler et al., 1990) }\end{array}$ & Xhol \\
\hline G377S (c.1246G>A) & Leve/Grave & Todos & $\begin{array}{l}\text { F: 5' gcctttgtccttaccctç } \\
\text { R: 5'acgaaagttacgcacccaatt }\end{array}$ & Alul or Pvull \\
\hline L444P (c.1448T>C) & Grave & Todos & $\begin{array}{l}\text { F: 5'ctgaaccccgaaggaggac } \\
\text { R: 5'tgaatggagtagccaggtga }\end{array}$ & Ncil \\
\hline V460V (c.1497G>C) & ** & Pacientes com a L444P & $\begin{array}{l}\text { F: 5'ctgaaccccgaaggaggac } \\
\text { R: 5'tgaatggagtagccaggtga }\end{array}$ & $B c g l$ \\
\hline 84insG (c.84insG) & Alelo nulo & Primeiros 100 pacientes & $\begin{array}{l}\text { F: 5' cactgcctgaagtagatgc } \\
\text { R: 5'gaatgtcccaagcctttga }\end{array}$ & BsaBI \\
\hline IVS2+1G>A & Alelo nulo & Primeiros 100 pacientes & $\begin{array}{l}\text { F: 5' gaatgtcccaagcctttga } \\
\text { R: 5'aacagagtaagactctggttc }\end{array}$ & Hphl \\
\hline $\mathrm{D} 409 \mathrm{H}(\mathrm{c} .1342 \mathrm{G}>\mathrm{C})$ & Grave & $\begin{array}{c}\text { - Tipos } 2 \text { e } 3 \\
\text { - Pacientes com a } \\
\text { V460V }\end{array}$ & $\begin{array}{l}\text { F: } 5^{\prime} \text { aaccatgattccctatcttc } \\
\text { R: } 5^{\prime} \text { gctccctcgtggtgtagagt }\end{array}$ & Styl \\
\hline E326K (c.1093G>A) & $* \star \star$ & - Tipos 2 e 3 & $\begin{array}{l}\text { primeiro PCR: } \\
\text { F: 5'acaaattagctgggtgtggc } \\
\text { R: 5'taagctcacactggccctgc } \\
\text { Nested PCR: } \\
\text { F: 5'tgtgcaaggtccaggatcag } \\
\text { R: 5'gaggtctgctttgcaggaag }\end{array}$ & Bbsl or Bpil \\
\hline 55del (c.1263_1317del) & Alelo nulo & $\begin{array}{c}\text { - Tipos } 2 \text { e } 3 \\
\text { - } \quad \text { Homozigotos para } \\
\text { N370S, G377S e } \\
\text { L444P } \\
\text { - Pacientes com a } \\
\text { V460V }\end{array}$ & $\begin{array}{l}\text { F: 5'aaccatgattccctatcttc } \\
\text { R: 5' gctccctcgtggtgtagagt } \\
\text { (Tayebi et al., 1996) }\end{array}$ & $* * * *$ \\
\hline
\end{tabular}

*Efeito fenotípico das mutações de acordo com Beutler et al., 2005 e GeneDis database (http://life2.tau.ac.il/GeneDis). A mutação G377S já foi caracterizada com efeito leve e grave (conforme o texto).

**A mutação V460V é uma alteração silenciosa usada para detectar a presença de um REC.

${ }^{\star * \star A}$ E $326 K$ é um modificador fenotípico que pode estar presente em combinação com outras mutações causadoras da DG.

${ }^{\star * * \star A}$ análise da mutação 55del pode ser visualizada diretamente após a PCR. 
Tabela 3.1.2. Freqüência das principais mutações em pacientes da DG tipo 1 Brasileiros, Norte-Americanos (não-judeus) e Portugueses.

\begin{tabular}{cccc}
\hline Mutação & $\begin{array}{c}\text { Brazil } \\
\text { Este estudo } \\
\text { N (\%) }\end{array}$ & $\begin{array}{c}\text { Estados Unidos da América } \\
\text { Zhao \& Grabowski, 2002 }\end{array}$ & $\begin{array}{c}\text { Portugal } \\
\text { Amaral et al., 1996 }\end{array}$ \\
\hline N370S & $232(47,0 \%)$ & $\mathbf{N}(\%)$ & N (\%) \\
L444P & $134(27,1 \%)$ & $183(43,7 \%)$ & $29(53,7 \%)$ \\
G3775* $^{*}$ & $11(2,2 \%)$ & $107(25,5 \%)$ & $7(13,0 \%)$ \\
Outras & $117(23,7 \%)$ & Não realizado & $4(7,4 \%)$ \\
\hline & 494 alelos $(100 \%)$ & $129(30,8 \%)$ & $14(25,9 \%)$ \\
\hline
\end{tabular}

*A análise estatística comparando este estudo com a amostra norte-Americana considerou a G377S na categoria "outras".

Tabela 3.1.3. Genótipos e fenótipos dos 15 pacientes neuronopáticos da DG.

\begin{tabular}{ll}
\hline Genótipo & Fenótipo \\
\hline L444P+E326K / L444P+E326K ** & Tipo 2 \\
L444P+V460V / L444P & Tipo 2 \\
L444P+E326K / L444P ** & Tipo 2 \\
\hline L444P / L444P & Tipo 3 \\
L444P / D409H & Tipo 3 \\
L444P / D409H & Tipo 3 \\
L444P+V460V / ? & Tipo 3 \\
L444P+V460V / ? & Tipo 3 \\
55del / ? & Tipo 3 \\
L444P+E326K / G377S & Tipo 3*/EM \\
L444P+E326K / G377S ** & Tipo 3* \\
L444P / G377S / E326K + & Tipo 3* \\
G377S / ? & Tipo 3* \\
G377S / ? & Tipo 3* \\
L444P+V460V / N370S & Tipo 3*/EM \\
\hline
\end{tabular}

EM: Epilepsia mioclônica.

* Os pais são primos em primeiro grau.

* Pacientes neuronopáticos com diagnóstico clínico de tipo 3, mas com mutações consideradas de efeito leve. O paciente com a N370S não recebeu avaliação oculomotora detalhada.

** Esses pacientes têm irmãos não incluídos neste estudo, apresentando o mesmo genótipo e fenótipo.

+ A fase da E326K não foi determinada (cis ou trans em relação à L444P). 


\subsection{DETECÇÃO DE MUTAÇÕES CAUSADORAS DA DOENÇA DE GAUCHER POR dHPLC SEGUI DO DE SEQÜENCI AMENTO DE DNA}

\subsubsection{Introdução}

Um dos principais objetivos da detecção de mutações em doença monogênicas é estabelecer relações genótipo-fenótipo. Na DG é particularmente importante associar um dos três graus de gravidade apresentados na tabela 1.4 às novas mutações encontradas. Essa classificação terá valor prognóstico para o tratamento e eventualmente para o aconselhamento genético de famílias. Para isso, a análise do fenótipo do paciente já é muitas vezes informativa, principalmente se uma mutação nova (ainda não descrita) ocorrer num heterozigoto composto, em trans a uma mutação conhecida de efeito grave ou um alelo nulo. Nesses casos, a presença ou ausência de sintomas neurológicos da DG revela o efeito fenotípico da mutação nova.

Alternativamente, análises funcionais de novas mutações têm sido descritas, utilizando sistemas de expressão celular ou camundongos transgênicos (Tybulewicz et al., 1992; Liu et al., 1998; Xu et al., 2003). No entanto, a atividade enzimática residual nem sempre tem uma correlação perfeita com o fenótipo clínico. Algumas mutações têm atividade residual alta, mais são instáveis nas células de pacientes, tendo uma degradação no retículo endoplasmático independente de sua atividade residual (Ron \& Horowitz, 2005).

A triagem das principais mutações causadoras da DG, descrita no capítulo anterior permitiu detectar mutações em $\sim 75 \%$ dos alelos dos pacientes estudados. Assim, fez-se necessário identificar as mutações desconhecidas por técnicas mais sensíveis e abrangentes, para a caracterização molecular completa da DG em pacientes Brasileiros. Para tal, optou-se pela utilização da cromatografia líquida denaturante de alta performance, ou denaturing high performance liquid cromatography (dHPLC) como técnica de pré-seqüenciamento, visando identificar 
os exons que apresentavam mutações. Em seguida passou-se ao seqüenciamento dos exons com perfil de dHPLC alterados.

A técnica de dHPLC foi escolhida por apresentar a maior sensibilidade dentre os métodos de pré-seqüenciamento descritos na literatura. Diversos trabalhos descrevendo mutações raras causadoras da DG já foram realizados utilizando principalmente as técnicas de single strand conformational polymorphism (SSCP) e denaturing gradient gel electrophoresis (DGGE) (Kawame et al., 1992; Alfonso et al., 2001; Beutler et al., 2005). Um trabalho recente, realizado na Colômbia, foi o primeiro a detectar mutações no gene GBA utilizando a técnica de dHPLC e apresentou alta sensibilidade (Pomponio et al., 2005). Outros trabalhos optaram por simplesmente dividir o gene GBA em 3 regiões e seqüenciá-las diretamente através de uma longa reação de PCR (Stone et al., 2000).

O dHPLC é uma técnica utilizada para detecção de mutações, identificando possíveis alterações na seqüência de DNA de um certo fragmento baseado na adstringência diferencial de fragmentos de DNA (heteroduplexes e homoduplexes) a uma matriz hidrofóbica (Oefner \& Underhill, 1995). Embora o cromatógrafo WAVE $^{\circledR}$ (Transgenomic, EUA) usado para o dHPLC tenha um alto custo, a técnica parece ter alta especificidade e sensibilidade (por volta de 96\%), consistindo numa metodologia com relação custo/benefício vantajosa, uma vez que tem um custo de análise por amostra menor que em outras técnicas, como o SSCP (O'Donovan et al., 1998; Xiao \& Oefner, 2001).

Atualmente já foram descritas 240 mutações causadoras da DG (Eyal et al., 1991; Amaral et al., 2000; Beutler et al., 2005; Dominissini et al., 2006). O objetivo central deste capítulo é a identificação de mutações raras, sejam elas novas ou já descritas, em pacientes da DG do Brasil, avaliando a existência de relações genótipo-fenótipo. 


\subsubsection{Material e métodos}

\section{a) Pacientes estudados}

Os pacientes inclusos neste estudo são aqueles analisados no capítulo 3 cuja amostra de mucosa bucal foi recebida no laboratório até março de 2003 e que não apresentaram as mutações triadas por RFLP em pelo menos um dos alelos. Isso correspondeu a 54 pacientes, incluindo apenas um paciente de cada família, que tiveram as mutações identificadas ou todos os exons analisados . A amostra foi composta por 53 pacientes de tipo 1 e 1 paciente de tipo 3 (amostra 319). Não houve seleção de pacientes por fenótipo para inclusão na análise. A classificação clínica dos pacientes foi realizada pelos médicos dos centros nos quais os pacientes são atendidos, baseada em exames clínicos e bioquímicos. No entanto, não é possível saber se avaliações neuro-oftalmológicas foram realizadas de forma cuidadosa visando estabelecer um diagnóstico clínico diferencial da DG tipo 3.

\section{b) Amplificação dos fragmentos de DNA}

O DNA genômico foi extraído das amostras de mucosa bucal, de acordo com Richards et al. (1993). Após a extração, o DNA foi amplificado através de PCR. Devido à presença do pseudogene, altamente homólogo ao gene GBA, foi utilizada a estratégia de realizar uma primeira PCR com primers desenhados de modo a anelar em regiões do gene não-homólogas ao pseudogene. Para isso, alinhou-se as seqüências do GBA e do psGBA com o programa ClustalW (http://www.ebi.ac.uk/clustalw/). Os primers foram escolhidos com a ajuda do programa Primer3 (http://www-genoma.wi.mit.edu/cgi-bin/primer/primer3.cgi) e analisados no programa GeneRunner (www.generunner.com) para verificação da qualidade dos mesmos. Quatro amplicons do gene GBA foram pré-amplificados, correspondendo aos exons 1 ao 4; exons 5 e 6; exon 7 e exons 8 ao 11. Como o propósito era obter fragmentos de até 600 pb para realização posterior do dHPLC, 
uma segunda PCR era realizada, a partir do produto do primeiro, para se obter separadamente a amplificação de cada um dos exons. Uma exceção foi a análise dos exons 10 e 11, que foram amplificados numa mesma reação, já que o intron 10 é muito curto. O amplicon do exon 1 incluiu o peptídeo sinalizador e parte da região promotora do gene. A tabela 3.2.1 mostra a região do gene GBA amplificada, as seqüências dos primers utilizados, o tamanho do amplicon e a temperatura de denaturação parcial.

Tabela 3.2.1. A região amplificada, primers usados nas PCRs, o tamanho do amplicon e a temperatura de análise por dHPLC.

\begin{tabular}{|c|c|c|c|}
\hline Região amplificada & $\begin{array}{l}\text { Sequência dos primers foward }(F) \text { e reverse }(R) \\
5^{\prime}-3^{\prime}\end{array}$ & $\begin{array}{l}\text { Tamanho do } \\
\text { amplicon }(\mathrm{pb})\end{array}$ & $\begin{array}{l}\text { Temperatura de análise } \\
\text { por dHPLC }\end{array}$ \\
\hline Exon 1 a $4\left(^{*}\right)$ & $\begin{array}{l}\text { F: CCTTTAGAAATATGGCTGTG } \\
\text { R: CAGAATGGGCAGAGTGAGAT }\end{array}$ & 1824 & - \\
\hline Exon 1 & $\begin{array}{l}\text { F: CTGTGTCATGTGACGCTCCT } \\
\text { R: TCATTAAATTCCAGTGCCAGG }\end{array}$ & 285 & $55^{\circ} \mathrm{C}$ \\
\hline Exon 2 & $\begin{array}{l}\text { F: TGCCCAGGAGAGTAGTTGAG } \\
\text { R: ACTGGAAGGCTACCAAAGGA }\end{array}$ & 230 & $61^{\circ} \mathrm{C}$ \\
\hline Exon 3 & $\begin{array}{l}\text { F: CATCAGACCTCACTCTGCTTG } \\
R: \text { TGACACCATTTACCTCTAGGA }\end{array}$ & 292 & $62^{\circ} \mathrm{C}$ \\
\hline Exon 4 & $\begin{array}{l}\text { F: TTCCCGCTGGGTACTGATAC } \\
\text { R: TGGCTCTATGTCATCTTGTCC }\end{array}$ & 226 & $59^{\circ} \mathrm{C}$ \\
\hline Exon 5 e $6\left(^{*}\right)$ & $\begin{array}{l}\text { F: CGAACTCCTGACCTCGTGAT } \\
R: \text { AGCCTGGGTGACAGAGAGAG }\end{array}$ & 1144 & - \\
\hline Exon 5 & $\begin{array}{l}\text { F: CTCCTATTGACTCGGACTACCA } \\
\text { R: TTTCTCAACCCCCAGACATC }\end{array}$ & 236 & $57,5^{\circ} \mathrm{C}$ e $61^{\circ} \mathrm{C}$ \\
\hline Exon 6 & $\begin{array}{l}F: \text { TTCCAACTCTGGGTGCTTCT } \\
R: \text { CAGTCСTGATCCСАСАTССТ }\end{array}$ & 250 & $61^{\circ} \mathrm{C}$ e $63^{\circ} \mathrm{C}$ \\
\hline Exon $7\left(^{*}\right)$ & $\begin{array}{l}\text { F: CTCGGCTTCCCAAAGTGCTG } \\
\text { R: ATAGTTGGGTAGAGAAATCG }\end{array}$ & 482 & - \\
\hline Exon 7 & $\begin{array}{l}F: \text { TTACAGTGTGAGCCACCACA } \\
R: \text { TGGATGCTGGATTTGAAGGT }\end{array}$ & 366 & $61^{\circ} \mathrm{C}$ e $62^{\circ} \mathrm{C}$ \\
\hline Exon 8 a $11\left(^{*}\right)$ & $\begin{array}{l}\text { F: ACAAATTAGCTGGGTGTGGC } \\
R: \text { TAAGCTCACACTGGCCCTGC }\end{array}$ & 1877 & - \\
\hline Exon 8 & $\begin{array}{l}\text { F: TGTGCAAGGTCCAGGATCAG } \\
R: \text { GAGGTCTGCTTTGCAGGAAG }\end{array}$ & 301 & $61^{\circ} \mathrm{C}$ \\
\hline Exon 9 & $\begin{array}{l}\text { F: CCCAGTGTTGAGCCTTTGTC } \\
R: \text { AAGCCATCCGATGTAGGAGA }\end{array}$ & 271 & $58^{\circ} \mathrm{C}$ e $61^{\circ} \mathrm{C}$ \\
\hline Exon 10 e 11 & $\begin{array}{l}\text { F: CGAGGGACTCTGACCATCTG } \\
R: \text { CCTTTAATGCCCAGGCTGA }\end{array}$ & 398 & $57^{\circ} \mathrm{C}$ e $62^{\circ} \mathrm{C}$ \\
\hline
\end{tabular}

(*) Pré-amplificações 
As quatro pré-amplificações (exons 1 a 4; 5 e 6; 7; 8 a 11) foram feitas de acordo com o seguinte protocolo: $3 \mu$ de DNA genômico (de mucosa bucal), 200 $\mu \mathrm{M}$ de cada um dos dNTPs, 1X Tampão (Amersham Pharmacia), 3,75 unidades de enzima Taq polimerase (Amersham Pharmacia), 0,4 $\mu \mathrm{M}$ de cada um dos primers (tabela 3.2.1) e água miliQ para o volume final de $50 \mu \mathrm{l}$. Em seguida, as amostras foram submetidas aos programas descritos na tabela 3.2.2.

Tabela 3.2.2. Programas de PCR.

\begin{tabular}{|c|c|}
\hline PCR & Programa \\
\hline Exon 1 a $4\left(^{*}\right)$ & $\begin{array}{l}3 \text { minutos a } 94^{\circ} \mathrm{C}, 29 \text { ciclos de } 30 \text { segundos a } 94^{\circ} \mathrm{C}, 30 \text { segundos a } 53^{\circ} \mathrm{C} \text { e } 2 \text { minutos a } 72^{\circ} \mathrm{C} \text {, } \\
\text { seguidos de } 3 \text { minutos a } 72^{\circ} \mathrm{C} \text {. }\end{array}$ \\
\hline Exon 1 & $\begin{array}{l}3 \text { minutos a } 94^{\circ} \mathrm{C}, 39 \text { ciclos de } 30 \text { segundos a } 94^{\circ} \mathrm{C}, 30 \text { segundos a } 65^{\circ} \mathrm{C} \text { e } 40 \text { segundos a } 72^{\circ} \mathrm{C} \text {, } \\
\text { seguidos de } 3 \text { minutos a } 72^{\circ} \mathrm{C} \text {. }\end{array}$ \\
\hline Exon 2 & $\begin{array}{l}3 \text { minutos a } 94^{\circ} \mathrm{C}, 39 \text { ciclos de } 30 \text { segundos a } 94^{\circ} \mathrm{C}, 25 \text { segundos a } 65^{\circ} \mathrm{C} \text { e } 40 \text { segundos a } 72^{\circ} \mathrm{C} \text {, } \\
\text { seguidos de } 5 \text { minutos a } 72^{\circ} \mathrm{C} \text {. }\end{array}$ \\
\hline Exon 3 & $\begin{array}{l}3 \text { minutos a } 94^{\circ} \mathrm{C}, 41 \text { ciclos de } 30 \text { segundos a } 94^{\circ} \mathrm{C}, 20 \text { segundos a } 64^{\circ} \mathrm{C} \text { e } 40 \text { segundos a } 72^{\circ} \mathrm{C} \text {, } \\
\text { seguidos de } 5 \text { minutos a } 72^{\circ} \mathrm{C} \text {. }\end{array}$ \\
\hline Exon 4 & $\begin{array}{l}3 \text { minutos a } 94^{\circ} \mathrm{C}, 37 \text { ciclos de } 30 \text { segundos a } 94^{\circ} \mathrm{C}, 30 \text { segundos a } 60^{\circ} \mathrm{C} \text { e } 40 \text { segundos a } 72^{\circ} \mathrm{C} \text {, } \\
\text { seguidos de } 3 \text { minutos a } 72^{\circ} \mathrm{C} \text {. }\end{array}$ \\
\hline Exon 5 e $6\left(^{*}\right)$ & $\begin{array}{l}3 \text { minutos a } 94^{\circ} \mathrm{C}, 31 \text { ciclos de } 30 \text { segundos a } 94^{\circ} \mathrm{C}, 40 \text { segundos a } 60^{\circ} \mathrm{C} \text { e } 70 \text { segundos a } 72^{\circ} \mathrm{C} \text {, } \\
\text { seguidos de } 5 \text { minutos a } 72^{\circ} \mathrm{C} \text {. }\end{array}$ \\
\hline Exon 5 & $\begin{array}{l}5 \text { minutos a } 94^{\circ} \mathrm{C}, 34 \text { ciclos de } 30 \text { segundos a } 94^{\circ} \mathrm{C}, 30 \text { segundos a } 61^{\circ} \mathrm{C} \text { e } 45 \text { segundos a } 72^{\circ} \mathrm{C} \text {, } \\
\text { seguidos de } 5 \text { minutos a } 72^{\circ} \mathrm{C} \text {. }\end{array}$ \\
\hline Exon 6 & $\begin{array}{l}5 \text { minutos a } 94^{\circ} \mathrm{C}, 42 \text { ciclos de } 30 \text { segundos a } 94^{\circ} \mathrm{C}, 30 \text { segundos a } 61^{\circ} \mathrm{C} \text { e } 45 \text { segundos a } 72^{\circ} \mathrm{C} \text {, } \\
\text { seguidos de } 5 \text { minutos a } 72^{\circ} \mathrm{C} \text {. }\end{array}$ \\
\hline Exon $7\left(^{*}\right)$ & $\begin{array}{l}4 \text { minutos a } 94^{\circ} \mathrm{C}, 29 \text { ciclos de } 30 \text { segundos a } 94^{\circ} \mathrm{C}, 30 \text { segundos a } 61^{\circ} \mathrm{C} \text { e } 50 \text { segundos a } 72^{\circ} \mathrm{C} \text {, } \\
\text { seguidos de } 7 \text { minutos a } 72^{\circ} \mathrm{C} \text {. }\end{array}$ \\
\hline Exon 7 & $\begin{array}{l}5 \text { minutos a } 94^{\circ} \mathrm{C}, 39 \text { ciclos de } 30 \text { segundos a } 94^{\circ} \mathrm{C}, 30 \text { segundos a } 59^{\circ} \mathrm{C} \text { e } 50 \text { segundos a } 72^{\circ} \mathrm{C} \text {, } \\
\text { seguidos de } 7 \text { minutos a } 72^{\circ} \mathrm{C} \text {. }\end{array}$ \\
\hline Exon 8 a $11\left(^{*}\right)$ & $\begin{array}{l}2 \text { minutos a } 94^{\circ} \mathrm{C}, 29 \text { ciclos de } 30 \text { segundos a } 94^{\circ} \mathrm{C}, 30 \text { segundos a } 66^{\circ} \mathrm{C} \text { e } 2 \text { minutos a } 72^{\circ} \mathrm{C} \text {, } \\
\text { seguidos de } 2 \text { minutos a } 72^{\circ} \mathrm{C} \text {. }\end{array}$ \\
\hline Exon 8 & $\begin{array}{l}5 \text { minutos a } 94^{\circ} \mathrm{C}, 35 \text { ciclos de } 30 \text { segundos a } 94^{\circ} \mathrm{C}, 30 \text { segundos a } 66^{\circ} \mathrm{C} \text { e } 45 \text { segundos a } 72^{\circ} \mathrm{C} \text {, } \\
\text { seguidos de } 5 \text { minutos a } 72^{\circ} \mathrm{C}\end{array}$ \\
\hline Exon 9 & $\begin{array}{l}5 \text { minutos a } 94^{\circ} \mathrm{C}, 36 \text { ciclos de } 30 \text { segundos a } 94^{\circ} \mathrm{C}, 30 \text { segundos a } 60^{\circ} \mathrm{C} \text { e } 45 \text { segundos a } 72^{\circ} \mathrm{C} \text {; } \\
\text { seguidos de } 5 \text { minutos a } 72^{\circ} \mathrm{C}\end{array}$ \\
\hline Exon 10 e 11 & $\begin{array}{l}5 \text { minutos a } 94^{\circ} \mathrm{C} ; 36 \text { ciclos de } 30 \text { segundos a } 94^{\circ} \mathrm{C}, 30 \text { segundos a } 57^{\circ} \mathrm{C} \text { e } 45 \text { segundos a } 72^{\circ} \mathrm{C} \text {; } \\
\text { seguidos de } 5 \text { minutos a } 72^{\circ} \mathrm{C}\end{array}$ \\
\hline
\end{tabular}

$\left(^{*}\right)$ Programas de pré-amplificação 
Na segunda PCR, reações contendo $3 \mu \mathrm{l}$ de produto da pré-amplificação, $200 \mu \mathrm{M}$ de cada um dos dNTPs, 1X Tampão (Amersham Pharmacia), 3,75 unidades de enzima Taq polimerase (Amersham Pharmacia), 0,2 $\mu \mathrm{M}$ de cada um dos primers e água miliQ para o volume final de $50 \mu \mathrm{l}$ foram submetidas aos programas descritos na tabela 3.2.2.

Os produtos de amplificação da segunda PCR foram submetidos à eletroforese em gel de agarose $2 \%$, corados com brometo de etídeo e visualizados com luz ultravioleta. O produto dessa PCR era então submetido ao processo de formação de heteroduplex e dHPLC.

\section{c) dHPLC}

A detecção de mutações por dHPLC está baseada na formação de homoduplexes e heteroduplexes em indivíduos heterozigotos (Liu et al., 1998). Para formação do heteroduplex o produto de PCR é aquecido a $95^{\circ} \mathrm{C}$ por 5 minutos para a denaturação, seguida de um resfriamento gradual à temperatura ambiente, formando homoduplexes (por hibridização dos fragmentos originais), e heteroduplexes (por hibridização de fragmentos cruzados) na presença de variações de seqüência (figura 3.2.1). Apesar da necessidade de formação de heteroduplex, o método de dHPLC é rápido e não requer outras manipulações da amostra após a PCR.

Após a formação dos heteroduplexes, a amostra é analisada por dHPLC. No cromatógrafo, o produto de PCR entra em contato com uma coluna que tem uma matriz composta por micropartículas hidrofóbicas de poliestireno. A coluna é aquecida a uma temperatura pré-estabelecida, na qual o fragmento encontra-se parcialmente denaturado (15\% a 30\% de denaturação). Na primeira fase, a fase estacionária, o íon trietilamônia (TEAA) se adsorve aos grãos da matriz e se liga ao DNA, servindo como "ponte" entre o DNA e a matriz. Na fase móvel, uma solução contendo o íon acetonitrila ( $A C N$ ) passa pela coluna, rompendo a ligação dos fragmentos de DNA com os grãos da matriz hidrofóbica. Como o heteroduplex se liga mais fracamente à matriz, esse se solta antes do que o homoduplex. Os 
fragmentos de DNA que se soltam da matriz passam então por um detector de UV, resultando num perfil cromatográfico, ou seja, em curvas mostradas em gráficos de intensidade da absorbância por tempo. Os cromatogramas de amostras teste devem ser comparados com os de amostras selvagens, para observação de possíveis alterações.

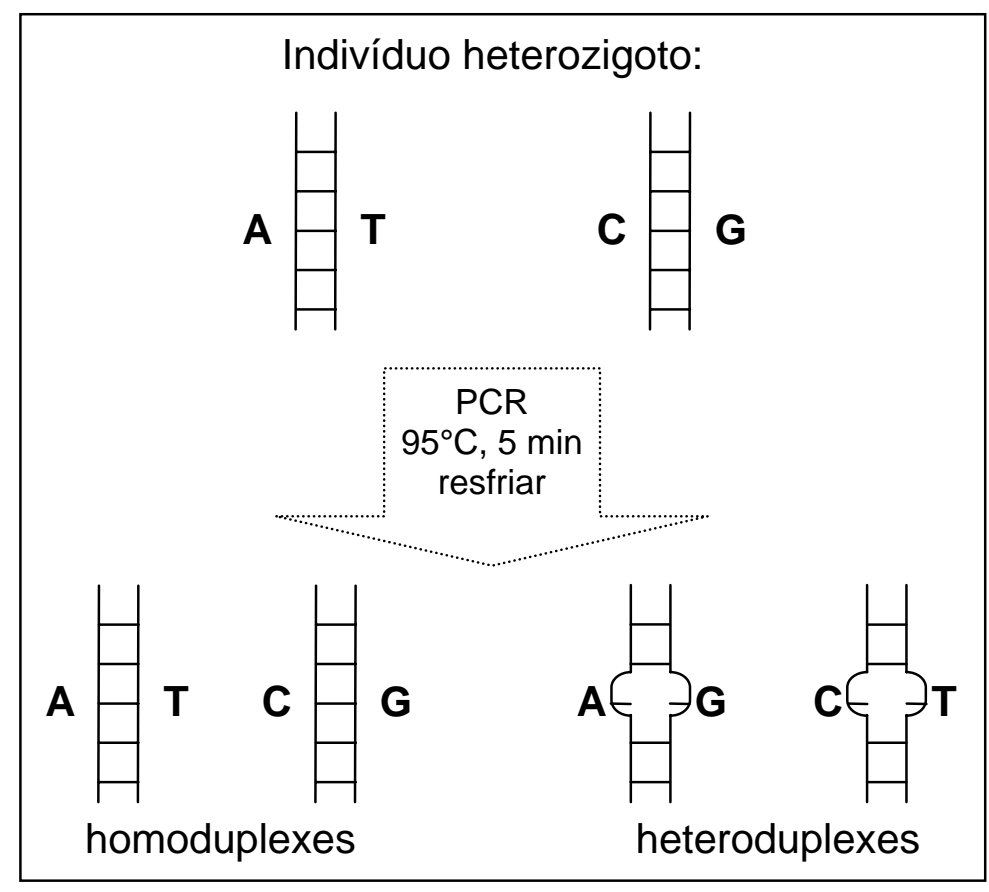

Figura 3.2.1. Processo de formação de heteroduplexes. Os dois alelos de um indivíduo heterozigoto estão esquematizados, mostrando que após a PCR seguida de um aquecimento a $95^{\circ} \mathrm{C}$ por 5 minutos e resfriamento gradual, são formados os fragmentos originais, ou homoduplexes, e fragmentos cruzados, contendo um erro de pareamento, caracterizando os heteroduplexes.

Para a detecção de mutações por dHPLC, o DNA deve estar em denaturação parcial, que é obtida ao se aquecer a amostra a uma temperatura específica para cada amplicon. A sensibilidade do dHPLC depende muito da temperatura de análise, diferente para cada fragmento estudado, conforme a seqüência do amplicon. Em alguns casos é necessário analisar um mesmo amplicon em diferentes temperaturas, já que o mesmo pode apresentar distintas temperaturas de denaturação parcial, dependendo da parte do fragmento observada (Gross et al., 2000). 
As temperaturas de análise de cada amplicon neste estudo foram estabelecidas com ajuda do software aplicativo do WAVE $^{\circledR}$ (Transgenomic) e também um software específico desenvolvido pela Universidade de Stanford e disponível na rede, o dHPLC Melt Program (http://insertion.stanford.edu/melt.html). As temperaturas sugeridas foram testadas em 10 amostras e após a visualizarão dos perfis, utilizou-se as temperaturas que se mostraram empiricamente melhores (tabela 3.2.1). A fim de verificar se os amplicons apresentavam boa qualidade para análise por dHPLC, um teste de qualidade a $50^{\circ} \mathrm{C}$ foi realizado para visualizar se apenas um pico era obtido, revelando um perfil uniforme de denaturação ao longo da seqüência do amplicon.

Os produtos de PCR que passaram pelo processo de formação de heteroduplex foram submetidos ao dHPLC no Centro de Estudos do Genoma Humano (Departamento de Genética e Biologia Evolutiva, Instituto de Biociências, USP). A maioria dos pacientes teve todos os exons analisados por dHPLC, no entanto em alguns casos, a busca de novas mutações foi sendo interrompida nos pacientes conforme seus genótipos eram definidos. Uma vez que vários pacientes apresentavam uma cópia das mutações N370S ou L444P, foram usadas como controles amostras de indivíduos sem qualquer mutação nos exons 9 e 10, amostras com apenas a N370S no exon 9, amostras com apenas a L444P no exon 10 e amostras com RECs nos exons 9 e 10.

\section{d) Seqüenciamento}

As amostras cujos perfis cromatográficos após o dHPLC apareceram alterados em exame visual foram seqüenciadas. Para isso, novas préamplificações, seguidas de PCR do amplicon alterado, foram utilizadas, visando aumentar a especificidade da análise. Os produtos de PCR foram purificados com QIAquick $^{\circledR}$ PCR Purification Kit (Qiagen), segundo protocolo do fabricante, e depois quantificados, através de eletroforese simultânea com Low DNA Mass Ladder (Invitrogen), em gel de agarose $2 \%$. 
Em seguida, o seqüenciamento foi realizado utilizando-se o DYEnamic $E T$ Dye Terminator Cycle Sequencing Kit, nas seguintes condições: 60 ng de produto de PCR purificado, $4 \mu \mathrm{l}$ de DYEnamic ${ }^{T M}$ ET Terminator Sequencing Premix, 0,5 $\mu \mathrm{l}$ de primer $5 \mu \mathrm{M}$ (forward/reverse) e água miliQ para completar o volume final de $10 \mu \mathrm{l}$ (essa reação foi preparada na penumbra). A reação de seqüenciamento foi realizada em 30 ciclos de 20 segundos a $95^{\circ} \mathrm{C}$ para denaturação, 15 segundos em temperatura de hibridização dos primers (tabela 3.2.1) e 1 minuto de extensão a $60^{\circ} \mathrm{C}$. A reação foi analisada no MegaBACE 1000 (Amersham Biosciences).

Alternativamente, o seqüenciamento foi realizado utilizando-se o Big Dye (Applied Biotechnologies) nas seguintes condições: 60ng de produto de PCR purificado, $2 \mu \mathrm{l}$ de Big Dye, $2 \mu \mathrm{l}$ de primer $5 \mu \mathrm{M}$ (forward/reverse), tampão fornecido pelo fabricante (1x), e água miliQ para completar o volume final de $10 \mu \mathrm{l}$. Essa reação era preparada na penumbra. A mistura era amplificada em 40 ciclos de 20 segundos a $95^{\circ} \mathrm{C}$ para denaturação, 15 segundos em temperatura de hibridização dos primers (tabela 3.2.1) e 1 minuto de extensão a $60^{\circ} \mathrm{C}$. Essa reação foi analisada no seqüenciador ABI PRISM 3700 (Applied Biotechnologies) do laboratório de Biologia Molecular de Plantas do Instituto de Biociências da Universidade de São Paulo.

O produto da reação de seqüenciamento era então purificado e precipitado adicionando-se $1 \mu \mathrm{l}$ de acetato de amônio $7,5 \mathrm{M}$ e $28 \mu \mathrm{l}$ de etanol absoluto e misturando. A reação era então mantida em temperatura ambiente e no escuro por 15 minutos. Logo após o produto era centrifugado a 12.000 rpm por 15 minutos. Descartava-se o sobrenadante e acrescentava-se $170 \mu \mathrm{l}$ de etanol 70\%. Após uma agitação vigorosa o produto era novamente centrifugado a $12.000 \mathrm{rpm}$ por 15 minutos. O sobrenadante era então descartado e os tubos eram mantidos abertos à temperatura ambiente, no escuro, até que todo resíduo de álcool evaporasse. Era então aplicado $10 \mu \mathrm{l}$ do tampão de seqüenciamento à reação e misturado. As amostras eram então encaminhadas para o seqüenciador automático.

As seqüências foram visualizadas com a ajuda do programa Chromas 2.2.3, sendo então impressas e comparadas com a seqüência normal do gene GBA, 
obtida no GeneBank (AF 023268). Seqüências senso e anti-senso foram obtidas visando aumentar o valor preditivo do seqüenciamento.

\subsubsection{Resultados}

\section{a) Análise por dHPLC seguido de seqüenciamento}

Após a triagem das principais mutações causadoras da DG, conforme descrito no capítulo 3.1 , as amostras que não tiveram as mutações identificadas nos dois alelos e foram recebidas no laboratório até Março de 2003 passaram para uma segunda fase de análise, onde se buscou identificar mutações raras ou novas com a técnica de dHPLC seguida de seqüenciamento. A amostragem dessa segunda fase foi composta de 54 pacientes, sendo 53 pacientes de tipo 1 e um paciente de tipo 3 (amostra BR319). Em 46 pacientes apenas uma mutação havia sido identificada na triagem de mutações principais ao passo que nos 8 restantes não foram identificadas mutações em nenhum dos alelos. Dentre os 46 heterozigotos compostos, oito tinham uma mutação de efeito grave num dos alelos e o fenótipo clínico de tipo 1. Nesses pacientes, a descrição da mutação do outro alelo é informativa sobre a sua relação genótipo-fenótipo, pois essa seria considerada uma mutação de efeito leve, responsável pela ausência de sintomas neuronopáticos.

A tabela 3.2.3 mostra os genótipos detectados nos 54 pacientes nãoaparentados da DG. A análise por dHPLC seguida de seqüenciamento permitiu detectar mutações em 45 dos 62 (73\%) alelos sem mutação identificada na primeira fase, sendo que foram identificadas 30 mutações diferentes que se repetiram em alguns pacientes. A estratégia utilizada permitiu definir o genótipo em 39 dos 54 (72\%) pacientes estudados. Dentre as 30 mutações encontradas, 14 são mutações novas, ou seja, mutações ainda não descritas na literatura em pacientes da DG. Oito mutações dentre as 30 identificadas ocorreram em mais de um paciente. A R120W e a W184R ocorreram em quatro pacientes cada; a IVS2+1g>a, a R120Q e a 1489T ocorreram em três casos; a G202R, a R496H e a V398I repetiram-se em duas amostras diferentes e o restante das mutações apareceram uma única vez. Quatro alterações silenciosas (sem mudança de 
aminoácido) ainda não descritas também foram identificadas entre os 54 pacientes.

Tabela 3.2.3. Genótipos dos 54 pacientes de tipo da DG após análises por RFLP, dHPLC e seqüenciamento.

\begin{tabular}{|c|c|c|c|c|}
\hline \multirow{2}{*}{$\begin{array}{c}\begin{array}{c}\text { Número } \\
\text { da } \\
\text { amostra }\end{array} \\
\text { SP30 } \\
\end{array}$} & \multicolumn{2}{|c|}{ Genótipo } & \multirow[t]{2}{*}{$\begin{array}{l}\text { Alterações } \\
\text { adicionais }\end{array}$} & \multirow[t]{2}{*}{ Observações } \\
\hline & N370S & $?$ & & \\
\hline SP33 & N370S & $?$ & & \\
\hline SP34 & N370S & G202R & & \\
\hline SP43 & $?$ & $?$ & & \\
\hline SP46 & N370S & G202R & & \\
\hline SP51 & N370S & I489T & & I489T nova (presente em BR294 e BR304) \\
\hline SP61 & N370S & L461P & & \\
\hline SP64 & N370S & H311R & & \\
\hline SP71 & N370S & Del 1403 & & Del 1403 nova \\
\hline SP83 & N370S & G389E & & \\
\hline SP86 & N370S & 595-596delCT & & \\
\hline SP118 & RecTL & R395C & & R395C nova; paciente tipo 1; \\
\hline SP122 & N370S & $?$ & & \\
\hline SP127 & N370S & $\mathrm{P}-28 \mathrm{~L}$ & & P-28L nova \\
\hline SP137 & L444P & $\mathrm{R} 496 \mathrm{H}$ & & \\
\hline SP174 & N370S & IVS2+1g>a & & Presente em BR53, BR315 \\
\hline SP183 & N370S & $?$ & & \\
\hline SP194 & N370S & $?$ & & \\
\hline SP210 & N370S & W184R & & presente em BR174, BR237 e BR405 \\
\hline SP226 & R120Q & R329C & & $\begin{array}{l}\text { R329C nova; R120Q presente em BR191 e } \\
\text { BR227; tipo } 1\end{array}$ \\
\hline SP231 & R48W & $?$ & & \\
\hline BR53 & N370S & IVS2 $+1 g>a$ & & presente em SP174, BR315 \\
\hline BR102 & RecNcil & N396T & & \\
\hline BR136 & L444P & N188S & & \\
\hline BR144 & V398I & V398I & & $\begin{array}{l}\begin{array}{l}\text { nova (presente } \\
\text { consangüineos }\end{array} \\
\text { com }\end{array}$ \\
\hline BR147 & N370S & $?$ & & \\
\hline
\end{tabular}




\begin{tabular}{|c|c|c|c|c|}
\hline \multirow{2}{*}{$\begin{array}{c}\begin{array}{c}\text { Número } \\
\text { da } \\
\text { amostra }\end{array} \\
\text { BR169 } \\
\end{array}$} & \multicolumn{2}{|c|}{ Genótipo } & \multirow{2}{*}{$\begin{array}{c}\begin{array}{c}\text { Alterações } \\
\text { adicionais }\end{array} \\
\mathrm{D} 137 \mathrm{D}\end{array}$} & \multirow{2}{*}{$\begin{array}{l}\text { Observações } \\
\text { Y220C nova; L-15F nova; D137D nova }\end{array}$} \\
\hline & N370S & L-15F e Y220C & & \\
\hline BR174 & N370S & W184R & & W184R presente em SP210, BR237 e BR405 \\
\hline BR182 & N370S & $K-27 R$ & & K-27R nova \\
\hline BR191 & N370S & R120Q & & R120Q presente em SP226 e BR227 \\
\hline BR204 & R120W & M123T & & R120W presente em BR262, BR292 e BR303 \\
\hline BR211 & N370S & E111K & & E111K nova \\
\hline BR216 & N370S & G35S & & G35S nova \\
\hline BR227 & N370S & R120Q & & R120Q presente em SP226 e BR191 \\
\hline BR233 & V398I & V398I & & $\begin{array}{l}\text { V398I nova (presente em BR144); pais } \\
\text { consangüíneos }\end{array}$ \\
\hline BR234 & L444P & $?$ & & \\
\hline BR237 & N370S & W184R & & W184R presente em SP210, BR174 e BR405 \\
\hline BR262 & N370S & R120W & & R120W presente em BR204, BR292 e BR303 \\
\hline BR265 & N370S & $?$ & & \\
\hline BR276 & N370S & $?$ & & \\
\hline BR280 & L444P & 222-224delTAC & E326K & \\
\hline BR292 & N370S & R120W & & R120W presente em BR204, BR262 e BR303 \\
\hline BR294 & I489T & $\mathrm{R} 496 \mathrm{H}$ & & I489T nova (presente em SP51 e BR304) \\
\hline BR295 & L444P+V460V & $?$ & & \\
\hline BR299 & N370S & A210V & G325G & A210V nova; G325 nova \\
\hline BR303 & N370S & R120W & D298D & $\begin{array}{l}\text { R120W presente em BR204, BR262 e BR303; } \\
\text { D298D nova }\end{array}$ \\
\hline BR304 & N370S & I489T & & I489T nova (presente em SP51 e BR294) \\
\hline BR315 & N370S & IVS2 $+1 g>a$ & & presente em SP174, BR53 \\
\hline BR319 & G377S & $?$ & & Paciente tipo 3 \\
\hline BR335 & $?$ & $?$ & & \\
\hline BR369 & N370S & 793delC & & 793delC nova \\
\hline BR405 & N370S & W184R & & presente em SP210, BR174 e BR237 \\
\hline BR410 & N370S & IVS4+1g>a & $\mathrm{F} 75 \mathrm{~F}$ & IVS4+1g>a nova; F75F nova \\
\hline BR423 & L444P+V460V & $?$ & & \\
\hline
\end{tabular}

?: mutações não identificadas

Os resultados apresentados na tabela 3.2.3 mostram que, considerando a primeira (RFLP) e segunda fase de análises (dHPLC e seqüenciamento), 91 dentre os 108 (84\%) alelos dos pacientes tiveram mutações identificadas.

As mutações encontradas estavam distribuídas homogeneamente ao longo do gene GBA. O amplicon que compreende o exon 1 foi o único no qual nenhuma 
mutação foi encontrada. A figura 3.2.2 mostra um esquema do gene GBA com todas mutações detectadas neste estudo.

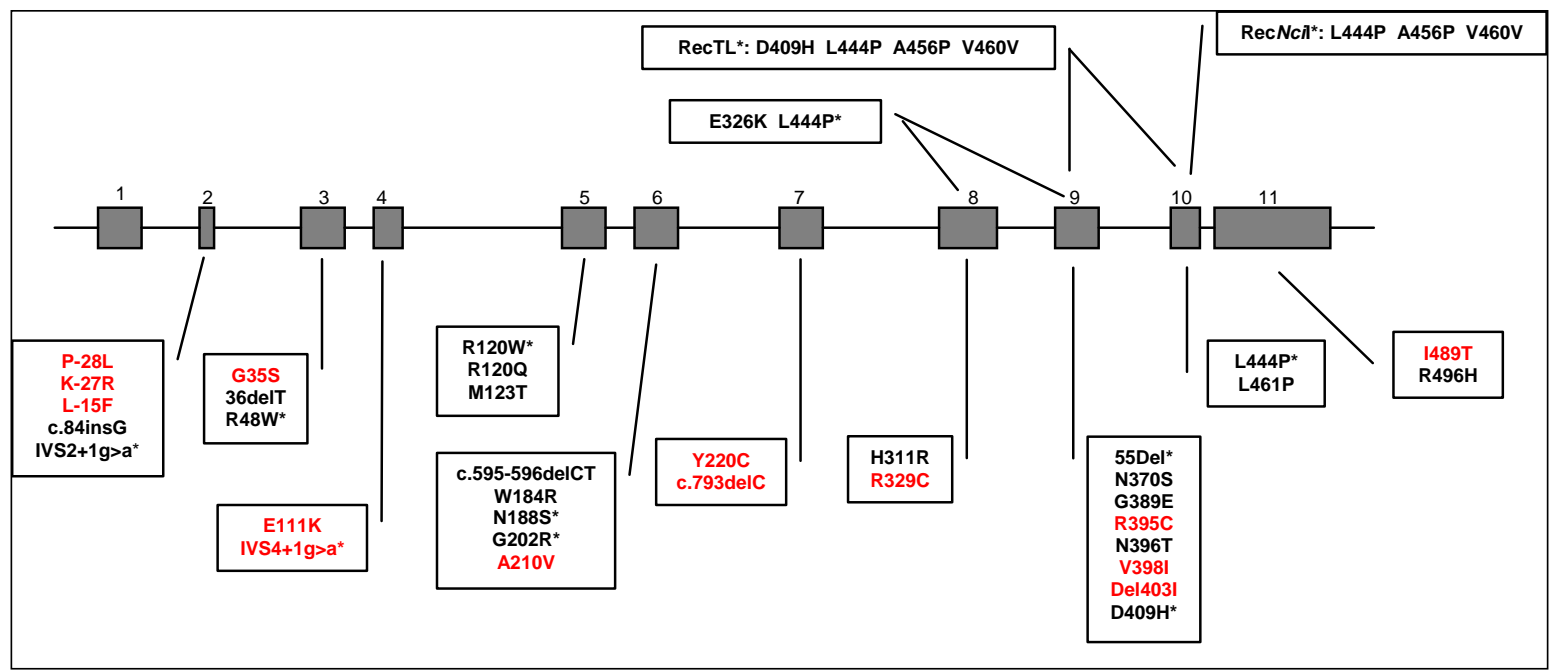

Figura 3.2.2. Esquema da estrutura do gene GBA e as mutações causadoras da GD detectadas neste estudo. Caixas cinzas numeradas: Exons 1 a 11. Caixas brancas: mutações identificadas. As 14 mutações novas estão representadas em vermelho. Mutações correspondendo à seqüência do pseudogene aparecem indicadas por um asterisco.

\section{b) Alterações silenciosas}

A genotipagem dos 54 pacientes permitiu detectar ainda quatro mutações silenciosas ainda não descritas no gene GBA. São elas a c.342C>T (F75F), a c.528C>T (D137D), a c.1011C>T (D298D) e a c.1092G>A (G325G). Essa última foi detectada inicialmente num indivíduo normal da população (amostra SP212), cuja triagem de mutações no gene GBA foi realizada visando o aconselhamento genético do casal, uma vez que a esposa desse indivíduo é paciente da DG e possui uma mutação de efeito grave (genótipo N370S/L444P). Logo depois, o paciente BR299 (genótipo N370S/A210V) foi identificado como portador dessa alteração. A presença da mutação A210V no paciente BR299 favorece a hipótese da G325G ser apenas uma alteração silenciosa e possivelmente um polimorfismo.

As outras alterações silenciosas também podem ser polimorfismos do gene $G B A$, ou variações mais raras do gene. Nenhuma dessas alterações correspondia 
à seqüência do pseudogene. Em todos os casos elas apareceram em indivíduos que tiveram outras duas mutações identificadas. No entanto, uma vez que mutações silenciosas patogênicas já foram descritas em outros genes (D’Souza et al., 1999; Liu et al., 2001), não é possível afirmar que essas mutações terão efeito fenotípico nulo.

\section{c) Exemplos de cromatogramas alterados}

As figuras 3.2.3 e 3.2.4 mostram exemplos de cromatogramas alterados, em relação a amostras controle. Na figura 3.2.3 são mostrados um controle sem mutação no amplicon 9 e dois controles com a mutação N370S em heterozigose. A amostra do paciente SP71, que já havia sido identificado como heterozigoto para a N370S teve que ser comparada a esses últimos controles. Essa amostra foi seqüenciada e a mutação identificada (Del 1403).

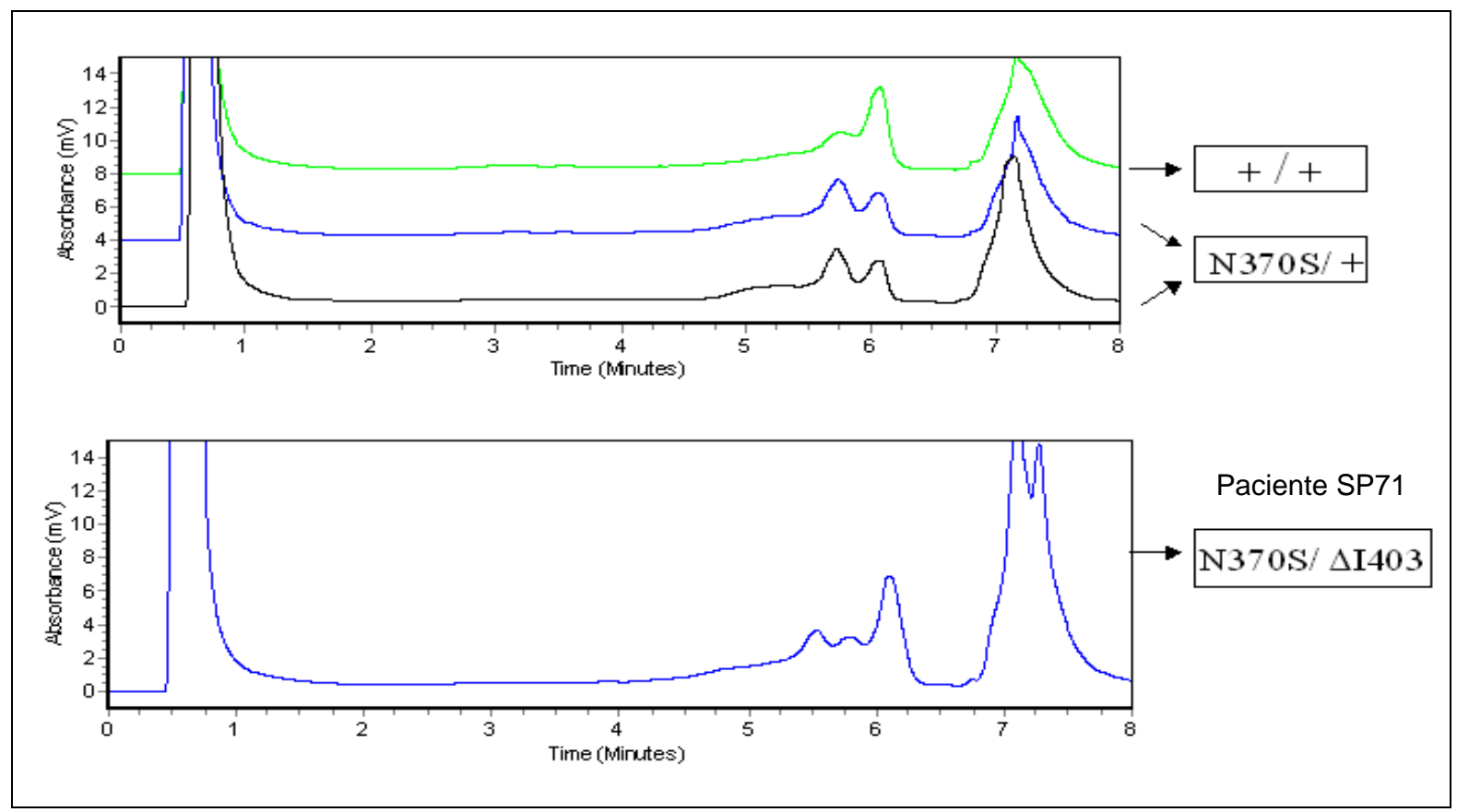

Figura 3.2.3. Visualização das mutações do paciente SP71, com duas mutações no exon 9 , a N370S e a deleção 1403. A alteração na curva de dHPLC a $61^{\circ} \mathrm{C}$ é observada em relação a um controle sem mutação (+/+) e dois controles com apenas N370S nesse exon. A região de interesse no perfil aparece entre 5 e 6 minutos. A curva formada aos 7 minutos de denaturação corresponde à lavagem da coluna e não tem interesse para a análise. 


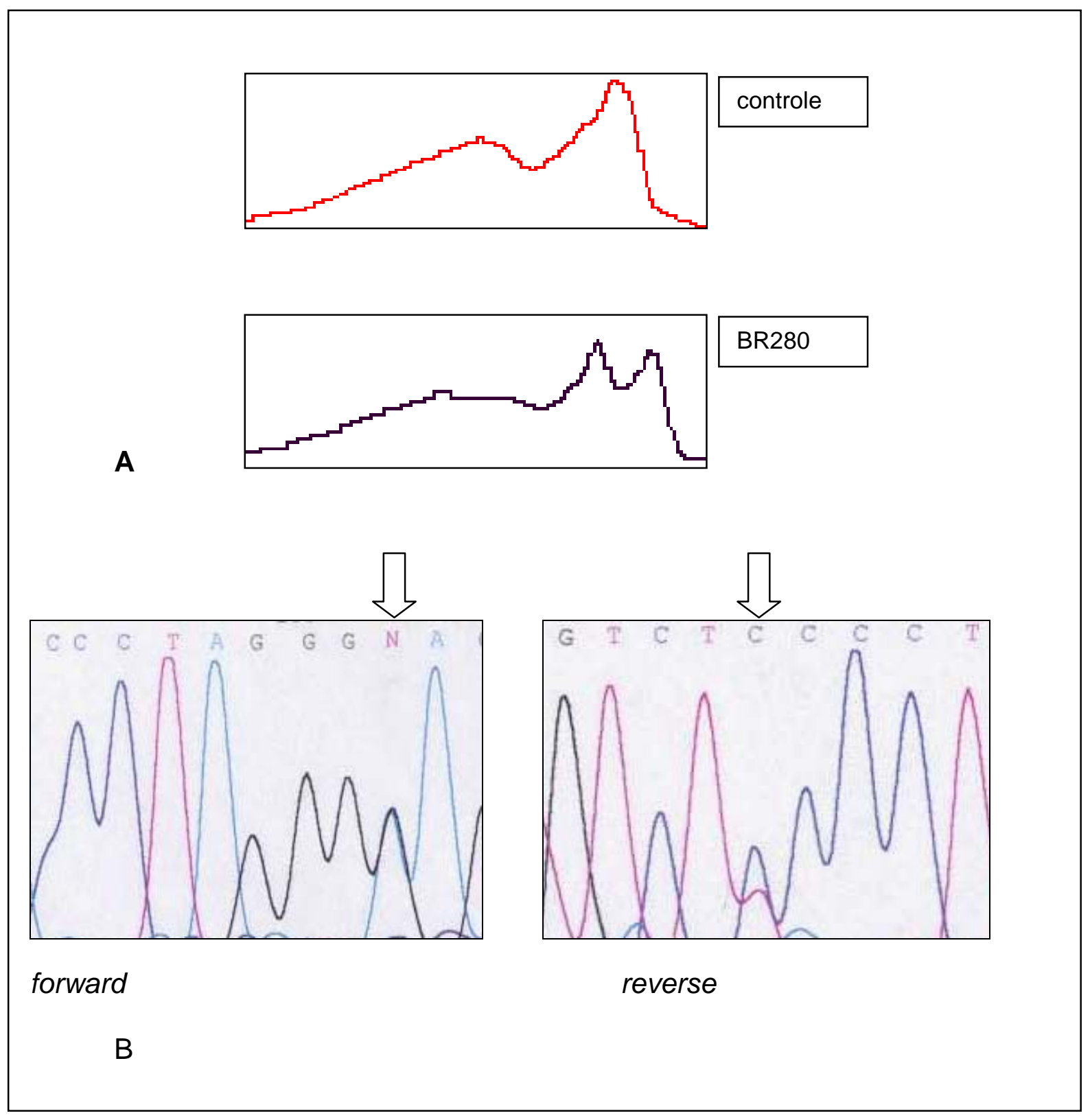

Figura 3.2.4. A) Detalhe da alteração nos cromatogramas do exon 8 , a $61^{\circ} \mathrm{C}$, de um controle e da amostra BR280, que aparece alterada. B) Seqüenciamento do BR280 para o exon 8, mostrando a transição de uma guanina (posição 1093 do cDNA) para adenina em um dos alelos do paciente, identificada por uma seta nas análises forward e reverse, levando à mutação E326K. 


\section{d) Mutações encontradas e relações genótipo-fenótipo}

No caso particular da DG, onde a relação genótipo-fenótipo consiste na classificação das mutações como leves, graves ou alelos nulos, e cujas combinações estão associadas aos 3 tipos principais da doença conforme a tabela 1.4, buscou-se descrever o grau de gravidade das mutações sempre que possível. A tabela 3.2.4 mostra a lista das 30 mutações detectadas na segunda fase deste estudo, suas posições relativas no gene GBA e as relações genótipo-fenótipo já conhecidas ou aquelas deduzidas dos pacientes aqui analisados.

Foram encontradas 14 mutações novas no gene GBA em pacientes da DG. A gravidade das mutações pode ser verificada em 10 casos diferentes (3 mutações novas e 7 já descritas), sendo 8 mutações de efeito leve e 2 alelos nulos. Nesses 10 pacientes foi possível descrever pela primeira vez a gravidade das mutações em 6 casos (destacados em amarelo na tabela 3.2.4) e confirmar a gravidade já descrita das mutações em outros 4 casos (destacados em verde).

As mutações caracterizaram-se por trocas de aminoácidos em 25 casos, alterações de quadro de leitura devido a pequenas deleções em 2 casos, mutações em sítios de processamento exon/intron em outros 2 casos e finalmente uma deleção em fase de 3 pb, levando a perda de um aminoácido. 
Tabela 3.2.4. As 30 mutações detectadas por dHPLC seguido de seqüenciamento do gene GBA entre os 54 pacientes da DG analisados.

\begin{tabular}{|c|c|c|c|c|c|}
\hline $\begin{array}{l}\text { mutação na } \\
\text { seqüência do } \\
\text { cDNA }\end{array}$ & Exon & $\begin{array}{l}\text { Substituição de } \\
\text { aminoácido }\end{array}$ & Gravidade & $\begin{array}{l}\text { Amostras com } \\
\text { a mutação }\end{array}$ & $\begin{array}{l}\text { Comentários; } \\
\text { (Descrição original) }\end{array}$ \\
\hline $35 \mathrm{C}>\mathrm{T}$ & 2 & Pro - 28 Leu & Desconhecida & SP127 & (Este estudo) \\
\hline $38 \mathbf{A}>\mathbf{G}$ & 2 & Lis - 27 Arg & Desconhecida & BR182 & (Este estudo) \\
\hline $73 \mathrm{C}>\mathrm{T}$ & 2 & Leu -15 Fen & Desconhecida & BR169 & (Este estudo) \\
\hline IVS2+1g>a & $\begin{array}{l}\text { Intron } \\
2\end{array}$ & Processamento & Alelo nulo & $\begin{array}{l}\text { SP174, BR53, } \\
\text { BR315 }\end{array}$ & $\begin{array}{l}\text { Seqüência idêntica à do pseudogene; } \\
\text { (Beutler et al., 1992) }\end{array}$ \\
\hline $220 \mathrm{G}>A$ & 3 & Gli 35 Ser & Desconhecida & BR216 & (Este estudo) \\
\hline 222-224 del TAC & 3 & 36 del Tre & Leve & BR280 & $\begin{array}{l}\text { Paciente confirma gravidade desta mutação; } \\
\text { (Koprivica et al., 2000) }\end{array}$ \\
\hline $259 \mathrm{C}>\mathrm{T}$ & 3 & Arg 38 Trp & Leve & SP231 & $\begin{array}{l}\text { Seqüência idêntica à do pseudogene; mutação } \\
\text { num dinucleotídeo CpG; } \\
\text { (Beutler et al., 1995) }\end{array}$ \\
\hline $448 \mathrm{G}>A$ & 4 & Glu 111 Lis & Desconhecida & BR211 & (Este estudo) \\
\hline IVS4+1g>a & $\begin{array}{l}\text { Intron } \\
4\end{array}$ & Processamento & Desconhecida & BR410 & $\begin{array}{l}\text { Seqüência idêntica à do pseudogene; } \\
\text { (Este estudo) }\end{array}$ \\
\hline $475 \mathrm{C}>\mathrm{T}$ & 5 & Arg 120 Trp & Grave & $\begin{array}{l}\text { BR204, BR262, } \\
\text { BR292, } 303\end{array}$ & $\begin{array}{l}\text { Seqüência idêntica à do pseudogene; mutação } \\
\text { num dinucleotídeo CpG; } \\
\text { (Beutler et al., 1996) }\end{array}$ \\
\hline $476 \mathrm{G}>\mathrm{A}$ & 5 & Arg 120 Gln & Grave & $\begin{array}{l}\text { SP226, BR191, } \\
\text { BR227 }\end{array}$ & $\begin{array}{l}\text { Mutação num dinucleotídeo CpG; } \\
\text { (Graves et al., 1988) }\end{array}$ \\
\hline $485 \mathrm{~T}>\mathrm{C}$ & 5 & Met 123 Tre & $\begin{array}{l}\text { Desconhecida: } \\
\text { Leve }\end{array}$ & BR204 & $\begin{array}{l}\text { Paciente com relação genótipo-fenótipo } \\
\text { informativa; } \\
\text { (Alfonso et al., 2001) }\end{array}$ \\
\hline 595-596 del CT & 6 & Leu160_fs62X & Alelo nulo & SP86 & (Pomponio et al., 2005) \\
\hline $667 \mathrm{~T}>\mathrm{C}$ & 6 & Trp 184 Arg & Desconhecida & $\begin{array}{l}\text { SP210, BR174, } \\
\text { BR237, BR405 }\end{array}$ & (Koprivica et al., 2000) \\
\hline $680 A>G$ & 6 & Asn 188 Ser & Leve/ Grave & BR136 & $\begin{array}{l}\text { Seqüência idêntica à do pseudogene; paciente } \\
\text { e irmão indicam que a mutação é de efeito } \\
\text { leve; } \\
\text { (Kim et al., 1996; Filocamo et al., 2002) }\end{array}$ \\
\hline $721 \mathrm{G}>\mathrm{A}$ & 6 & Gli 202 Arg & Grave & SP34, 46 & $\begin{array}{l}\text { Seqüência idêntica à do pseudogene; mutação } \\
\text { num dinucleotídeo CpG; } \\
\text { (Beutler et al., 1994) }\end{array}$ \\
\hline $746 \mathrm{C}>\mathrm{T}$ & 6 & Ala 210 Val & Desconhecida & BR299 & (Este estudo) \\
\hline $776 \mathrm{~A}>\mathbf{G}$ & 7 & Tir 220 Cis & Desconhecida & BR169 & (Este estudo) \\
\hline 793 del $C$ & 7 & GIn226_fs4X & Nova: alelo nulo & BR369 & (Este estudo) \\
\hline $1049 \mathrm{~A}>\mathrm{G}$ & 8 & His 311 Arg & Grave & SP64 & (Stone et al., 1999) \\
\hline $1093 \mathrm{G}>\mathrm{A}$ & 8 & Glu 326 Lis & $\begin{array}{l}\text { modificador } \\
\text { fenotípico }\end{array}$ & BR280 & (Stone et al., 2000; Zhao et al., 2003) \\
\hline $1102 \mathrm{C}>\mathrm{T}$ & 8 & Arg 329 Cis & $\begin{array}{l}\text { Desconhecida: } \\
\text { Leve }\end{array}$ & SP226 & $\begin{array}{l}\text { Descrita uma vez em heterozigose num } \\
\text { paciente da DP; nunca descrita antes em } \\
\text { paciente da DG; mutação num } \\
\text { dinucleotídeo CpG; } \\
\text { (Lwin et al., 2004) }\end{array}$ \\
\hline $1283 \mathrm{G}>\mathrm{A}$ & 9 & Gli 389 Glu & Grave & SP83 & (Cormand et al., 1998) \\
\hline $1300 \mathrm{C}>\mathrm{T}$ & 9 & Arg 395 Cis & Nova: Leve & SP118 & $\begin{array}{l}\text { Paciente com relação genótipo-fenótipo } \\
\text { informativa; mutação num dinucleotídeo } \\
\text { CpG; } \\
\text { (Este estudo) }\end{array}$ \\
\hline $1304 \mathrm{~A}>\mathrm{C}$ & 9 & Asn 396 Tre & Leve & BR102 & $\begin{array}{l}\text { Paciente confirma gravidade desta mutação } \\
\text { (Amaral et al., 1996) }\end{array}$ \\
\hline 1309 G > A & 9 & Val 398 Ile & Nova: Leve & BR144, BR233 & $\begin{array}{l}\text { Dois pacientes homozigotos com relação } \\
\text { genótipo-fenótipo informativa; } \\
\text { (Este estudo) }\end{array}$ \\
\hline 1342-1326 del ATT & 9 & 403 del I le & Desconhecida & SP71 & (Este estudo) \\
\hline $1499 \mathrm{~T}>\mathrm{C}$ & 10 & Leu 461 Pro & Desconhecida & SP61 & (Beutler et al., 2005) \\
\hline $1583 \mathrm{~T}>\mathrm{C}$ & 11 & I le 489 Tre & Desconhecida & $\begin{array}{l}\text { SP51, BR294, } \\
\text { BR304 }\end{array}$ & (Este estudo) \\
\hline $1604 \mathrm{G}>\mathrm{A}$ & 11 & Arg 496 His & Leve & SP137, BR294 & $\begin{array}{l}\text { Paciente SP137 confirma gravidade desta } \\
\text { mutação; mutação num dinucleotídeo CpG; } \\
\text { (Beutler et al., 1993) }\end{array}$ \\
\hline
\end{tabular}

As 14 mutações novas estão indicadas em negrito. As 6 mutações em pacientes com relação genótipo-fenótipo descritas por este estudo aparecem destacadas em amarelo. As 4 mutações em pacientes com relação genótipo-fenótipo confirmadas por este estudo aparecem destacadas em verde. DP: doença de Parkinson. 


\subsubsection{Discussão}

A análise por dHPLC seguido de seqüenciamento nos 54 pacientes analisados permitiu a detecção de 30 mutações diferentes, das quais 14 são mutações novas, ainda não descritas na literatura. Em 4 dessas mutações novas e em 6 descritas anteriormente a relação genótipo-fenótipo pode ser verificada. Das 6 mutações já descritas anteriormente, 2 ainda não tinham a sua gravidade descrita ao passo que as outras 4 (c.222-224delTAC; c.595-596delCT; N396T e $\mathrm{R} 496 \mathrm{H}$ ) já tinham um efeito estabelecido anteriormente e que foi confirmado por este estudo.

\section{a) Novos efeitos fenotípicos descritos neste estudo}

As seis mutações (incluindo quatro novas) que puderam ter sua relação genótipo-fenótipo esclarecida por este estudo, aparecem destacadas em amarelo na tabela 3.2.4 e são apresentadas a seguir, onde se discute as implicações das trocas de aminoácidos na GCase, considerando a estrutura tridimensional da proteína.

\section{$\underline{\mathrm{M} 123 \mathrm{~T}}$}

A mutação M123T (c.485T>C) foi detectada na amostra BR204, de um paciente afetado pelo tipo 1 da DG, com 22 anos de idade. Trata-se de uma mutação já descrita (Alfonso et al., 2001), porém sem efeito fenotípico estabelecido. Uma vez que ela ocorreu em combinação com a mutação R120W, de efeito grave (Beutler et al., 1996), pode-se concluir que a M123T é uma mutação de efeito leve.

A caracterização funcional da M123T, através da expressão em células COS (Alfonso et al., 2004), revelou uma atividade residual alta (34,3\%), comparável à da N370S e compatível com a classificação de mutação de efeito leve. Essa atividade residual foi aumentada em 10 vezes, pelo tratamento de uma cultura de células COS contendo a mutação M123T, através de adição de quantidades subinibitórias de NB-DNJ (Zaveska ${ }^{\circledR}$, Miglustat, Actelion) que age 
como chaperone (Alfonso et al., 2005). O aminoácido M123 está localizado no final de uma alça $\beta$ (N117 a M123) e pode ajudar a estabelecer um núcleo hidrofóbico com F213 e F216 (na $\alpha$ hélice de I204 a A221) e P178. A troca de metionina pela treonina, um aminoácido polar e pequeno, nesse núcleo hidrofóbico, pode desestabilizar o interior da proteína (figuras 1.4 e 1.5). A região adjacente a M123 é possivelmente um sítio de fosforilação da S129, que também pode ser afetado pela mutação (Alfonso et al., 2004).

\section{$\underline{\mathrm{N} 188 \mathrm{~S}}$}

A mutação N188S (c.680A $>$ G) foi identificada na paciente BR136, que apresentou a mutação grave L444P no outro alelo e um fenótipo clínico de tipo 1, aos 30 anos de idade. Ademais, a paciente tem um irmão afetado de 27 anos também manifestando o tipo 1 da DG. Assim, essa família indica um efeito leve da mutação N188S, responsável pelo fenótipo de tipo 1 da DG.

Essa mutação é geralmente descrita como tendo efeito leve (Kim et al., 1996; Montfort et al., 2004), mas também já foi descrita num paciente de tipo $3 \mathrm{em}$ combinação com a S107L, uma mutação de efeito grave (Filocamo et al., 2002; Beutler et al., 2005). Assim, a N188S é uma das raras mutações com relação genótipo-fenótipo inconsistente. A asparagina e a serina são aminoácidos neutros e polares, indicando um possível efeito leve da mutação, como ocorre na N370S.

Em 14 pacientes descritos até hoje com essa mutação, 8 (57\%) apresentaram epilepsia mioclônica (Monfort et al., 2004). O genótipo L444P/N188S foi encontrado em dois desses 14 casos da literatura, ambos sem epilepsia. Uma vez que os 8 pacientes epiléticos apresentaram mutações de efeito mais grave que a L444P no outro alelo, é possível que exista um efeito de dose alélica para a N188S (Monfort et al., 2004). Os irmãos descritos neste estudo (L444P/N188S) também não apresentam nenhum sintoma neuronopático, mas uma avaliação neurológica detalhada dos pacientes foi sugerida ao seu médico. 


\section{$\underline{793 \mathrm{delC}}$}

A mutação 793delC é descrita neste estudo pela primeira vez. Essa deleção leva a um códon de parada prematura 4 aminoácidos após o códon 226 (p.GIn226_fs4X). Nesse caso específico é possível determinar a gravidade da mutação, embora o paciente de tipo 1 apresentasse no outro alelo a mutação de efeito leve N370S. Isso porque a deleção altera o quadro de leitura da GCase e corresponde a um polipetídeo com menos da metade do tamanho da proteína normal e sem os sítios ativos. Todas as deleções no gene GBA que tiram de fase o quadro de leitura são consideradas alelos nulos (Beutler et al., 2005).

\section{$\underline{\mathrm{R} 329 \mathrm{C}}$}

A mutação R329C, localizada na hélice $\alpha-6$ do domínio III da GCase, foi descrita pela primeira vez num paciente da DG neste estudo. Anteriormente ela havia sido identificada apenas em heterozigose, num paciente da doença de Parkinson, durante uma triagem de mutações no gene GBA (Lwin et al., 2004). Assim, torna-se claro que essa mutação pode ser considerada patogênica. $O$ paciente parkinsoniano com a R329C apresentou uma atividade enzimática de $64 \%$ em relação a um controle, comparável a de heterozigotos para a N370S, falando a favor de um efeito leve dessa mutação. Neste estudo, a paciente SP226 apresenta o tipo 1 da DG, onde a R329C ocorre em trans com a mutação R120Q, de efeito grave. Assim, essa mutação apresenta provavelmente um efeito leve. No entanto, a paciente ainda tem 9 anos de idade, e uma relação genótipo-fenótipo mais precisa será possível apenas numa idade mais avançada. Uma avaliação neuro-oftalmológica detalhada do paciente foi recomendada ao médico responsável.

\section{$\underline{\mathrm{R} 395 \mathrm{C}}$}

A mutação R395C está sendo descrita pela primeira vez neste estudo. Ela ocorreu em heterozigose composta com a mutação de efeito grave RecTL, no paciente SP118 que apresenta o tipo 1 da DG e 17 anos de idade. Assim, a R395C deve ter uma atividade enzimática residual suficiente para não levar ao 
aparecimento de sintomas neurológicos, podendo ser classificada como uma mutação de efeito leve.

$\underline{\text { V398I }}$

Dois pacientes não aparentados e filhos de casais consangüíneos (BR144 e BR233) apresentaram a mesma mutação ainda não descrita, a V398I, em homozigose. Ambos não apresentam sintomas neuronopáticos. Ao passo que um deles tem 10 anos de idade, o outro, aos 60 anos, permite classificar a mutação V398I como tendo efeito leve.

Duas outras mutações já foram descritas nesse códon, alterando a valina para leucina (Seeman et al., 1996) e para fenilalanina (Stone et al., 1999). No entanto, essas duas mutações foram associadas a um efeito grave. Nos dois casos já descritos (V398L e V398F) e na mutação nova V398I a alteração mantém aminoácidos apolares na posição 398. Assim, não é possível estabelecer essa diferença de efeito das mutações baseado apenas na propriedade química dos aminoácidos nas proteínas mutantes, principalmente porque a isoleucina e a leucina são aminoácidos que compartilham todas as propriedades físico-químicas mais importantes na determinação da estrutura protéica (figura 3.2.6). Assim, efeitos mais sutis dessas mutações, tais como interações com diferentes aminoácidos na estrutura terciária da molécula podem explicar a diferença de efeito fenotípico de mutações para aminoácidos com propriedades idênticas.

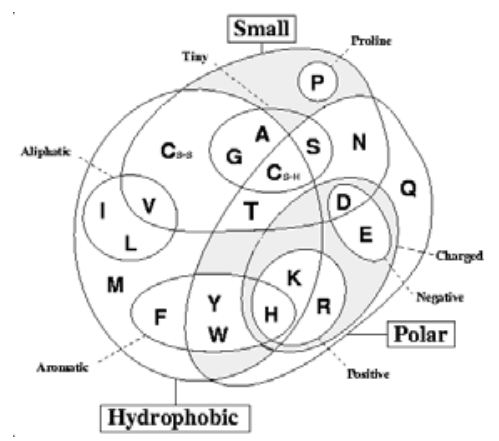

Figura 3.2.6. Um diagrama de Venn mostrando a relação entre os 20 tipos de aminoácidos com uma seleção de propriedades físico-químicas importantes na determinação da estrutura protéica. Aminoácidos básicos: positivos; aminoácidos ácidos: negativos; aminoácidos alifáticos: de cadeia carbônica aberta. Note que a Isoleucina (I) e a Leucina (L) compartilham as principais propriedades físico-químicas. 
Curiosamente, três mutações de efeito leve detectadas neste estudo, a R395C, a N396T e a V398I ocorreram na alça dois da GCase (aminoácidos 394399), que controla o acesso aos sítios ativos da enzima, conforme mostra a figura 3.2.7. Mutações nessa alça podem desestabilizar a conformação aberta (figura 3.2.7a) ou estabilizar a conformação fechada (figura 3.2.7b), tratando-se assim de uma região crítica para o correto funcionamento da GCase (Premkumar et al., 2005).

A alça 2 é formada por 6 aminoácidos, dos quais 5 já tiveram mutações identificadas anteriormente. A mutação R395C é a primeira descrita nessa posição. Quatro aminoácidos de posição intermediária da alça, R395, N396, F397 e V398 já apresentaram mutações de efeito leve (sendo duas descritas neste estudo), ao passo que nas posições da extremidade da alça as mutações V394L e D399N têm efeito grave. Assim, é possível que as posições extremas dessa alça sejam críticas para o correto funcionamento de um mecanismo de rotação que limita o acesso ao sítio ativo da enzima, conforme visualizado na figura 3.2.7c e d, embora novas mutações nessa região devam esclarecer essa possibilidade. 


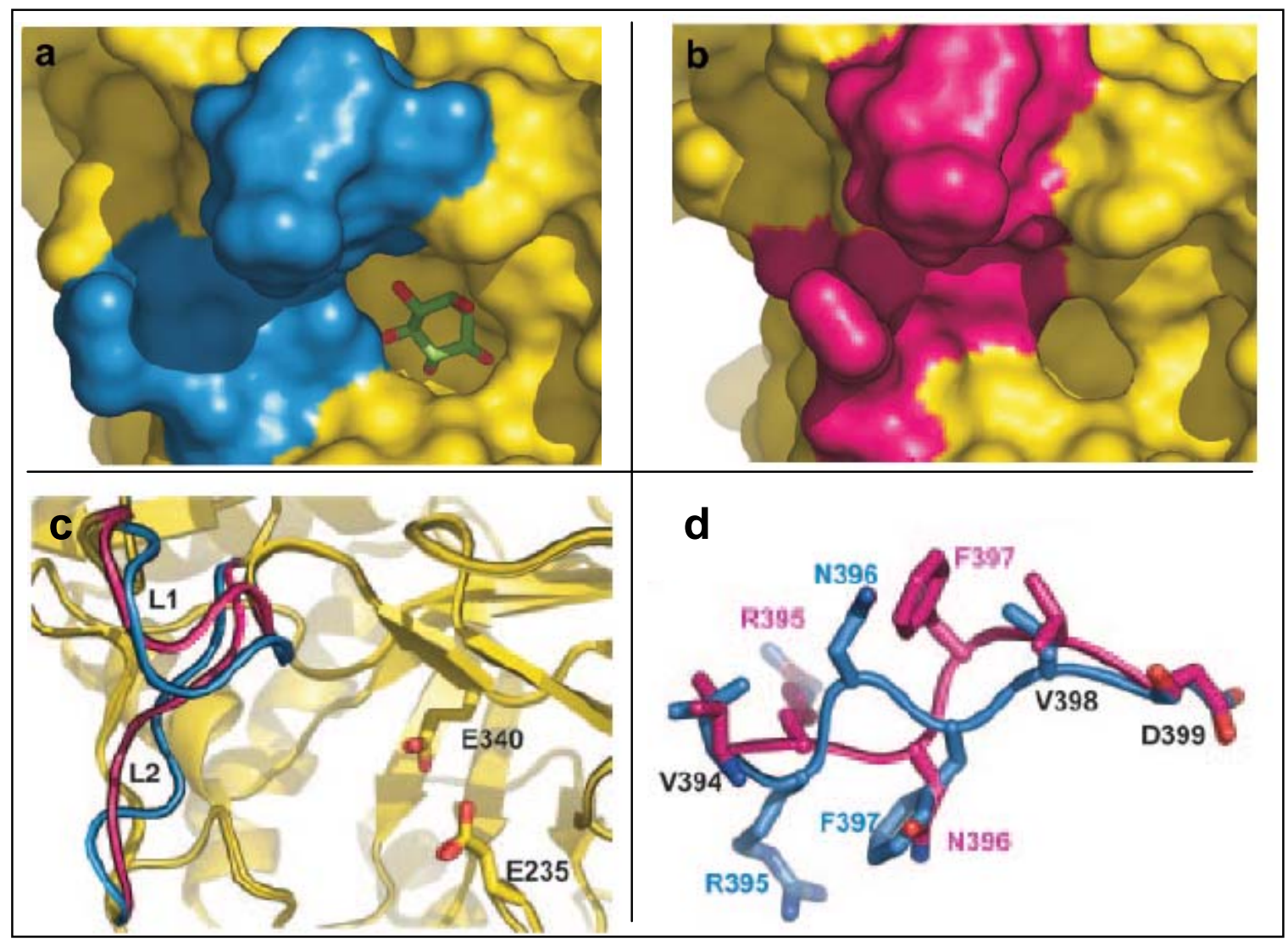

Figura 3.2.7 Conformações alternativas da GCase, limitando o acesso ao sítio ativo da enzima (E325 e E340). A conformação aberta aparece na cor azul e a fechada em rosa. a) Superfície da GCase mostrando a conformação aberta e o acesso ao sítio ativo da enzima, aonde se vê em verde um inibidor acoplado. b) Conformação fechada restringindo o acesso ao sítio ativo. c) Conformações alternativas das alças L1 (S345-E348) e L2 (V394-D399). d) Modificações conformacionais dos aminoácidos específicos da alça L2 controlando o acesso ao sítio ativo (Premkumar et al., 2005).

\section{b) E326K: modificador fenotípico}

A E326K é considerada atualmente um modificador de fenótipo (Beutler et al., 2005). Essa mutação nunca foi descrita num paciente sem estar no mesmo alelo com uma segunda mutação. Adicionalmente, a E326K ocorreu em trans com a G202R ou com a L444P numa família, em indivíduos normais (Zhao et al., 2003). A GCase com a E326K é uma enzima estável e apresenta uma atividade residual bastante alta de acordo com análises de CRIM SA (Liou et al., 2006). No entanto, análises bioquímicas demonstraram que a E326K em cis com uma 
segunda mutação, é responsável por uma diminuição na atividade enzimática residual (Chabás et al., 2005). A mutação E326K foi descrita primeiramente por Eyal et al. (1991) em pacientes de uma mesma família com tipo 1 da DG, compartilhando um mesmo alelo com a mutação $\mathrm{D} 140 \mathrm{H}$, enquanto que o outro alelo apresentou a mutação K157Q. Estudos posteriores a identificaram a E326K em cis com a L444P em pacientes do tipo 2 e 3 (Grace et al., 1999; Monfort et al., 2004) e também em cis com a N188S (Monfort et al., 2004), sendo por isso considerada um modificador fenotípico.

A paciente BR280 apresentou a E326K além das mutações L444P e 36delT. Ela tem 28 anos de idade e não apresenta sintomas neuronopáticos, o que está de acordo com a classificação da 36delT como uma mutação de efeito leve (Koprivica et al., 2000). No entanto, a fase da E326K não pode ser determinada uma vez que amostras de DNA dos pais não puderam ser obtidas.

Um estudo anterior encontrou a E326K em freqüências polimórficas na população Norte-Americana: $0,95 \%$ (3/316) dos alelos da população normal e 1,29\% (4/310) dos alelos de pacientes da DG (Park et al., 2002). Com a possibilidade de se tratar de um polimorfismo, nós testamos neste estudo 100 alelos normais, não sendo encontrada a E326K em nenhum dos casos (dados não apresentados). No capítulo 3.1 deste estudo foram encontrados 5 pacientes de formas neuronopáticas da DG apresentando a E326K em combinação com outras mutações, além do paciente BR280 descrito aqui. Assim, embora a E326K possa ser uma alteração mais rara no Brasil, uma análise de um grupo controle maior poderia conferir maior precisão a essa análise. Os alelos complexos apresentando a L444P+E326K alertam para a necessidade de verificar a presença deste modificador fenotípico, principalmente em pacientes com mutações detectadas por RFLP. 


\section{c) Sensibilidade dos métodos}

Tanto a análise dos perfis cromatográficos após o dHPLC como a análise das seqüências de DNA dependem do olho do observador e de seus critérios de julgamento. Assim, o valor preditivo desses métodos pode variar em diferentes trabalhos, bem como nas diferentes condições de análise e qualidade de reagentes usados. A taxa de detecção neste estudo é inferior àquela descrita na literatura científica, onde são descritas taxas de detecção de $92 \%$ ou mais, na maioria dos trabalhos que utilizaram a técnica de dHPLC (Liu et al., 1998; O’Donovan et al., 1998; Jones et al., 1999; Bennett et al., 2001; Pfeiffer et al., 2002).

O uso do dHPLC na análise do gene GBA foi descrito apenas uma vez, num estudo Colombiano, onde permitiu identificar todas as mutações presentes em 25 pacientes (Pomponio et al., 2005). Esse estudo fez uso da Platinum Taq (Invitrogen, EUA), ao passo que aqui se utilizou uma Taq polimerase de qualidade inferior. Ao passo que Pomponio et al., (2005) utilizaram DNA extraído de sangue, neste trabalho optou-se pela utilização de DNA extraído de mucosa bucal. Os 11 exons foram analisados em 14 fragmentos (em comparação com 10 fragmentos neste estudo) sem a necessidade de utilizar a estratégia de nested PCR. Os 25 casos Colombianos apresentaram a mutação N370S em 22 heterozigotos compostos e dois homozigotos, correspondendo a $52 \%$ dos alelos, ao passo que neste estudo os pacientes da segunda fase apresentaram essa mutação em 34\% dos alelos. Assim, algumas dessas diferenças podem ser responsáveis pela menor taxa de detecção neste estudo.

Embora o dHPLC seja usado para responder a uma pergunta qualitativa: "Existe variação na seqüência do amplicon analisado em relação a um controle?", a resposta vem na forma de um perfil cromatográfico. Idealmente a resposta do método deveria ser um simples sim ou não, de preferência obtido de maneira automática, independente do olho do observador. Pfeiffer et al. (2002), cientes dessa limitação metodológica, procuraram desenvolver métodos de análise computacional de alterações nos cromatogramas resultantes de dHPLC de 
amplicons do gene BRCA1. Esses métodos estavam restritos aos cromatogramas do gene BRCA1 e apresentaram uma alta especificidade (acima de 99\%). Esse grupo observou que a característica mais discriminatória de um cromatograma alterado era a localização do pico mais alto no perfil.

A sensibilidade do dHPLC neste estudo pode ter sido negativamente influenciada por vários fatores. O PCR tradicional não permite detectar deleções gênicas grandes, maiores que os amplicons analisados, ou deleções do gene inteiro, que já foram descritas em alguns estudos da DG, usando as técnicas de long range PCR e Southern Blot (Beutler \& Gelbart, 1994; Filocamo et al., 2002). No entanto, esse tipo de mutação é extremamente raro, não tendo sido encontrado numa análise de 304 alelos de pacientes Norte-americanos (Koprivica et al., 2000). Assim, outros fatores devem ter reduzido a sensibilidade neste estudo.

Em dois pacientes não foi possível identificar nenhuma das mutações (amostras SP43 e BR335). Apesar dos pais não serem consangüíneos, é possível que esses pacientes sejam homozigotos e que a análise por dHPLC não apresentou cromatogramas alterados. Outra possibilidade é um erro de identificação de amostras. As amostras fornecidas foram coletadas por médicos e profissionais de saúde, algumas vezes incluindo a triagem de vários pacientes simultaneamente. Um pedido de nova coleta, para descartar a possibilidade de erro de identificação de amostras, e a mistura dessas amostras com DNA de um indivíduo controle seriam desejáveis numa eventual repetição dessas análises.

Outros fatores também podem ter influenciado a sensibilidade do dHPLC neste estudo. O procedimento de nested PCR pode ter tornado os perfis cromatográficos menos precisos pois poderia haver um ruído, produto do primeiro PCR, que impediu a visualização de alterações mais sutis nos cromatogramas. A forma de impressão dos cromatogramas, que inicialmente eram obtidos com uma intensidade baixa ( 3 a $8 \mathrm{mV}$ ) pode ter "achatado" os perfis, mascarando eventuais alterações. A intensidade ideal para análise tinha entre $20 \mathrm{mV}$ e $25 \mathrm{mV}$.

As restrições do próprio método também devem ser levadas em conta uma vez que algumas mutações podem simplesmente não ter alterado o perfil 
cromatográfico do amplicon. A figura 3.2.8 mostra um exemplo de mutação detectada por RFLP na primeira fase do estudo, no paciente com o genótipo L444P/RecNcil cuja análise do amplicon por dHPLC não mostra um perfil claramente diferente do controle.

Em relação aos seqüenciamentos, não foram raras vezes em que a qualidade do seqüenciamento não permitiu um resultado conclusivo. Em alguns casos, foi possível observar nas seqüências realizadas pelo MegaBace o fenômeno de allele-dropout, ou seja, o seqüenciamento de apenas um dos alelos, fazendo com que alterações em heterozigose aparecessem como homozigotas. Nesses casos, foi necessário realizar um segundo seqüenciamento para confirmação do genótipo. Os resultados apresentados na tabela 3.2.3 indicam as amostras para as quais se obteve um seqüenciamento de boa qualidade, com a aparência conclusiva de mutação, nas análises senso e anti-senso.

Finalmente, é interessante notar que as mutações detectadas neste estudo (tabela 3.2.4) eram transições em 96\% (25/26) dos casos, ao passo que apenas $4 \%$ eram transversões. No entanto, a preponderância de transições (em detrimento das transversões) é observada ao longo de todo o genoma, encontrada em 60\% das mutações (Gojobori et al., 1982; Cooper \& Krawczak, 1990) e também no gene GBA, encontrada em 54\% de 120 mutações estudadas (Martinez-Arias et al., 2001). Uma possível explicação para a maior preponderância de transições neste estudo é o fato de que $23 \%$ (6/26) das trocas de bases encontradas ocorreram em dinucleotídeos CpG. Uma vez que mutações dos dinucleotídeos CpG são geralmente as transições C>T ou G>A (MartinezArias et al., 2001), essa pode ser uma das razões da preponderância de transições encontrada. De fato, as 6 trocas nos dinucleotídeos CpG deste estudo eram $C>T$ ou $G>A$ (tabela 3.2.4). No entanto, a alta freqüência de transições detectada neste estudo pode ser devida ao acaso ou indicar uma restrição metodológica, com uma maior detecção de transições. 

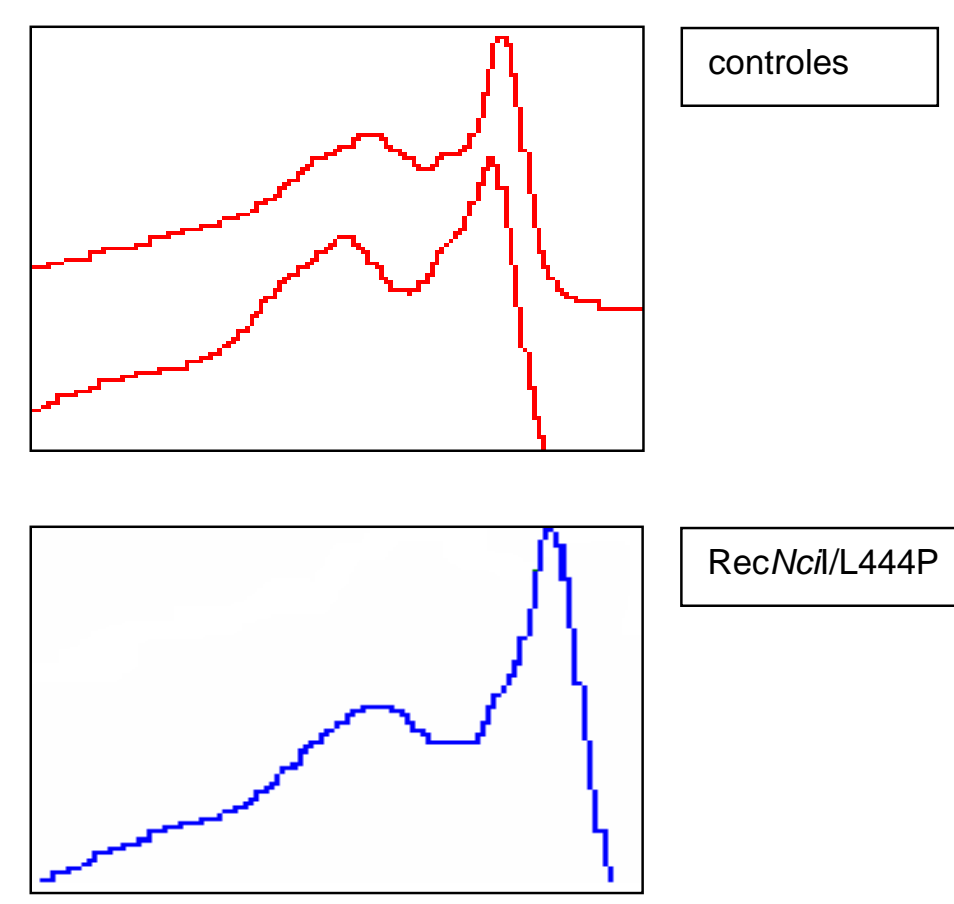

RecNcil/L444P

Figura 3.2.8. Curvas de dHPLC do amplicon incluindo os exons 10 e 11 a $62^{\circ} \mathrm{C}$, de dois controles e de uma amostra com o genótipo RecNcil/L444P, identificado por RFLP, mostrando que o perfil não aparece claramente alterado em relação aos controles, sendo portanto um falso-negativo.

\section{d) Especificidade dos métodos}

Visando avaliar a especificidade dos métodos (definida como a capacidade do método de excluir corretamente da análise amplicons sem mutação) foi feita uma contagem de amostras apresentando perfil cromatográfico alterados mas com seqüenciamento indicando uma seqüência normal. Esse procedimento indicou que 50 dentre 98 (51\%) resultados do dHPLC que indicavam uma aparente alteração eram falso-positivos, utilizando o seqüenciamento como método controle. A figura 3.2.9 mostra um exemplo de cromatograma alterado, mas cujo seqüenciamento se mostrou normal. Uma vez que foram realizadas 500 análises de dHPLC, uma taxa de exclusão de amplicons sem alteração do dHPLC de 90\% (450/500) foi obtida na segunda fase deste estudo. É possível que alguns dos fatores mencionados que influenciaram a sensibilidade do método possam ter também diminuído a especificidade do dHPLC. Algumas vezes os primers 
sintetizados podem estar contaminados com fragmentos incompletamente sintetizados que tem uma base a menos do que o esperado (Kosaki et al., 2005). Nesse caso o padrão cromatográfico do dHPLC pode mostrar uma variação e ser interpretado de modo falso-positivo. A incorporação errônea de bases durante os procedimentos de PCR também podem ter levado a uma alteração detectada no dHPLC, mas que não se repetiu na segunda PCR que antecipava os seqüenciamentos. A Taq polimerase utilizada neste estudo não tem atividade de correção 3'-5' (proof reading), o que pode ter levado a algumas incorporações errôneas durante as PCRs para o dHPLC, que não foram repetidas nas novas PCRs feitas para o seqüenciamento. A maioria dos artigos descrevendo análises por dHPLC utiliza Taq polimerases de qualidade superior, com atividade de correção 3'-5' (Liu et al., 1998; Jones et al., 1999; Bennett et al., 2001; Pfeiffer et al., 2002; Kosaki et al., 2005; Pomponio et al., 2005). Por fim, os resultados alterados no dHPLC que não tiveram mutação detectada no seqüenciamento não são necessariamente falso-positivos uma vez que o seqüenciamento pode ter sido falso-negativo.

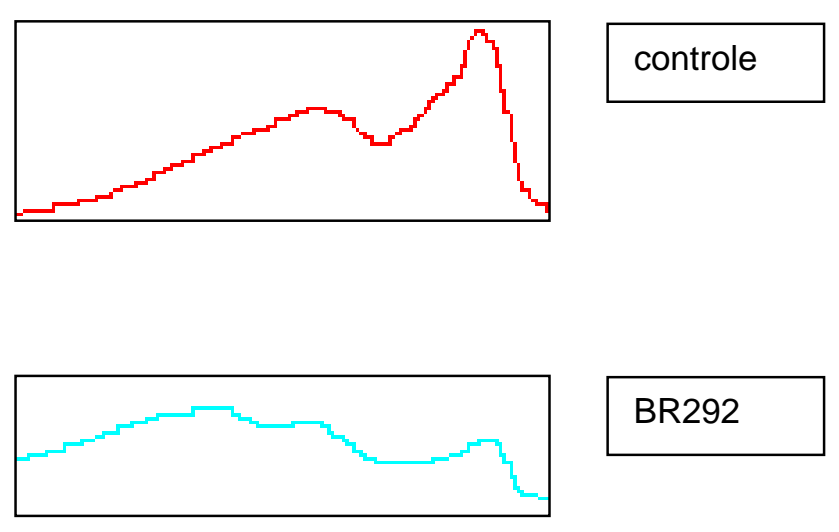

Figura 3.2.9: Curvas de dHPLC a $62^{\circ} \mathrm{C}$ do amplicon compreendendo os exons 10 e 11, mostrando um cromatograma alterado detectado no paciente BR292 em relação ao controle, mas cujo seqüenciamento não mostrou nenhuma mutação, podendo caracterizar um resultado falso-positivo. 


\title{
3.3 A doença de Parkinson e mutações no gene GBA no Brasil
}

\author{
Roberto Rozenberg ${ }^{1 *}$, Mariana Spitz ${ }^{2 *}$, Egberto R Barbosa ${ }^{2 * *}$, \\ Lygia $\vee$ Pereira $^{1^{* *}}$
}

Artigo submetido à Neurology

${ }^{1}$ Departamento de Genética e Biologia Evolutiva, Instituto de Biociências, Universidade de São Paulo, São Paulo, Brasil

${ }^{2}$ Centro de Estudos de Distúrbios do Movimento, Departamento de Neurologia, Faculdade de Medicina, Universidade de São Paulo, São Paulo, Brasil

*Esses autores contribuíram igualmente para esse trabalho

**Esses autores seniores contribuíram igualmente para esse trabalho 


\begin{abstract}
Objective

To evaluate the association between parkinsonism and Gaucher disease (GD), which has been increasingly recognized in recent years, in Brazilian patients. Mutations in the glucocerebrosidase gene (GBA), which may cause GD in homozygosis, are thought to be a rare but significant risk factor for Parkinson's disease (PD), even in heterozygosis. However, controversy still exists.

Methods

We searched for GBA common mutations (N370S, L444P and G377S) in 65 Brazilian patients affected by PD with disease onset before the age of 55 and compared the results to 267 age- and sex-matched controls.

Results

GBA mutations were detected at a significantly higher frequency among PD patients $(2 / 65=3 \%)$, when compared to the control group (0/267): $P=0,038$; (odds ratio $=21.06$; confidence interval $=99 \%, 1.05$ to 420.89). The two PD patients heterozygous for GBA mutations are male, with disease onset at the ages of 42 and 46 years and both have a good response to levodopa therapy. They carry the L444P mutation and one of them has additionally the E326K phenotype modifier in the same allele.

Interpretation
\end{abstract}

These results provide further evidence for GBA mutations being a rare, but definite hereditary risk factor for PD. 


\section{Resumo}

Objetivo

Mutações no gene GBA, que podem causar a DG em homozigose podem ser um fator de risco raro mas significativo para a doença de Parkinson (PD), mesmo em heterozigose. No entanto, ainda existe controvérsia. Esse estudo visa verificar a associação da doença de Gaucher (DG) e de Parkinsonismo em pacientes Brasileiros.

Métodos

Nós verificamos a presença das mutações mais comuns do gene GBA (N370S, L444P e G377S) em 65 pacientes Brasileiros afetados pela DP, com início dos sintomas anterior aos 55 anos e comparamos os resultados com 267 controles equiparados em gênero e idade.

Resultados

Mutações no gene GBA foram detectadas numa freqüência significativamente maior entre pacientes da DP $(2 / 65=3 \%)$ comparando com o grupo controle (0/267); $\mathrm{P}=0,038$ (odds ratio $=21,06$; intervalo de confiança $=99 \%, 1,05 \mathrm{a}$ $420,89)$. Os dois pacientes da DP heterozigotos para mutações no gene GBA são do sexo masculino com início dos sintomas aos 42 e 46 anos de idade e ambos apresentam uma boa resposta à terapia com levodopa. Ambos apresentam a mutação L444P e um deles possui o modificador fenotípico E326K no mesmo alelo.

Interpretação

Esses resultados apresentam uma evidência adicional de que mutações no gene GBA são um provável fator de risco para a DP. 


\section{Introdução}

A doença de Parkisnon (DP) é um distúrbio neurodegenerativo caracterizado por tremor, bradicinesia e instabilidade postural. A DP é causada pela perda neuronal progressiva na substância cinzenta e outras estruturas cerebrais (Tolosa et al., 2006). A doença tem uma prevalência estimada de 150 a 200 em cada 100.000 indivíduos, sendo uma das principais doenças neurológicas (Barbosa et al., 1997). De acordo com o critério de diagnóstico clínico da DP idiopática do United Kingdom Parkinson's Disease Society Brain Bank (Hughes et al., 1992; Hughes et al., 2001), além de apresentar bradicinesia e pelo menos um dos sinais cardinais mencionados anteriormente, o paciente deve ser investigado para diversos critérios de exclusão (Hardy et al., 2003).

O estudo da genética da DP recebeu intensa atenção na última década. Conforme novos genes envolvidos na DP são encontrados, novas expectativas aparecem de que a compreensão da patogênese da doença venha a resultar em estratégias de tratamento mais eficientes, visando não apenas o tratamento sintomático mas também a prevenção da degeneração de neurônios dopaminérgicos. Diversos locos já foram descritos levando à predisposição dessa doença heterogênea, a maioria deles causando as formas de herança monogênica altamente penetrantes. A concentração familial é encontrada em aproximadamente $20 \%$ dos pacientes, ao passo que a maioria dos casos é esporádica, de causas multifatoriais. Quanto mais precoce o aparecimento da DP, maiores as chances de que fatores genéticos tenham um papel predominante (Warner \& Schapira, 2003).

A doença de Gaucher (DG) é a principal doença de armazenamento lisossômico e apresenta um padrão de herança autossômico recessivo. Clinicamente é caracterizada por uma doença multi-sistêmica de expressão variável, apresentando hepatoesplenomegalia, anemia e trombocitopenia. Sintomas ósseos e pulmonares também podem estar presentes. A presença e a gravidade de sintomas neurológicos definem os três tipos da DG. Aproximadamente $95 \%$ dos casos da doença são do tipo 1, com apresentação 
infantil ou adulta e sem envolvimento neurológico (Beutler \& Grabowski, 2001). Os tipos 2 e 3 da DG são variantes neuronopáticas: no tipo 2 o início é precoce e a sobrevida limitada até os dois anos de idade; no tipo 3 a apresentação é infantil ou juvenil e o curso clínico é menos ominoso, com sobrevida até a idade adulta. A DG é um paradigma de intervenção terapêutica em genética médica devido a existência de uma eficiente terapia de reposição enzimática (Brady \& Schffmann, 2004). Esse tratamento confere à DG uma acentuada importância econômica, apesar de sua baixa prevalência.

A DG é causada normalmente por mutações no gene GBA (1q21) que codifica a enzima $\beta$-glicosidase ácida, também chamada de glicocerebrosidase (GCase). Heterozigotos para mutações no gene GBA são sempre assintomáticos para a DG. Na ausência da enzima, seus substratos, o glicocerebrosídeo e a glicosilesfingosina, derivados da quebra de células sanguíneas, acumulam-se no sistema reticuloendotelial. Mais de 230 mutações causadoras da DG já foram identificadas, sendo mais freqüentes a [c.1226A>G;N370S] e a [c.1448T>C;L444P], aqui tratadas apenas por N370S e L444P (Beutler et al., 2005). A análise de mutações tem acentuado valor preditivo na DG, embora a relação genótipo-fenótipo não seja absoluta.

A associação incidental da DP e da DG no mesmo paciente foi descrita pela primeira vez em 1939 (Van Bogaert, 1939) e desde então seguiram diversas descrições (Neudorfer et al., 1996; Machaczka et al., 1999; Bembi et al., 2003; Tayebi et al., 2003b) incluindo uma de nosso grupo (Spitz et al., 2006), mostrando que pacientes da DG podem desenvolver Parkinsonismo, mesmo antes dos primeiros sintomas da DG (Lwin et al., 2004). Muitos desses casos apresentam sinais que não caracterizam a forma clássica da DP, tais como um início mais precoce e uma resposta subótima à terapia com levodopa.

Baseados nesses achados, Lwin et al. (2004) decidiram investigar a possível presença de mutações no gene GBA em pacientes da DP. O grupo analisou 57 amostras de cérebros de pacientes da DP e encontraram uma freqüência surpreendentemente alta de mutações (21\%). Esse trabalho foi seguido por estudos em Israel (Aharon-Peretz et al., 2004), Estados Unidos (Clark et al., 
2005), Canadá (Sato et al., 2005) e Noruega (Tofto et al., 2006) visando confirmar essa associação (esses estudos estão sumariados na tabela 3.3.1). Os resultados variaram de uma freqüência não significativamente diferente na população Norueguesa até uma diferença marginalmente significativa na população Canadense, quando comparados com grupos controle. Uma associação positiva foi encontrada na população Judaica Ashkenazita, embora tenha sido usado um grupo controle não corrigido.

É interessante notar que a maioria dos pacientes da DG nunca desenvolve Parkinsonismo assim como a maioria dos pacientes da DP não tem mutações no gene GBA (Sidransky et al., 2005). Mais ainda, os estudos de associação em grandes amostras de pacientes da DP nunca identificaram o loco do gene GBA (DeStefano et al., 2001; Warner \& Schapira, 2003; Maraganore et al., 2005). Assim, existem evidências contra e a favor da associação da DG e da DP. Uma vez que diferentes fatores genéticos e vias metabólicas podem influenciar a suscetibilidade à DP, é importante o estudo de diversas populações. Este estudo descreve a análise das principais mutações causadoras da DG em 65 pacientes Brasileiros da DP, comparados a um grupo controle equiparado em gênero e faixa etária, composto de 267 indivíduos. 
Tabela 3.3.1. Trabalhos publicados descrevendo mutações no gene GBA em pacientes da DP

\begin{tabular}{|c|c|c|c|c|}
\hline Referência & $\begin{array}{l}\text { População } \\
\text { estudada }\end{array}$ & $\begin{array}{l}\text { Mutações no } \\
\text { gene GBA } \\
\text { analisadas }\end{array}$ & Resultados & Grupo controle \\
\hline Lwin et al., 2004 & $\begin{array}{l}57 \text { amostras de } \\
\text { pacientes norte- } \\
\text { americanos da } \\
\text { DP* }\end{array}$ & $\begin{array}{l}\text { Seqüenciamento } \\
\text { completo do gene }\end{array}$ & $\begin{array}{l}12 \text { pacientes (21\%) com } \\
\text { mutações no gene GBA: } \\
2 \text { homozigotos } \\
\text { (N370S/N370S) e } 10 \\
\text { heterozigotos }\end{array}$ & Não \\
\hline $\begin{array}{l}\text { Aharon-Peretz et } \\
\text { al.,2004 }\end{array}$ & $\begin{array}{l}99 \text { pacientes da } \\
\text { DP judeus } \\
\text { Israelenses }\end{array}$ & $\begin{array}{l}6 \text { mutações: } \\
\text { N370S, L444P, } \\
\text { 84insG, } \\
\text { IVS2+1g>a, } \\
\text { V394L e R496H }\end{array}$ & $\begin{array}{l}31 \text { pacientes (31\%) com } \\
\text { mutações no gene GBA: } \\
3 \text { homozigotos e } 28 \\
\text { heterozigotos. } \\
\text { Pacientes da DP com } \\
\text { mutações no gene GBA } \\
\text { apresentaram início dos } \\
\text { sintomas parkinsonianos } \\
\text { mais precocemente. }\end{array}$ & $\begin{array}{l}\text { Os resultados } \\
\text { mostraram um aumento } \\
\text { significativo de } 5 \text { vezes, } \\
\text { quando comparados a } \\
\text { um grupo controle não } \\
\text { corrigido ( } n=1543) \text {. }\end{array}$ \\
\hline Clark et al., 2005 & $\begin{array}{l}160 \text { pacientes da } \\
\text { DP judeus de } \\
\text { Nova York }\end{array}$ & $\begin{array}{l}1 \text { mutação: } \\
\text { N370S }\end{array}$ & $\begin{array}{l}17 \text { pacientes }(11 \%) \text { com } \\
\text { mutações no gene GBA: } \\
2 \text { homozigotos e } 15 \\
\text { heterozigotos }\end{array}$ & $\begin{array}{l}\text { Grupo controle de } 92 \\
\text { judeus mostrando uma } \\
\text { freqüência da mutação } \\
\text { N370S de } 4 \% \text {. Uma } \\
\text { diferença } \\
\text { estatisticamente não } \\
\text { significativa ( } P=0.2) \text {. }\end{array}$ \\
\hline Sato et al., 2005 & $\begin{array}{l}88 \text { pacientes } \\
\text { Canadenses da } \\
\text { DP }\end{array}$ & $\begin{array}{l}7 \text { mutações: } \\
\text { N370S, L444P, } \\
\text { 84insG, } \\
\text { IVS2+1g>a, } \\
\text { K198T, R329C e } \\
\text { Rec }\end{array}$ & $\begin{array}{l}5 \text { pacientes }(5,6 \%) \text { com } \\
\text { mutações no gene GBA em } \\
\text { heterozigose. }\end{array}$ & $\begin{array}{l}\text { Grupo controle }(n=122) \\
\text { mostrando uma } \\
\text { freqüência de mutações } \\
\text { de } 0,8 \% \text {, um diferença } \\
\text { marginalmente } \\
\text { significativa }(P=0.048)\end{array}$ \\
\hline Toft et al., 2006 & $\begin{array}{l}311 \text { pacientes } \\
\text { Noruegueses da } \\
\text { DP }\end{array}$ & $\begin{array}{l}2 \text { mutações: } \\
\text { N370S, L444P }\end{array}$ & $\begin{array}{l}7 \text { pacientes }(2,3 \%) \text { com } \\
\text { mutações no gene GBA em } \\
\text { heterozigose }\end{array}$ & $\begin{array}{l}\text { Grupo controle }(n=474) \\
\text { com uma freqüência de } \\
\text { mutações de } 1,7 \% \text {, uma } \\
\text { diferença não } \\
\text { significativa }(P=0,58)\end{array}$ \\
\hline
\end{tabular}

(*) Amostras de pacientes da DP de origem étnica desconhecida, coletadas em diferentes bancos de cérebros dos Estados Unidos.

\section{Material e métodos}

\section{Pacientes da DP e grupo controle}

Foram analisadas amostras de DNA de 65 pacientes da DP diagnosticados conforme os critérios clínicos do United Kingdom Parkinson's Disease Society Brain Bank (Hughes et al., 1992; Hughes et al., 2001) atendidos no Centro de Estudos de Distúrbios do Movimento do Hospital das Clínicas da Faculdade de 
Medicina da Universidade de São Paulo. Foram selecionados pacientes com idade de início dos sintomas anterior aos 55 anos, com idades variando de 30 a 76 anos. Havia 41 homens e 24 mulheres, uma proporção estabelecida para equiparar-se com a maior prevalência da doença em homens. Apenas um paciente foi selecionado de cada família. Quatorze pacientes (21,5\%) tinham um histórico familial da DP. Todos os pacientes e controles eram voluntários e assinaram formulários de consentimento. O projeto foi aprovado pelo comitê de ética local.

Um grupo controle de 267 indivíduos foi obtido, corrigido para gênero e idade visando equiparar-se com a amostra de pacientes da DP. Nenhum dos participantes deste estudo tinha ancestralidade judaica, uma população que representa apenas $0,06 \%$ da população Brasileira. A análise estatística foi feita utilizando-se o teste exato de Fisher e um teste de odds ratio ao nível de $1 \%$.

\section{Análise das principais mutações causadoras da DG}

O DNA foi extraído da mucosa bucal dos participantes de acordo com Richards et al. (1993). Todos os participantes foram triados para as mutações N370S e L444P, as mais freqüentes entre pacientes da DG no mundo e também no Brasil (manuscrito em preparação). A mutação G377S é a terceira mais freqüente em Portugal e no Brasil e foi também incluída na análise. Pacientes portadores da mutação L444P foram analisados para as mutações V460V e E326K visando detectar respectivamente, alelos recombinantes (derivados de pseudogene) e alelos complexos (a E326K é um modificador fenotípico associado à L444P em diversos pacientes da DG). A análise molecular baseou-se em polimorfismos de tamanho de fragmentos de restrição. A estratégia de triagem, os primers e as enzimas de restrição utilizadas na detecção das mutações e o método de referência quando estabelecidos previamente estão descritos na Tabela 3.3.2. Após a restrição enzimática, os fragmentos foram submetidos à eletroforese em gel de poliacrilamida 12\% (mutações N370S e G377S) ou gel de agarose 2\% (mutações L444P, V460V e E326K). Controles positivos e negativos foram incluídos em todas análises. 
Tabela 3.3.2. Estratégia de detecção das mutações causadoras da DG analisadas

\begin{tabular}{|c|c|c|c|}
\hline $\begin{array}{c}\text { MUTAÇÃO } \\
\text { (seqüência do cDNA) }\end{array}$ & INDIVÍDUOS TESTADOS & PRIMERS F e R & $\begin{array}{l}\text { ENZIMA DE } \\
\text { RESTRIÇÃO }\end{array}$ \\
\hline N370S (c.1226A>G) & Todos & $\begin{array}{c}\text { F: 5' gcctttgtccttaccctç } 3^{\prime} \\
\text { R: } 5^{\prime} \text { acgaaagttacgcacccaatt } 3^{\prime}\left({ }^{*}\right)\end{array}$ & Xhol \\
\hline G377S (c.1246G>A) & Todos & $\begin{array}{c}\text { F: 5'gcctttgtccttaccctcg 3' } \\
\text { R: 5'acgaaagttacgcacccaatt 3' }\end{array}$ & Alul ou Pvull \\
\hline L444P (c.1448T>C) & Todos & $\begin{array}{l}\text { F: 5'ctgaaccccgaaggaggac 3' } \\
\text { R: 5'tgaatggagtagccaggtga } 3^{\prime}\end{array}$ & Ncil \\
\hline V460V (c.1497G>C) & Pacientes com a L444P & $\begin{array}{l}\text { F: 5'ctgaaccccgaaggaggac 3' } \\
\text { R: 5'tgaatggagtagccaggtga } 3^{\prime}\end{array}$ & $B c g l$ \\
\hline E326K (c.1093G>A) & Pacientes com a L444P & $\begin{array}{l}\text { primeiro PCR: } \\
\text { F: 5'acaaattagctgggtgtggc 3' } \\
\text { R: 5'taagctcacactggccctgc 3' } \\
\text { Nested PCR: } \\
\text { F: 5'tgtgcaaggtccaggatcag 3' } \\
\text { R: 5'gaggtctgctttgcaggaag 3' }\end{array}$ & Bbsl ou Bpil \\
\hline
\end{tabular}

(*) primers descritos em Beutler et al., 1990

\section{Resultados}

Entre os 65 pacientes da DP analisados foram encontrados 2 (3\%) heterozigotos para a DG. A tabela 3.3.3 mostra os dados clínicos desses pacientes. Os dois heterozigotos apresentam a mutação L444P. Ambos são do sexo masculino e têm um histórico familial da DP. Um deles (paciente 1) tem atualmente 64 anos de idade e apresentou como primeiro sintoma da DP um tremor da mão esquerda aos 46 anos. A mãe e o avô materno também eram afetados. Ele apresentou uma progressão lenta da doença e atualmente mantém uma boa resposta à terapia com levodopa, após quase duas décadas em tratamento.

O outro heterozigoto (paciente 2) tem atualmente 54 anos de idade. $O$ início dos sintomas da DP foi aos 42, com rigidez do braço direito. Esse paciente apresenta, além da L444P, a mutação E326K. A mãe não apresenta a L444P ou a E326K. O pai, que também apresentou a DP, não pode ser testado pois foi a óbito há vários anos. A E326K é considerada um modificador fenotípico que quando presente em cis com a L444P confere uma menor atividade residual à enzima 
mutante se comparada a L444P sem a E326K (Monfort et al., 2004). Esse paciente tem 17 irmãos (dos mesmos pais) dos quais 15 estão vivos. A família informa que nenhum outro caso da DP existe entre os irmãos.

Os dois pacientes com mutações no gene GBA tiveram amostras de sangue enviadas para dosagem de atividade da GCase. O paciente 1 apresentoua na parte inferior do limite normal e o paciente 2 no intervalo normal (dados não apresentados). Apesar do início mais precoce (46 e 42 anos de idade) esses pacientes têm um quadro clínico clássico da DP e são tratados com levodopa, apresentando uma boa resposta. Ambos apresentaram um quadro inicial assimétrico e sem sinais atípicos.

Nenhum heterozigoto foi detectado no grupo controle. As freqüências de heterozigotos para mutações causadoras da DG, entre os pacientes da DP (2 em 65) e no grupo controle (0 em 267), foram comparadas e a diferença foi estatisticamente significativa ( $P=0,0379$ pelo teste exato de Fisher; odds ratio=21,06; intervalo de confiança $=99 \%, 1,05$ a 420,89).

Tabela 3.3.3. Características clínicas dos pacientes da DP com mutações no gene GBA

\begin{tabular}{lll}
\hline & Paciente 1 & Paciente 2 \\
\hline Mutações presentes & L444P & L444P + E326K \\
Histórico familial & Mãe e avô materno afetados & Pai (início aos 65 anos) \\
Início da PD & 46 anos & 42 anos \\
Idade atual & 64 anos & 54 anos \\
Primeiros sintomas & Tremor na mão esquera & Rigidez no braço direito \\
Resposta à levodopa & Boa & Boa \\
\hline
\end{tabular}

\section{Discussão}

Após a descrição inicial da associação entre a DP e mutações no gene $G B A$, diversos estudos buscaram verificar se pacientes da DP realmente apresentavam uma maior freqüência de mutações causadoras da DG. A maioria dos estudos encontrou uma freqüência ligeiramente aumentada, variando de 5 a 
30\% (tabela 3.3.1). No entanto, a maioria desses estudos não comprovou que esse aumento era estatisticamente significativo, comparando seus resultados ao de um grupo controle corrigido para gênero e faixa etária. Recentemente, Toft et al., (2006) publicaram um estudo controlado, onde descrevem que na população Norueguesa, não há uma freqüência aumentada de mutações no gene GBA em pacientes da DP.

Nosso estudo mostrou um resultado diferente para a população Brasileira. Nós encontramos 3\% (2/65) de heterozigotos para mutações no gene GBA entre 65 pacientes da DP. A análise estatística confirmou que esse aumento é significativo quando comparamos à freqüência de um grupo controle corrigido para sexo e idade de 267 indivíduos normais. Nossos dados indicam que mutações causadoras da DG podem contribuir para o aparecimento da DP em alguns indivíduos. Assim, mutações no gene GBA constituem um fator de risco hereditário raro mas consistente para a DP no Brasil.

Alguns dos estudos avaliando as mutações no gene GBA entre pacientes da PD foram realizados na população judaica Ashkenazita, uma população que apresenta uma alta incidência da DG, de aproximadamente 1 em cada 10.000 indivíduos (Fried, 1973). É possível que essa alta prevalência possa se refletir nos resultados demonstrando uma alta freqüência de mutações no gene GBA nos pacientes da DP dessa população. No Brasil porém a DG é muito rara e embora não existam dados publicados sobre sua prevalência, uma busca ativa realizada nos últimos 8 anos identificou aproximadamente 450 pacientes (Michelin et al., 2005) correspondendo a uma incidência de aproximadamente 1 a cada 400.000 indivíduos, uma redução de 40 vezes em comparação à população judaica Ashkenazita. Dessa forma, nossos achados mostrando uma alta freqüência de mutações no gene GBA entre pacientes da DP numa população de baixa prevalência da DG reforçam ainda mais a existência dessa associação.

Os dois pacientes apresentando mutações no gene GBA nesse estudo são do sexo masculino e apresentam um início precoce e também um histórico familial da DP (um do lado materno e outro do lado paterno). Uma vez que formas de início precoce da DP tendem a mostrar concentração familial, é possível que um 
componente genético de maior influência esteja presente nesses casos. Esta é a razão pela qual nós optamos por incluir no nosso estudo pacientes de formas de início precoce.

Os dois heterozigotos detectados apresentam a mutação L444P e o paciente 2 apresentou um alelo complexo com a L444P + E326K. A mãe do paciente 2 não apresentou as mutações detectadas no filho, demonstrando que o pai, também afetado pela DP, era provavelmente um portador das mutações no gene $G B A$.

Uma maior suscetibilidade à DP entre portadores de mutações no gene GBA é notável pois implica numa manifestação heterozigótica de mutações causadoras da DG, uma doença de padrão de herança claramente recessivo. Isso causa uma redução ainda maior na adaptabilidade do heterozigoto, influenciando positivamente a seleção contrária a esses alelos. Por outro lado, a DG é a mais freqüente doença de armazenamento lisossômico, atingindo freqüências altas em populações específicas. Tanto deriva genética como vantagem heterozigótica já foram aventadas como explicações para essa alta freqüência na população judaica Ashkenazita (Beutler \& Grabowski, 2001). Os efeitos de mutações no gene GBA devem ser completamente conhecidos para possibilitar a compreensão dos mecanismos da genética populacional da DG. A manifestação pleiotrópica de mutações causando distúrbios mendelianos tem sido cada vez mais reconhecida em diversas outras doenças recessivas (Dipple \& McCabe, 2000; Sidransky, 2005).

A importância de informação oriunda da genética para a compreensão de mecanismos patogênicos em doenças comuns é exemplificado pelo fato de que o descobrimento de mutações no gene da $\alpha$-sinucleína entre pacientes da DP levou à identificação dessa proteína como um componente importante dos corpos de Lewy, o marco patológico da DP. Nossos dados reforçam a idéia de que embora não sejam um fator universal de risco para a DP, mutações no gene GBA estão associadas a essa doença. O mecanismo biológico dessa associação ainda é desconhecido. Já foi proposto que mutações no gene GBA podem alterar a constituição da membrana lisossomal, aumentando o seu conteúdo de 
fosfatidilcolina e liberando a $\alpha$-sinucleína que se agregaria então nos corpos de Lewy (Feany, 2004; Wong et al., 2004). Se existe um mecanismo dominante negativo na associação da DG e da DP, devido à presença de GCase mutante, o uso de terapia mediada por chaperones pode ser uma opção terapêutica ou de prevenção para portadores da DG nessas famílias. Novos estudos sobre a associação DG-DP podem indicar novas estratégias terapêuticas específicas para esse grupo de pacientes. No presente, o teste de mutações no gene GBA para pacientes da DP está restrito à pesquisa científica. 


\section{RESUMO / ABSTRACT}

\section{Resumo}

Este estudo descreve a análise molecular de pacientes da doença de Gaucher (DG) e Tay-Sachs (DTS) no Brasil. Foram estudados nove casos de formas clássicas da DTS que mostraram uma prevalência da mutação IVS7+1g>c, já descrita em pacientes Portugueses e dez casos das variantes de início juvenil e tardio da DTS, mostrando heterogeneidade genética. Nos casos da variante B1, percebeu-se uma maior incidência da mutação $\mathrm{R} 178 \mathrm{H}$, também descrita previamente em pacientes Portugueses. A presença das mesmas mutações nos casos Brasileiros e Portugueses se deve provavelmente à ancestralidade comum. Uma família com quatro pacientes da variante de início tardio da DTS mostrou uma extensa variabilidade clínica intrafamilial e identificou relevantes aspectos do diagnóstico e das implicações dos programas de triagem populacional.

A análise por RFLP de nove mutações causadoras da DG, em 262 pacientes permitiu detectar $76 \%$ das alterações e mostrou uma prevalência das mutações N370S e L444P, similar à descrita em diversas outras populações. Os pacientes com variantes neuronopáticas da doença apresentaram uma alta freqüência da mutação G377S, que também é encontrada em pacientes Portugueses. Os pacientes apresentando a G377S indicaram a existência de um provável mecanismo de efeito de dose alélica para essa mutação. Foi observada uma alta freqüência de alelos resultantes da recombinação do gene GBA com seu pseudogene. Diversas outras relações genótipo-fenótipo puderam ser verificadas, mostrando uma baixa penetrância do genótipo N370S/N370S e corroborando a importância do diagnóstico molecular da DG, devido a seu valor preditivo.

A análise de mutações raras no gene GBA usando as técnicas de RFLP, dHPLC e seqüenciamento de DNA possibilitou detectar mutações em $84 \%$ dos alelos de 54 pacientes. Foram identificadas 14 novas mutações causadoras da 
DG. Diversas relações genótipo-fenótipo puderam ser verificadas, conferindo valor preditivo para a detecção dessas mutações.

Por fim, a análise da associação da DG e da DP permitiu encontrar uma freqüência significativamente maior de portadores das principais mutações no gene GBA em pacientes parkinsonianos ( $2 / 65=3 \%)$, com aparecimento precoce da doença, comparados a um grupo controle de 267 indivíduos. Esse trabalho fornece nova evidência de que mutações no gene GBA são um raro, mas consistente fator de risco para a DP.

\section{Abstract}

This study describes the molecular diagnosis of Gaucher (GD) and TaySachs disease (TSD) patients in Brazil. Nine cases of the classic infantile form of TSD were analyzed disclosing a prevalence of the IVS7+1g>c mutation, described previously in Portuguese patients. Ten cases of juvenile and late-onset TSD forms were diagnosed showing genetic heterogeneity. Among the $B 1$ variant cases, there was a predomenance of mutation $\mathrm{R} 178 \mathrm{H}$ that was also associated to Portuguese ancestry. The presence of the same mutations in Brazilian and Portuguese cases are probably due to common ancestry. A family with 4 affected patients of late onset TSD showed and extensive intrafamilial clinical variability, highlighting relevant characteristics of diagnosis and implications of heterozygote screening programs.

Among 263 GD patients, the detection of nine mutations by RFLP revealed $76 \%$ of the mutant alleles and a preponderance of N370S and L444P, similar to other populations. The type 3 neuronopathic patients presented a high frequency of mutation G377S, that is also described among Portuguese cases. The patients with G377S indicated the possibility of an allele dose effect for this mutation. Recombinant alleles, presenting pseudogene mutations were detected at a high frequency. Several genotype-phenotype correlations could be verified, highlighting a low penetrance of genotype N370S/N370S and corroborating the importance of molecular diagnosis in GD cases, due to its predictive value. 
The search for rare mutations at the GBA gene, using $A H P L C$ and DNA sequencing after RFLP analysis, allowed the detection of $84 \%$ of the alleles among 54 patients. Fourteen new GD causing mutations were described. Several genotype-phenotype correlations could be established, confering prective value to the identification of these mutations.

Finally, the study of the association of GD and Parkinson disease (PD) lead to the detection of a significant increase in the frequency of GBA mutations carriers, among 65 PD patients (2/65=3\%) with earlier disease onset compared to a control group ( $n=267$ individuals). This work confers further evidence for the fact that GBA mutations are a rare but consistent risk factor for $P D$. 


\section{REFERÊNCI AS BI BLI OGRÁFICAS}

Aharon-Peretz J, Rosenbaum $\mathrm{H}$, Gershoni-Baruch R. Mutations in the Glucocerebrosidase Gene and Parkinson's Disease in Ashkenazi Jews. N Engl J Med 351(19): 1972-1977, 2004.

Alfonso P, Rodriguez-Rey JC, Ganan A, Perez-Calvo JI, Giralt M, Giraldo P, Pocovi $M$. Expression and functional characterization of mutated glucocerebrosidase alleles causing Gaucher disease in Spanish patients. Blood Cells Mol Dis 32: 218-225, 2004.

Alfonso P, Pampin S, Estrada J, Rodriguez-Rey JC, Giraldo P, Sancho J, Pocovi M. Miglustat (NB-DNJ) works as a chaperone for mutated acid beta-glucosidase in cells transfected with several Gaucher disease mutations. Blood Cells Mol Dis 35: 268-276, 2005.

Altarescu G, Phillips M, Foldes AJ, Elstein D, Zimran A, Mates M. The interleukin6 promoter polymorphism in Gaucher disease: a new modifier gene? QJM 96: 575-578, 2003.

Amaral O, Pinto E, Fortuna M, Lacerda L, sa Miranda MC. Type 1 Gaucher disease: identification of N396T and prevalence of glucocerebrosidase mutations in the Portuguese. Hum Mutat 8: 280-281, 1996.

Amaral O, Lacerda L, Marcao A, Pinto E, Tamagnini G, sa Miranda MC. Homozygosity for two mild glucocerebrosidase mutations of probable Iberian origin. Clin Genet 56: 100-102, 1999.

Amaral O, Marcao A, Sa Miranda M, Desnick RJ, Grace ME. Gaucher disease: expression and characterization of mild and severe acid beta-glucosidase mutations in Portuguese type 1 patients. Eur J Hum Genet 8: 95-102, 2000.

Barbosa ER, Limongi JC, Cummings JL. Parkinson's disease. Psychiatr Clin North Am 20: 769-790, 1997.

Barton NW, Furbish FS, Murray GJ, Garfield M, Brady RO. Therapeutic Response to Intravenous Infusions of Glucocerebrosidase in a Patient with Gaucher Disease. PNAS 87: 1913-1916, 1990.

Beiguelman B. Dinâmica dos genes nas famílias e nas populações. Sociedade Brasileira de Genética, $2^{\mathrm{a}}$ ed, 284-288, 1995.

Bembi B, Zambito Marsala S, Sidransky E, Ciana G, Carrozzi M, Zorzon M, Martini C, Gioulis M, Pittis MG, Capus L. Gaucher's disease with Parkinson's disease: Clinical and pathological aspects. Neurology 61: 99-101, 2003. 
Bembi B, Marchetti F, Guerci VI, Ciana G, Addobbati R, Grasso D, Barone R, Cariati R, Fernandez-Guillen L, Butters T, Pittis MG. Substrate reduction therapy in the infantile form of Tay-Sachs disease. Neurology 66: 278-280, 2006.

Bennett RR, den Dunnen J, O'Brien KF, Darras BT, Kunkel LM. Detection of mutations in the dystrophin gene via automated DHPLC screening and direct sequencing. BMC Genet 2: 17, 2001.

Beutler E, Gelbart T, West C. The facile detection of the nt 1226 mutation of glucocerebrosidase by 'mismatched' PCR. Clin Chim Acta 194: 161-166, 1990.

Beutler E, Gelbart T, Kuhl W, Sorge J, West C. Identification of the Second Common Jewish Gaucher Disease Mutation Makes Possible Population-Based Screening for the Heterozygous State. PNAS 88: 10544-10547, 1991.

Beutler E, Nguyen NJ, Henneberger MW, Smolec JM, McPherson RA, West C, Gelbart T. Gaucher disease: gene frequencies in the Ashkenazi Jewish population. Am J Hum Genet 52: 85-88, 1993.

Beutler E, Gelbart T, West C. Identification of six new Gaucher disease mutations. Genomics 15: 203-205, 1993b.

Beutler E, Demina A, Gelbart T. Glucocerebrosidase mutations in Gaucher disease. Mol Med 1: 82-92, 1994.

Beutler E, Gelbart T. Erroneous assignment of Gaucher disease genotype as a consequence of a complete gene deletion. Hum Mutat 4: 212-216, 1994.

Beutler E, Gelbart T, Balicki D, Demina A, Adusumalli J, Elsas II LJ, Grinzaid KA, Gitzelmann R, Superti-Furga A, Kattamis C, Liou BBH. Gaucher disease: four families with previously undescribed mutations. Proc Assoc Amer Phys 108 179184, 1996.

Beutler E, Gelbart T. Hematologically important mutations: Gaucher disease. Blood Cells Mol Dis 24: 2-8, 1998.

Beutler E \& Grabowski, GA. Gaucher disease. In: Scriver CR, Beaudet AL, Sly WS, Valle DV (Editors), The metabolic and molecular bases of inherited disease. $8^{\text {th }}$ ed. McGraw-Hill, New York, 3635-3668, 2001.

Beutler E, Gelbart T, Scott CR. Hematologically important mutations: Gaucher disease. Blood Cells Mol Dis 35: 355-364, 2005.

Bordo D, Argos P. Suggestions for "safe" residue substitutions in site-directed mutagenesis. J Mol Biol 217: 721-729, 1991.

Boustany RM, Tanaka A, Nishimoto J, Suzuki K. Genetic cause of a juvenile form of Tay-Sachs disease in a Lebanese child. Ann Neurol 29: 104-107, 1991. 
RO Brady. The sphingolipidoses. N Engl J Med 275(6): 312-8, 1996.

Brady RO, Schiffmann R. Enzyme-replacement therapy for metabolic storage disorders. Lancet Neurol 3: 752-756, 2004.

Brautbar A, Elstein D, Abrahamov A, Zeigler M, Chicco G, Beutler E, Scott CR, Zimran A. The 1604A (R496H) mutation in Gaucher disease: genotype/phenotype correlation. Blood Cells Mol Dis 31: 187-189, 2003.

Chabas A, Gort L, Diaz-Font A, Montfort M, Santamaria R, Cidras M, Grinberg D, Vilageliu L. Perinatal lethal phenotype with generalized ichthyosis in a type 2 Gaucher disease patient with the [L444P;E326K]/P182L genotype: effect of the E326K change in neonatal and classic forms of the disease. Blood Cells Mol Dis 35: 253-258, 2005.

Chan LL, Lin HP. Enzyme replacement therapy for Gaucher Disease: the only experience in Malaysia. Med J Malaysia 57: 348-352, 2002.

Clark LN, Nicolai A, Afridi S, et al. Pilot association study of the betaglucocerebrosidase N370S allele and Parkinson's disease in subjects of Jewish ethnicity. Mov Disor 20: 100-103, 2005.

Conzelmann E, Kytzia HJ, Navon R, Sandhoff K. Ganglioside GM2 N-acetyl-betaD-galactosaminidase activity in cultured fibroblasts of late-infantile and adult GM2 gangliosidosis patients and of healthy probands with low hexosaminidase level. Am J Hum Genet 35: 900-913, 1983.

Cooper DN, Krawczak M. The mutational spectrum of single base-pair substitutions causing human genetic disease: patterns and predictions. Hum Genet 85: 55-74, 1990.

Cormand B, Harboe TL, Gort L, Campoy C, Blanco M, Chamoles N, Chabas A, Vilageliu L, Grinberg D. Mutation analysis of Gaucher disease patients from Argentina: high prevalence of the RecNcil mutation. Am J Med Genet 80: 343351, 1998.

Cormand B, Grinberg D, Gort L, Chabas A, Vilageliu L. Molecular analysis and clinical findings in the Spanish Gaucher disease population: putative haplotype of the N370S ancestral chromosome. Hum Mutat 11: 295-305, 1998.

Cox T, Lachmann R, Hollak C, Aerts J, van Weely S, Hrebicek M, Platt F, Butters $\mathrm{T}$, Dwek R, Moyses C, Gow I, Elstein D, Zimran A. Novel oral treatment of Gaucher's disease with N-butyldeoxynojirimycin (OGT 918) to decrease substrate biosynthesis. Lancet 355: 1481-1485, 2000.

d'Azzo A, Proia RL, Kolodny EH, Kaback MM, Neufeld EF. Faulty association of alpha- and beta-subunits in some forms of beta- hexosaminidase A deficiency. $J$ Biol Chem 259: 11070-11074, 1984. 
deDuve C. From cytases to lysosomes. Fed Proc 23: 1045-1049, 1964.

Desnick RJ, Bernlohr RW, Krivit W. Enzyme therapy in genetic diseases, Birth defects. Original article series. New York: The National Foundation, 1973.

Desnick RJ. Enzyme replacement and enhancement therapies for lysosomal diseases. J Inherit Metab Dis 27: 385-410, 2004.

DeStefano AL, Golbe LI, Mark MH, et al. Genome-wide scan for Parkinson's disease: The Gene PD Study. Neurology 57: 1124-1126, 2001.

Diaz-Font A, Cormand B, Blanco M, Chamoles N, Chabas A, Grinberg D, Vilageliu L. Gene rearrangements in the glucocerebrosidase-metaxin region giving rise to disease-causing mutations and polymorphisms. Analysis of $25 \mathrm{Rec}$ Ncil alleles in Gaucher disease patients. Hum Genet 112: 426-429, 2003.

Dipple KM, McCabe ER. Phenotypes of patients with "simple" Mendelian disorders are complex traits: thresholds, modifiers, and systems dynamics. Am J Hum Genet 66: 1729-1735, 2000.

Dobrens K, Joseph A, Rattazzi MC. Neuronal Lysosomal Enzyme Replacement Using Fragment C of Tetanus Toxin. PNAS 89: 2297-2301, 1992.

Dominissini S, Buratti E, Bembi B, Baralle M, Pittis MG. Characterization of two novel GBA mutations causing Gaucher disease that lead to aberrant RNA species by using functional splicing assays. Hum Mutat 27: 119, 2006.

Dominissini S, Buratti E, Bembi B, Baralle M, Pittis MG. Characterization of two novel GBA mutations causing Gaucher disease that lead to aberrant RNA species by using functional splicing assays. Hum Mutat 27: 119, 2006.

dos Santos MR, Tanaka A, sa Miranda MC, Ribeiro MG, Maia M, Suzuki K. GM2gangliosidosis B1 variant: analysis of beta-hexosaminidase alpha gene mutations in 11 patients from a defined region in Portugal. Am J Hum Genet 49: 886-890, 1991.

Dvir H, Harel M, McCarthy AA, Toker L, Silman I, Futerman AH, Sussman JL. Xray structure of human acid-beta-glucosidase, the defective enzyme in Gaucher disease. EMBO Rep 4: 704-709, 2003.

Erikson A, Astrom M, Mansson JE. Enzyme infusion therapy of the Norrbottnian (type 3) Gaucher disease. Neuropediatrics 26: 203-207, 1995.

Fausouliotis SJ, Schenker JG. Pre-implantation genetic diagnosis principles and ethics. Human Reproduction 13: 2238-2245, 1998.

Feany MB. New genetic insights into Parkinson's disease. N Engl J Med 351: 1937-1940, 2004. 
Fernandes M, Boulay B, Hechtman P, Kaplan F, Strasberg P. Five novel HEXA mutations in non-Jewish Tay-Sachs disease (TSD) patients. Am J Hum Genet 51: A656, 1992.

Fried K. Population study of chronic Gaucher's disease. Isr J Med Sci 9: 13961398, 1973.

GeneDis: Human Genetic Disease Database, G.S. Wise Faculty of Life Sciences, Tel Aviv University (http://life2.tau.ac.il/GeneDis).

Germain DP, Kaneski CR, Brady RO. Mutation analysis of the acid betaglucosidase gene in a patient with type 3 Gaucher disease and neutralizing antibody to alglucerase. Mutat Res 483: 89-94, 2001.

Germain DP. Gaucher's disease: a paradigm for interventional genetics. Clin Genet 65: 77-86, 2004.

Giraldo P, Pocovi M, Perez-Calvo J, Rubio-Felix D, Giralt M. Report of the Spanish Gaucher's disease registry: clinical and genetic characteristics. Haematologica 85: 792-799, 2000.

Glew RH, Basu A, Prence EM, Remaley AT. Lysosomal storage diseases: Biology of Disease. Lab Invest 53(3): 250-269, 1985.

Gojobori T, Li WH, Graur D. Patterns of nucleotide substitution in pseudogenes and functional genes. J Mol Evol 18: 360-369, 1982.

Goker-Alpan O, Schiffmann R, Park JK, Stubblefield BK, Tayebi N, Sidransky E. Phenotypic continuum in neuronopathic Gaucher disease: an intermediate phenotype between type 2 and type 3. J Pediatr 143: 273-276, 2003.

Goker-Alpan O, Hruska KS, Orvisky E, Kishnani PS, Stubblefield BK, Schiffmann $\mathrm{R}$, Sidransky E. Divergent phenotypes in Gaucher disease implicate the role of modifiers. J Med Genet 42: e37, 2005.

Grabowski GA. Gaucher's disease. Enzyme therapy is not enough. Lancet 358 Suppl: S29, 2001.

Grabowski GA, Barton NW, Pastores G, Dambrosia JM, Banerjee TK, McKee MA, Parker C, Schiffmann R, Hill SC, Brady RO. Enzyme Therapy in Type 1 Gaucher Disease: Comparative Efficacy of Mannose-terminated Glucocerebrosidase from Natural and Recombinant Sources. Ann Intern Med 122: 33-39, 1995.

Grace ME, Graves PN, Smith FI, Grabowski GA. Analyses of catalytic activity and inhibitor binding of human acid beta- glucosidase by site-directed mutagenesis. Identification of residues critical to catalysis and evidence for causality of two Ashkenazi Jewish Gaucher disease type 1 mutations. J Biol Chem 265: 68276835, 1990. 
Gravel RA, Clarke JT, Kaback MM, Mahuran D, Sandhoff K, Suzuki K. The GM2 gangliosidosis. Em: Scriver CR, Beaudet AL, Sly WS, Valle DV (eds): The Metabolic and Molecular Bases of Inherited Disease. 7th ed., New York: McGrawHill, 2839-2879, 1995.

Hardy J, Cookson MR, Singleton A. Genes and parkinsonism. Lancet Neurol 2: 21-28, 2003.

He GS, Grabowski GA. Gaucher disease: A G+1----A+1 IVS2 splice donor site mutation causing exon 2 skipping in the acid beta-glucosidase mRNA. Am J Hum Genet 51: 810-820, 1992.

Hechtman P, Kaplan F. Tay-Sachs disease screening and diagnosis: evolving technologies. DNA Cell Biol 12: 651-665, 1993.

Heitner R, Arndt S, Levin JB. Imiglucerase low-dose therapy for paediatric Gaucher disease--a long-term cohort study. S Afr Med J 94: 647-651, 2004.

Hodanova K, Melkova Z, Horowitz M, Hrebicek M. Transient expression of wildtype and mutant glucocerebrosidases in hybrid vaccinia expression system. Eur J Hum Genet 11: 369-374, 2003.

Horowitz M, Wilder S, Horowitz Z, Reiner O, Gelbart T, Beutler E. The human glucocerebrosidase gene and pseudogene: structure and evolution. Genomics 4: 87-96, 1989.

Horowitz M, Pasmanik-Chor M, Borochowitz Z, Falik-Zaccai T, Heldmann K, Carmi R, Parvari R, Beit-Or H, Goldman B, Peleg L, Levy-Lahad E, Renbaum P, Legum S, Shomrat R, Yeger H, Benbenisti D, Navon R, Dror V, Shohat M, Magal $\mathrm{N}$, Navot N, Eyal N. Prevalence of glucocerebrosidase mutations in the Israeli Ashkenazi Jewish population. Hum Mutat 12: 240-244, 1998.

Hughes AJ, Daniel SE, Lees AJ. Improved accuracy of clinical diagnosis of Lewy body Parkinson's disease. Neurology 57: 1497-1499, 2001.

Hughes AJ, Daniel SE, Kilford L, et al. Accuracy of clinical diagnosis of idiopathic Parkinson 's disease: a clinico-pathological study of 100 cases. J Neurol Neurosurg Psychiatry 55: 181-84, 1992.

Jmoudiak M, Futerman AH. Gaucher disease: pathological mechanisms and modern management. Br J Haematol 129: 178-188, 2005.

Jones AC, Austin J, Hansen N, Hoogendoorn B, Oefner PJ, Cheadle JP, O'Donovan MC. Optimal Temperature Selection for Mutation Detection by Denaturing HPLC and Comparison to Single-Stranded Conformation Polymorphism and Heteroduplex Analysis. Clin Chem 45: 1133-1140, 1999. 
Jorde LB, Carey JC, Bamshad MJ, White RL. Genética Médica. Guanabara Koogan. Rio de Janeiro, $2^{\mathrm{a}}$ ed., 236-250, 2000.

Kaback MM, Lim-Steele J, Dabholkar D, Brown D, Levy N, Zeiger K. Tay-Sachs disease - carrier screening, prenatal diagnosis, and the molecular era - an international perspective, 1970 to 1993. J Am Med Assoc 270: 2307-2315, 1993.

Kanamura AH. O dilema do gestor do sistema de saúde. Tendências/debates, pg A3, 10/07/2003.

Kolodny EH. Tay-Sachs disease. Genetic Diseases Among Ashkenazi Jews. Goodman and Motulsky, Raven Press, New York, 217-229, 1979.

Koprivica V, Stone DL, Park JK, Callahan M, Frisch A, Cohen IJ, Tayebi N, Sidransky E. Analysis and classification of 304 mutant alleles in patients with type 1 and type 3 Gaucher disease. Am J Hum Genet 66: 1777-1786, 2000.

Kosaki K, Udaka T, Okuyama T. DHPLC in clinical molecular diagnostic services. Mol Genet Metab 86: 117-123, 2005.

Kyrkanides S, Miller JH, Brouxhon SM, Olschowka JA, Federoff HJ. betahexosaminidase lentiviral vectors: transfer into the CNS via systemic administration. Brain Res Mol Brain Res 133: 286-298, 2005.

Lacerda L, Amaral O, Pinto R, Oliveira P, Aerts J, sa Miranda MC. Gaucher disease: N370S glucocerebrosidase gene frequency in the Portuguese population. Clin Genet 45: 298-300, 1994.

Lachmann RH, Grant IR, Halsall D, Cox TM. Twin pairs showing discordance of phenotype in adult Gaucher's disease. QJM 97: 199-204, 2004.

Latham T, Grabowski GA, Theophilus BD, Smith FI. Complex alleles of the acid beta-glucosidase gene in Gaucher disease. Am J Hum Genet 47: 79-86, 1990.

Liou B, Kazimierczuk A, Zhang M, Scott CR, Hegde RS, Grabowski GA. Analyses of Variant Acid beta-Glucosidases: EFFECTS OF GAUCHER DISEASE MUTATIONS. J Biol Chem 281: 4242-4253, 2006.

Liu W, Smith DI, Rechtzigel KJ, Thibodeau SN, James CD. Denaturing high performance liquid chromatography (DHPLC) used in the detection of germline and somatic mutations. Nucleic Acids Res 26: 1396-1400, 1998.

Liu Y, Suzuki K, Reed JD, Grinberg A, Westphal H, Hoffmann A, Doring T, Sandhoff K, Proia RL. Mice with type 2áand 3áGaucher disease point mutations generated by a single insertion mutagenesis procedure (SIMP). PNAS 95: 25032508, 1998. 
Lwin A, Orvisky E, Goker-Alpan O, et al E. Glucocerebrosidase mutations in subjects with parkinsonism. Mol Genet Metab 81(1): 70-73, 2004.

Machaczka M, Rucinska M, Skotnicki AB, et al Parkinson's syndrome preceding clinical manifestation of Gaucher's disease. Am J Hematol 61(3): 216-217, 1999.

MacQueen GM, Rosebush PI, Mazurek MF. Neuropsychiatric Aspects of the Adult Variant of Tay-Sachs Disease. J Neuropsychiatry Clin Neurosci 10: 10-19, 1998.

Mange AP, Mange EJ. Inborn errors of metabolism. Em: Genetics: Human Aspects. Sinauer Associated Inc, 314-317/511-512, 1989.

Maraganore DM, de Andrade M, Lesnick TG, et al. High-Resolution WholeGenome Association Study of Parkinson Disease. Am J Hum Genet 77:685-693, 2005.

Mark BL, Mahuran DJ, Cherney MM, Zhao D, Knapp S, James MN. Crystal structure of human beta-hexosaminidase B: understanding the molecular basis of Sandhoff and Tay-Sachs disease. J Mol Biol 327: 1093-1109, 2003.

Martin PL, Carter SL, Kernan NA, Sahdev I, Wall D, Pietryga D, Wagner JE, Kurtzberg J. Results of the cord blood transplantation study (COBLT): outcomes of unrelated donor umbilical cord blood transplantation in pediatric patients with lysosomal and peroxisomal storage diseases. Biol Blood Marrow Transplant 12: 184-194, 2006.

Martins AM, Lobo CL, Sobreira E, Valadares ME, Porta G, Semionato JF, Pianovisky MA, Kerstenetzky MS, Montoril MFP, Aranda PC, Pires RF, Mota RMV, Bortolheiro TC, Paula MTM. Tratamento da Doença de Gaucher: um consenso Brasileiro. Rev Bras Hematol Hemoter 25(2): 89-95, 2003.

Martinez-Arias R, Mateu E, Bertranpetit J, Calafell F. Profiles of accepted mutation: from neutrality in a pseudogene to disease-causing mutation on its homologous gene. Hum Genet 109: 7-10, 2001.

Martinez-Arias R, Calafell F, Mateu E, Comas D, Andres A, Bertranpetit J. Sequence Variability of a Human Pseudogene. Genome Res 11: 1071-1085, 2001.

McCormack PL, Goa KL. Miglustat. Drugs 63: 2427-2434, 2003.

Meikle PJ, Hopwood JJ. Lysosomal storage disorders: emerging therapeutic options require early diagnosis. Eur J Pediatr 162 Suppl 1: S34-S37, 2003.

Michelin K, Wajner A, de Souza FT, de Mello AS, Burin MG, Pereira ML, Pires RF, Giugliani R, Coelho JC. Application of a comprehensive protocol for the identification of Gaucher disease in Brazil. Am J Med Genet A 136: 58-62, 2005. 
Michelin K, Wajner A, Bock H, Fachel A, Rosenberg R, Pires RF, Pereira ML, Giugliani R, Coelho JC. Biochemical properties of beta-glucosidase in leukocytes from patients and obligated heterozygotes for Gaucher disease carriers. Clin Chim Acta 362: 101-109, 2005.

Mignot C, Gelot A, Bessieres B, Daffos F, Voyer M, Menez F, Fallet Bianco C, Odent S, Le Duff D, Loget P, Fargier P, Costil J, Josset P, Roume J, Vanier MT, Maire I, Billette de Villemeur T. Perinatal-lethal Gaucher disease. Am J Med Genet A 120: 338-344, 2003.

Mignot C, Doummar D, Maire I, de Villemeur TB, . Type 2 Gaucher disease: 15 new cases and review of the literature. Brain Dev 28: 39-48, 2006.

Mitchell JJ, Capua A, Clow C, Scriver CR. Twenty-year outcome analysis of genetic screening programs for Tay-Sachs and $\beta$-Thalassemia disease carriers in high schools. Am J Hum Genet 59: 793-798, 1996.

Montalvo AL, Filocamo M, Vlahovicek K, Dardis A, Lualdi S, Corsolini F, Bembi B, Pittis MG. Molecular analysis of the HEXA gene in Italian patients with infantile and late onset Tay-Sachs disease: detection of fourteen novel alleles. Hum Mutat 26(3): 282, 2005.

Montfort M, Chabas A, Vilageliu L, Grinberg D. Functional analysis of 13 GBA mutant alleles identified in Gaucher disease patients: Pathogenic changes and "modifier" polymorphisms. Hum Mutat 23: 567-575, 2004.

Muchowski PJ, Wacker JL. Modulation of neurodegeneration by molecular chaperones. Nat Rev Neurosci 6: 11-22, 2005.

Navon R, Argov Z, Frisch A. Hexosaminidase A deficiency in adults. Am J Med Genet 24: 179-196, 1986.

Navon R, Proia RL. The mutations in Ashkenazi Jews with adult GM2 gangliosidosis, the adult form of Tay-Sachs disease. Science 243: 1471-1474, 1989.

Neudorfer O, Giladi N, Elstein D et al. Occurrence of Parkinson's syndrome in type I Gaucher disease. QJM 89(9): 691-694, 1996.

Neudorfer O, Kolodny EH. Late-onset Tay-Sachs disease. Isr Med Assoc J 6: 107-111, 2004.

O'Donovan MC, Oefner PJ, Roberts SC, Austin J, Hoogendoorn B, Guy C, Speight G, Upadhyaya M, Sommer SS, McGuffin P. Blind analysis of denaturing high-performance liquid chromatography as a tool for mutation detection. Genomics 52: 44-49, 1998. 
Oefner PJ, Underhill PA. Comparative DNA sequencing by denaturing high performance liquid chromatography (DHPLC). Am J Hum Genet 57: A266, 1995.

OMIM, Online Mendelian Inheritance in Man Johns Hopkins University, Baltimore, MD. World Wide Web URL:http://www.ncbi.nlm.nih.gov/omim/

Park JK, Koprivica V, Andrews DQ, Madike V, Tayebi N, Stone DL, Sidransky E. Glucocerebrosidase mutations among African-American patients with type 1 Gaucher disease. Am J Med Genet 99: 147-151, 2001.

Park JK, Orvisky E, Tayebi N, Kaneski C, Lamarca ME, Stubblefield BK, Martin BM, Schiffmann R, Sidransky E. Myoclonic Epilepsy in Gaucher Disease: Genotype-Phenotype Insights from a Rare Patient Subgroup. Pediatr Res 53: 387-395, 2003.

Park JK, Tayebi N, Stubblefield BK, LaMarca ME, MacKenzie JJ, Stone DL, Sidransky E. The E326K mutation and Gaucher disease: mutation or polymorphism? Clin Genet 61(1): 32-34, 2003.

Pasmanik-Chor M, Elroy-Stein O, Aerts H, Agmon V, Gatt S, Horowitz M. Overexpression of human glucocerebrosidase containing different-sized leaders. Biochem J 317: 81-88, 1996.

Pasmanik-Chor M, Madar-Shapiro L, Stein EO, Aerts H, Gatt S, Horowitz M. Expression of mutated glucocerebrosidase alleles in human cells. Hum Mol Genet 6: 887-895, 1997.

Pastores GM, Barnett NL. Current and emerging therapies for the lysosomal storage disorders. Expert Opin Emerg Drugs 10: 891-902, 2005.

Paw BH, Moskowitz SM, Uhrhammer N, Wright N, Kaback MM, Neufeld EF. Juvenile GM2 gangliosidosis caused by substitution of histidine for arginine at position 499 or 504 of the alpha-subunit of beta- hexosaminidase. J Biol Chem 265: 9452-9457, 1990.

Pfeiffer RM, Bura E, Smith A, Rutter JL. Two approaches to mutation detection based on functional data. Stat Med 21: 3447-3464, 2002.

Pinto R, Caseiro C, Lemos M, Lopes L, Fontes A, Ribeiro H, Pinto E, Silva E, Rocha S, Marcao A, Ribeiro I, Lacerda L, Ribeiro G, Amaral O, sa Miranda MC. Prevalence of lysosomal storage diseases in Portugal. Eur J Hum Genet 12: 8792, 2004.

Platt FM, Neises GR, Reinkensmeier G, Townsend MJ, Perry VH, Proia RL, Winchester B, Dwek RA, Butters TD. Prevention of Lysosomal Storage in TaySachs Mice Treated with N-Butyldeoxynojirimycin. Science 276: 428-431, 1997. 
Pomponio RJ, Cabrera-Salazar MA, Echeverri OY, Miller G, Barrera LA. Gaucher disease in Colombia: mutation identification and comparison to other Hispanic populations. Mol Genet Metab 86: 466-472, 2005.

Premkumar L, Sawkar AR, Boldin-Adamsky S, Toker L, Silman I, Kelly JW, Futerman AH, Sussman JL. X-ray Structure of Human Acid-\{beta\}-Glucosidase Covalently Bound to Conduritol-B-Epoxide: IMPLICATIONS FOR GAUCHER DISEASE. J Biol Chem 280: 23815-23819, 2005.

Raw, I. Mentindo ou escondendo a verdade. Folha de São Paulo. Opinião, pg A3, 30/11/2003.

Rapin I, Suzuki K, Suzuki K, Valsamis MP. Adult (chronic) GM2 gangliosidosis. Atypical spinocerebellar degeneration in a Jewish sibship. Arch Neurol 33: 120130, 1976.

Reiner $\mathrm{O}$, Horowitz M. Differential expression of the human glucocerebrosidasecoding gene. Gene 73: 469-478, 1988.

Ribeiro MG, Pinto R, Miranda MC, Suzuki K. Tay-Sachs disease: intron 7 splice junction mutation in two Portuguese patients. Biochim Biophys Acta 1270: 44-51, 1995.

Richards B, Skoletsky J, Shuber AP, Balfour R, Stern RC, Dorkin HL, Parad RB, Witt $D$, Klinger KW. Multiplex PCR amplification from the CFTR gene using DNA prepared from buccal brushes/swabs. Hum Mol Genet 2: 159-163, 1993.

Rijnboutt S, Aerts HM, Geuze HJ, Tager JM, Strous GJ. Mannose 6-phosphateindependent membrane association of cathepsin $\mathrm{D}$, glucocerebrosidase, and sphingolipid-activating protein in HepG2 cells. J Biol Chem 266: 4862-4868, 1991.

Ringden O, Remberger M, Svahn BM, Barkholt L, Mattsson J, Aschan J, Le Blanc K, Gustafsson B, Hassan Z, Omazic B, Svenberg P, Solders G, von Dobeln U, Winiarski J, Ljungman $P$, Malm $G$. Allogeneic hematopoietic stem cell transplantation for inherited disorders: experience in a single center. Transplantation 81: 718-725, 2006.

Ron I, Horowitz M. ER retention and degradation as the molecular basis underlying Gaucher disease heterogeneity. Hum Mol Genet 14: 2387-2398, 2005.

Rozenberg R, Pereira LV. The frequency of Tay-Sachs disease causing mutations in the Brazilian Jewish population justifies a carrier screening program. Sao Paulo Med J 119: 146-149, 2001.

Rozenberg R, Martins AM, Micheletti C, Mustacchi Z, Pereira LV. Tay-Sachs disease in Brazilian patients: prevalence of the IVS7+1g $>c$ mutation. J Inherit Metab Dis 27: 109-110, 2004. 
Santos MR, Tanaka A, Miranda MCS, et al: GM2 gangliosidosis B1 variant: Analysis of $\beta$-hexosaminidase $A$ gene mutations in 11 patients from a defined region in Portugal. Am J Hum Genet 49:886-890, 1991.

Sato $C$, Morgan A, Lang AE, et al. Analysis of the glucocerebrosidase gene in Parkinson's disease. Mov Disord 20(3): 367-70, 2005.

Sawkar AR, Cheng WC, Beutler E, Wong CH, Balch WE, Kelly JW. Chemical chaperones increase the cellular activity of N370S beta -glucosidase: A therapeutic strategy for Gaucher disease. PNAS 99: 15428-15433, 2002.

Schmitz M, Alfalah M, Aerts JM, Naim HY, Zimmer KP. Impaired trafficking of mutants of lysosomal glucocerebrosidase in Gaucher's disease. Int J Biochem Cell Biol 37: 2310-2320, 2005.

Sibille A, Eng CM, Kim SJ, Pastores G, Grabowski GA. Phenotype/genotype correlations in Gaucher disease type I: clinical and therapeutic implications. Am J Hum Genet 52: 1094-1101, 1993.

Sidransky E. Gaucher disease: complexity in a "simple" disorder. Mol Genet Metab 83: 6-15, 2004.

Sidransky E. Gaucher disease and parkinsonism. Mol Genet Metab 84(4): 302304, 2005.

Slatkin M. A population-genetic test of founder effects and implications for Ashkenazi Jewish diseases. Am J Hum Genet 75(2): 282-93, 2004.

Slome, D. The genetic basis of amaurotic family idiocy. J Genet 27: 363-376, 1933.

Sorge J, West C, Westwood B, Beutler E. Molecular cloning and nucleotide sequence of human glucocerebrosidase cDNA. PNAS 82: 7289-7293, 1985.

Sorge J, Gross E, West C, Beutler E. High level transcription of the glucocerebrosidase pseudogene in normal subjects and patients with Gaucher disease. J Clin Invest 86: 1137-1141, 1990.

Sorge JA, West C, Kuhl W, Treger L, Beutler E. The human glucocerebrosidase gene has two functional ATG initiator codons. Am J Hum Genet 41: 1016-1024, 1987.

Spitz M, Rozenberg R, Silveira PAA, et al. Parkinsonism in type 1 Gaucher's disease. J Neurol Neurosurg Psychiatry 77: 709-710, 2006.

Stone DL, van Diggelen OP, de Klerk JB, Gaillard JL, Niermeijer MF, Willemsen $\mathrm{R}$, Tayebi N, Sidransky E. Is the perinatal lethal form of Gaucher disease more 
common than classic type 2 Gaucher disease? Eur J Hum Genet 7: 505-509, 1999.

Stone DL, Tayebi N, Orvisky E, Stubblefield B, Madike V, Sidransky E. Glucocerebrosidase gene mutations in patients with type 2 Gaucher disease. Hum Mutat 15: 181-188, 2000.

Tayebi N, Stubblefield BK, Park JK, Orvisky E, Walker JM, LaMarca ME, Sidransky E. Reciprocal and nonreciprocal recombination at the glucocerebrosidase gene region: implications for complexity in Gaucher disease. Am J Hum Genet 72: 519-534, 2003.

Tayebi N, Walker J, Stubblefield B, et al. Gaucher disease with parkinsonian manifestations: does glucocerebrosidase deficiency contribute to a vulnerability to parkinsonism? Mol Genet Metab 79(2): 104-109, 2003b.

Toft M, Pielsticker L, Ross OA, et al. Glucocerebrosidase gene mutations and Parkinson disease in the Norwegian population. Neurology 66(3): 415-417, 2006.

Tolosa E, Wenning G, Poewe W. The diagnosis of Parkinson's disease. Lancet Neurol 5: 75-86, 2006

Triggs-Raine BL, Feigenbaum AS, Natowicz M, Skomorowski MA, Schuster SM, Clarke JT, Mahuran DJ, Kolodny EH, Gravel RA. Screening for carriers of TaySachs disease among Ashkenazi Jews. A comparison of DNA-based and enzyme-based tests. N Engl J Med 323: 6-12, 1990.

Tropak MB, Reid SP, Guiral M, Withers SG, Mahuran D. Pharmacological Enhancement of \{beta\}-Hexosaminidase Activity in Fibroblasts from Adult TaySachs and Sandhoff Patients. J Biol Chem 279: 13478-13487, 2004.

Tsuji S, Choudary PV, Martin BM, Stubblefield BK, Mayor JA, Barranger JA, Ginns El. A mutation in the human glucocerebrosidase gene in neuronopathic Gaucher's disease. N Engl J Med 316: 570-575, 1987.

Tsuji S, MARTIN BM, Barranger JA, STUBBLEFIELD BK, LAMARCA ME, Ginns El. Genetic Heterogeneity in Type 1 Gaucher Disease: Multiple Genotypes in Ashkenazic and Non-Ashkenazic Individuals. PNAS 85: 2349-2352, 1988.

Tutor JC. Biochemical characterization of the GM2 gangliosidosis B1 variant. Braz J Med Biol Res 37: 777-783, 2004.

Tybulewicz VL, Tremblay ML, LaMarca ME, Willemsen R, Stubblefield BK, Winfield S, Zablocka B, Sidransky E, Martin BM, Huang SP. Animal model of Gaucher's disease from targeted disruption of the mouse glucocerebrosidase gene. Nature 357: 407-410, 1992. 
Van Bogaert LF. Un cas de maladie de Gaucher de ládulte avec syndrome de Raynaud, pigmentation, et rigidite du type extrapyrajidal aux membres inferieurs. Ann Med 45: 57-70, 1939.

Vellodi A, Bembi B, de Villemeur TB, Collin-Histed T, Erikson A, Mengel E, Rolfs A, Tylki-Szymanska A. Management of neuronopathic Gaucher disease: a European consensus. J Inherit Metab Dis 24: 319-327, 2001.

Vogler C, Levy B, Grubb JH, Galvin N, Tan Y, Kakkis E, Pavloff N, Sly WS. From The Cover: Overcoming the blood-brain barrier with high-dose enzyme replacement therapy in murine mucopolysaccharidosis VII. PNAS 102: 1477714782, 2005.

Warner TT, Schapira AH. Genetic and environmental factors in the cause of Parkinson's disease. Ann Neurol 53 Suppl 3: S16-23; discussion S23-5, 2003.

Wafaei JR, Choy FY. Glucocerebrosidase recombinant allele: molecular evolution of the glucocerebrosidase gene and pseudogene in primates. Blood Cells Mol Dis 35: 277-285, 2005.

Wong K, Sidransky E, Verma A, Mixon T, Sandberg GD, Wakefield LK, Morrison A, Lwin A, Colegial C, Allman JM, Schiffmann R. Neuropathology provides clues to the pathophysiology of Gaucher disease. Mol Genet Metab 82: 192-207, 2004.

Xu YH, Quinn B, Witte D, Grabowski GA. Viable Mouse Models of Acid \{beta\}Glucosidase Deficiency: The Defect in Gaucher Disease. Am J Pathol 163: 20932101, 2003.

Zhao H, Grabowski GA. Gaucher disease: Perspectives on a prototype lysosomal disease. Cell Mol Life Sci 59: 694-707, 2002.

Zhao H, Bailey LA, Elsas LJ, Grinzaid KA, Grabowski GA. Gaucher disease: in vivo evidence for allele dose leading to neuronopathic and nonneuronopathic phenotypes. Am J Med Genet A 116: 52-56, 2003.

Zhao H, Keddache M, Bailey L, Arnold G, Grabowski G. Gaucher's disease: identification of novel mutant alleles and genotype-phenotype relationships. Clin Genet 64: 57-64, 2003.

Zimran A, Elstein D, Kannai R, Zevin S, Hadas-Halpern I, Levy-Lahad E, Cohen Y, Horowitz M, Abrahamov A. Low-dose enzyme replacement therapy for Gaucher's disease: effects of age, sex, genotype, and clinical features on response to treatment. Am J Med 97: 3-13, 1994. 